\title{
A SENSE OF SPACE: CONCEPTUALIZATION IN WAYFINDING AND NAVIGATION
}

\author{
by \\ RYAN DEWEY \\ Submitted in partial fulfillment of the requirements for the degree of \\ Master of Arts
}

Thesis Adviser: Dr. Todd Van Evera Oakley

Department of Cognitive Science

CASE WESTERN RESERVE UNIVERSITY

August, 2012 


\title{
Case Western Reserve University School of Graduate Studies
}

\author{
We hereby approve the thesis of
}

Ryan Alan Dewey

Candidate for the Master of Arts degree

(signed)

- Professor Todd Oakley (Chair of the Committee)

- Professor Mark Turner (Committee Member)

- Professor Fey Parrill (Committee Member)

(date)

April 4, 2012

*we also certify that written approval has been obtained for any proprietary material contained therein. 


\section{CONTENTS}

LIST OF FIGURES

LIST OF IMAGES Vii

LIST OF TABLES viii

ABSTRACT Ix Ix I ix

INTRODUCTION 1

MAP READING

$\begin{array}{ll}\text { Layout of the chapter } & 7\end{array}$

An initial look at the data: $\quad 9$

The Stanford Trail study details: $\quad 10$

Trials and groups: 11

The three basic stimulus questions: 12

Priming activity: matching contour lines to terrain profiles: 13

The Stanford Trail map: $\quad 15$

Semiotic characteristics of FM constructions: 16

FM typology and the SYMBOL world: $\quad 16$

$\begin{array}{ll}\text { Four-category typology of FM: } & 19\end{array}$

Suggested dimensions of FM: 20

Examples of SYMBOL and SUBSTRATE FM: 22

Distinguishing between SYMBOL and SUBSTRATE: 24

Frequency of FM occurrences across trials: $\quad 29$

Conceptual integration and compression in

SYMBOL and SUBSTRATE FM: 32

Data differences across trials: $\quad 36$ 
A-Trial data: $\quad 36$

$\begin{array}{ll}\text { Path shape: } & 37\end{array}$

$\begin{array}{ll}\text { B-Trial data: } & 44\end{array}$

Consciousness of the need for a map in B-Trial subjects: 52

C-Trial data: $\quad 53$

$\begin{array}{ll}\text { Comparing the three trials: } & 58\end{array}$

Scale \& FM construal in SYMBOL: $\quad 59$

Palpability of map SYMBOL and trail SUBSTRATE: 62

$\begin{array}{ll}\text { Mental scanning without a map in B-Trial sketch-maps: } & 71\end{array}$

PATH vs. TRAIL distinctions in B-Trial subjects: 77

Demonstrative path fictive motion and perceptual wholes

[SYMBOL domain]: $\quad 78$

$\begin{array}{ll}\text { TOURIST WAYFINDING } & 81\end{array}$

Layout of the chapter: $\quad 82$

Walking around looking at things - scale \& scanning: $\quad 84$

Access path: approaching I.M. Pei's Louvre Pyramid: 86

Access path: Arc de Triomphe from Place de la Concorde: $\quad 94$

Emanation path (targeting path type): sighting between landmarks: 95

Emanation path (prospect path \& access path type): Grande Arche facing the Arc de Triomphe:

Subject denial and speculative analysis of an access path: 101

FM while drawing a sketch-map of the Champ de Mars: 105

$\begin{array}{ll}\text { Looking out windows in Paris: } & 109\end{array}$

$\begin{array}{ll}\text { Relations between views and visual FM: } & 110\end{array}$ 
View-related FM: views in verbal construal:

Emanation path (prospect path type): cooking classes and the Unique Vector Constraint:

Emanation path (prospect path type): Le musée Carnavalet: 116

Almost FM: views as nouns:

The view (vision construed as a noun): the apartment:

Another view: the apartment:

Comparing palpability parameters across images:

Grammatical differences (seeing differences):

A functional difference?:

A final note on palpability and time:

CONCLUSIONS

The Stanford Trail study:

The Paris study:

General conclusions about the facilitation of fictive motion:

145

Areas for further research:

APPENDIX A: DATA TABLES

150

BIBLIOGRAPHY 


\section{LIST OF FIGURES}

Figure 2.1 - priming activity: matching contour lines to terrain profiles 14

Figure 2.2 Brandywine Falls Area Map featuring Stanford Trail 16

Figure 2.3 Fictive Motion in Terrain World - path compressed in blend 34

Figure 2.4 Fictive Motion in the Map World - path pre-compressed in map 35

$\begin{array}{ll}\text { Figure 2.5 Stacked contour lines forming a perceptual whole } & 79\end{array}$

Figure 3.1 The Axe Historique $\quad 91$

Figure 3.2 Line of sight: Place de la Concorde - Arc de Triomphe - Eiffel 96

Figure 3.3 Line of sight from Arc de Triomphe to Eiffel Tower 101

Figure 3.4 The Eiffel Tower and the Champ de Mars 105 


\section{LIST OF IMAGES}

Image 2.1 Sketch-Maps 1 (left) Holly \& 2 (right) Carl 74

Image 3.1 The Louvre (pyramid visible through far archway) 87

Image 3.2 The glass pyramid through arch 88

Image 3.3 I.M. Pei's glass and steel Louvre Pyramid 89

Image 3.3 Place de la Concorde to Eiffel (left) and Arc (right) 97

Image 3.5 Looking out window of cooking school 114

Image 3.6 Hotel Carnavalet $\quad 117$

Image 3.7 View out of apartment onto rooftops and toward streets $\quad 120$

Image 3.8 View from apartment out other window onto courtyard 122 


\section{LIST OF TABLES}

Table 2.1 The structure of the trials and groups 11

Table 2.2 Between group differences (CNTRL) 12

Table 2.3 Between group differences (TEST) 12

Table 2.4 Descriptions of select types of fictive motion with examples 17

Table 2.5 Distribution of fictive motion types across trial groups 29

$\begin{array}{ll}\text { Table 2.6 A-Trial blending options } & 37\end{array}$

Table 2.7 B-Trial blending options $\quad 44$

Table 2.8 C-Trial blending options $\quad 54$

Table 3.1 Palpability parameters across the four images 123

Table 5.1 FM data from Stanford Trail Study 150

Table 5.2 FM Data from Paris slide show 155 


\title{
A Sense of Space: Conceptualization in Wayfinding and Navigation
}

\author{
by \\ RYAN DEWEY \\ Abstract: \\ This thesis addresses a gap in current cognitive work on fictive motion by \\ exploring the factors involved in the production of fictive motion rather than the \\ standard approach of investigating fictive motion processing. \\ Part 1 of this study consists of an experimental study of the production of \\ coextension path fictive motion (such as the ravine ran beside the trail) in \\ language used by hikers as they move along a trail through a complex terrain. \\ Part 2 is an ethnographic study of the wayfinding strategies recruited by \\ American tourists in Paris in the production of general emanation path fictive \\ motion (such as the museum overlooked the courtyard). The major findings in \\ this work suggest 1) that the role of compression in conceptual blends is a \\ facilitating force in the production of fictive motion, and 2) this facilitating force \\ motivates a semiotic typology of fictive motion that refines Talmy's original \\ analysis.
}

\section{Keywords:}

mental scanning, fictive motion, palpability, map usage, figure-ground organization, semiotics, compression, conceptual blending 


\section{INTRODUCTION}

What makes the use of fictive motion important to the processes of wayfinding and navigation? The answers to this question provide insight into the relationships that link perception of space to conceptualization of space.

Roughly, fictive motion is linguistic description of motion that occurs when nonmoving static entities are described as if they were moving. In reality, this results in attention moving along a path rather than the non-moving static entity doing the moving. Fictive motion is then the nonveridical description of motion such as:

$$
\text { Don: “...that ravine ran beside the trail..." [3.102] }
$$

The ravine is not moving. This motion description is Don applying motion to a non-moving scene. This type of language seems to happen more frequently when the element conceived of as moving is at a scale that the speaker can understand and easily imagine or mentally scan. In other words, fictive motion seems to happen when the trajectors are at human scale.

Maps and photographs are good sources for large items compressed to human scale. Might there be a link between the use of maps and the occurrence of fictive motion? 
In the present study there is evidence that seems to suggest that the scale in the symbolic representation of space (on maps and in photographs) facilitates the production of fictive motion descriptions. This might be the result of the reduced scale on the map working to increase the palpability of the element described as moving. In other words, it might be that maps and pictures make trajectors more obvious. It might be that this obviousness makes mental scanning easier. On the other hand it might be that the scale permits a map user to see the broader context and to see how the moving element starts and finishes within a larger space.

Consider a sentence like "Well, it looks like it kind of zigzags through some...short, uh, well for Ohio, moderate like ridges" [2.026 Raleigh]. Raleigh could not see the entire trail by looking straight ahead on the ground, but by looking at a map the entire trail was resized and brought into a scale that lets him see the end points of the trail and the pattern of the path shape between the two end points. Maybe seeing the entire pattern of the path facilitated his recruitment of the fictive motion construction "...zigzags through...".

A vivid green line on a map symbolically represents the trail on a crisp background of white paper. This contrast causes the trail symbol to stand out as a figure against a ground. Perhaps this facilitates a fictive motion description since it makes the trail shape more obvious. 
Fictive motion has long been analyzed as a conceptual blend (Fauconnier \& Turner 2002) in which static elements in one mental space form relationships with general motion elements in another mental space, resulting in an integration of the motion trajector and the non-moving entity in the fictive motion blend. The structure of this blend is simple, but the process of selective projection of elements from the mental spaces into the blend is subtly complex.

In the case of the fictive motion in this study, different types of fictive motion will be explored, but they will be explored differently than they are treated in other works. For instance, this study will make a distinction between fictive motion that describes a symbolic element (like the green line of the trail on the map) and fictive motion that describes a substrate element (like the actual compacted dirt trail on the ground). It will be seen that these both share the same path shape; they are both coextension path fictive motion, but they were achieved in distinctly different blends. The SYMBOL fictive motion occurs when symbol elements are projected into the blend. The SUBSTRATE fictive motion occurs when substrate elements are projected into the blend. The main difference between these two results is a matter of attention. Consider the significance of this with respect to the idea that maps which achieve human scale also facilitate the production of fictive motion.

Conceptual blending is the heart of the way that people understand and describe space. Conceptual blends have profound impact on the way that people make 
sense out of space, especially in semi-formal navigation in which people utilize maps to make sense out of the surrounding landscape. Blends are required for lining up the symbolic map world with the actual terrain world. Interestingly, maps themselves sometimes embody conceptual blends, this is certainly the case when a map presents space at human scale, since one of the chief functions of a blend is to achieve human scale (312, Fauconnier \& Turner: 2002).

When a map achieves human scale and that map is being used in a navigation blend, a tightly compressed blend is being used as the input for a secondary blend. Similarly, when maps that have achieved human scale enable a person to form the conceptual blend of fictive motion, that pre-compressed map is being used as an input for the fictive motion. This raises an interesting question: Do pre-compressed blends facilitate the production of fictive motion? From the initial data in this study it is suggested that yes, these compressed blends do seem to facilitate fictive motion. For instance, from raw numbers alone, 92 out of $99 \mathrm{FM}$ utterances were made by subjects who had access to maps in the study, leaving a mere 7 utterances to come from subjects who did not have access to maps. Other findings about the nature of fictive motion suggest that it is a strong tool for directing attention, not only in coextension path fictive motion (in which a path extends over the surface of a spatially extended object (see 138, Talmy: 2000)), but also in visual fictive motion like emanation path fictive motion (in which an intangible entity emerges from a source (see 105, Talmy: 2000). In fact, they are seen to feature strongly in the process of reconstructing memory such as in 
moments of giving directions between two points in a city, or by directing people's attention to specific elements in a scene.

\section{MAP READING}

A map is a symbolic representation of physical space. The basic function of a map is to help the reader engage with the physical space by putting it at a scale that the reader is able to apprehend and able to perform various computations with the symbology of the map. One of the most basic computations is answering the question "where am I?" Another basic computation involves identifying routes (i.e., paths) between points (i.e, landmarks). Maps can be used anywhere. For instance, a map can be used to plan a course in a different location or a map can be used in the particular location that it represents.

The interaction of the reader with the map is not the only interaction that takes place in the use of a map. Other interactions include imagining the texture of the mapped area, orienting the map according to the user's position relative to a fixed absolute position, orienting the map to the immediate surroundings, finding distances between locations, comparing and evaluating alternative routes, and many more.

This study looks at the way that maps are used to scale the participant's experience of terrain to a level that makes it available for mental scanning of that terrain area. 
A topographical map displays a flattened representation of the variation in elevation of a three dimensional space by using a standardized representation called a contour line.

Contour lines are demarcations of elevation, and points at the same elevation are connected with the contour line. Part of reading a topographical map involves reconstructing the texture of the landscape by interpreting the elevation variation encoded in those contour lines. A route outlined on the map is assumed to follow the route in the actual landscape (Stjernfelt 2007), and so if a map user correctly reads the contours and texture of the terrain on the map, and the trail moves through the contours and elevation changes, then mental scanning of the route on the map can be assumed to reflect the path shape of the route on the ground.

In this study, participants experienced different elements of topology and were questioned about a map that represented the complexity of spatial configuration and the morphology of path shape in the environment in which the experience took place. Their descriptions were recorded and analyzed to determine conditions that affect the frequency of fictive motion constructions in the conceptualization of space. Three groups of participants were assigned different task sets to determine the effect of visual priming on the production of fictive motion. 
Traditional empirical studies of fictive motion as cognitive simulation study the ways in which the mind processes fictive motion sentences based on a series of prompts (Matlock: 2004a \& 2004b; Matlock, Ramscar, Boroditsky: 2005). The present study seeks to compliment that work by approaching the question from a different angle; specifically, by investigating how the non-linguistic priming of directionality in topographical maps contributes to the production of fictive motion. A second goal is to study how actual motion and embodied cognition affect the conceptualization of space and interpretation of a map. Since maps are visual simulations of physical space, and actual motion constructs a mental map, if people produce fictive motion during a physical experience (such as traversing zigzagging terrain, or taking a trail that goes up a hill) this might provide confirming evidence that the mental model constructed through the experience includes motion.

\subsection{Layout of the chapter:}

The chapter opens with a description of the study including the structure of the protocol, priming activity, and the resources available to subjects (such as access to the trail for walking, access to a map, et cetera).

At this point an early discussion of the findings of the study is explored in a section about the semiotic characteristics of the fictive motion constructions in the trail study data, specifically proposing an ad hoc fictive motion (FM) typology 
that breaks the data into fictive motion that refers to the world of the map SYMBOL and fictive motion that refers to the world of the trail SUBSTRATE. This is compared with existing views on FM typologies, and examples from the data are presented. Following the data examples is a discussion of the distribution of the FM data, explaining why 67 out of 99 FM constructions related to the SYMBOL world, and it is argued that access to the map SYMBOL facilitates FM production in subjects.

The next section discusses the role of conceptual integration in SYMBOL and SUBSTRATE FM, looking at the compounding nature of the fictive motion blend. The nature of selective projection is explored to see how during map usage blends emerge where SYMBOL elements are projected into the blend producing SYMBOL-oriented blends, and with other blends SUBSTRATE elements are projected into the blend producing SUBSTRATE-oriented blends. This is seen as a result of attention.

The next section explores the FM data separated by trial (A-Trial, B-Trial, CTrial). The blends that are available to subjects are discussed, path shape is discussed, and basic grammatical differences are explored. The discussion turns to the role of the map as a central unit in helping people move between the spectator-role (third person perspective) in maps and the participant-role (first person perspective) in real experience. Next, the role of scale as an FMfacilitating feature of the SYMBOL world is explored, which leads to a discussion 
of the role that the palpability of the trail substrate plays in subjects who do not experience the human-scale afforded by the map SYMBOL. Sketch-maps produced by subjects who did not have access to the map are explored to see if mental scanning (one of Talmy's distinguishing features - 105, Talmy: 2000) is present in subjects who did not previously encounter the compressed scale afforded by the map SYMBOL.

\subsection{An initial look at the data:}

Consider the following typical dynamic descriptions in the following fictive motion constructions from three map users:

(2) Raleigh: Well, it looks like it kind of zigzags through some...short, uh, well for Ohio, moderate like ridges, kind of uh weaves its way through, goes around one, goes kinda through another... [2.026]

(3)

Herman: The Stanford Trail, is, um, well, it uh, looks steeper than the [clears throat] Brandywine Gorge Trail, because, um, based on the topographical map, it um, does, it does go around some of the hills but I can see in some parts it is um going up the hills, down the hills, and, in, in one portion it levels out over here by uh Stanford House, um and obviously it becomes less difficult, but um, over by the Averill Pond this is where the most of the, probably the heavy-duty hiking will uh, be taking place. [7.086]

(4) Polonius: It starts pretty easy, but I guess it does go over some hills here, and it looks like it comes down... and it winds around, um, it looks like it goes back over some ridges here, and... [8.023]

Contrast this with typical static descriptions of the environment from subjects who did not have access to a map during their trail experience:

(5) Carl: Um, uphill most of the way, uh, a lot of trees have uprooted, but uh, just beautiful sight. Hills. [5.029] 
(6) Holly: I'm happy that the ground is level, because now I can breathe again. [Laughs] [5.030]

(7) Holly: [laughs] Um, the first part of it like I said was a little difficult going uphill, especially with it being so wet and muddy, but um, the rest of the way has been really easy, so. [5.121]

(8) Bob: The trail is muddy, [6.007]

(9) Bob: This is a pretty, pretty big decline. [6.067]

(10) Bob: So there was a, there was a break, there was like an intersection that we had to make a decision, on our trail, so we, um, corporately went down to the falls. um. [6.094]

\subsection{The Stanford Trail study details:}

Nestled in the Cuyahoga Valley National Park, the Stanford Trail is a 1.75 mile trail that connects the Towpath Trail to the Brandywine Gorge Trail by passing through a field, entering the forest and crossing several creeks as it ascends, descends, crawls through valleys and weaves its way around the contours of ridges and hills. It is a linear trail that does not loop back, thus the return trip is along the same path as the original trip.

The main draw for using the Stanford Trail in this study emerges from the topography of the trail, specifically, that the terrain and the substrate of the trail followed a fairly consistent zigzagging pattern. The trail featured a horizontal zigzag path back and forth, as well as a vertical zigzag path up and down. These features contribute to a rich experience of the terrain in which map miles do not seem to correspond to trail miles in any way. For instance, because of the constant ascending and descending that occurs on the trail the elevation 
changes seem to be greater than the 190 feet measured in the map legend, but this is illusion and a mere compounding experience of the hilly forest.

\subsubsection{Trials and groups:}

Table 2.1 The structure of the trials and groups

$\begin{array}{cccccccc}\text { Trial } & \text { Group } & \text { Priming } & \text { Map } & \begin{array}{c}\text { Pre-Walk } \\ \text { Questions }\end{array} & \text { Walk } & \begin{array}{c}\text { Walk } \\ \text { Questions }\end{array} & \begin{array}{c}\text { \# of } \\ \text { Subjects }\end{array} \\ \text { A } & \text { CNTRL } & \begin{array}{c}\text { Contour } \\ \text { Matching }\end{array} & \text { Y } & \text { Y } & \text { Y } & \text { Y } & 4 \\ \text { B } & \text { TEST } & \text { No Priming } & \text { Y } & \text { Y } & \text { Y } & \text { Y } & 3 \\ & \text { TEST } & \begin{array}{c}\text { Contour } \\ \text { No Priming }\end{array} & \text { N } & \text { N/A } & \text { Y } & \text { Y } & 2 \\ \text { C } & \text { CNTRL } & \begin{array}{c}\text { Contour } \\ \text { Matching }\end{array} & \text { Y } & \text { Y } & \text { Y } & \text { Y } & 2 \\ & \text { TEST } & \text { No Priming } & \text { Y } & \text { Y } & \text { N } & \text { N/A } & 1\end{array}$

With the exception of one A-Trial subject and two C-Trial subjects, all subjects participated as pairs. The extent to which this affected the production of FM is not readily clear, but it is possible to look at the FM-usage numbers and draw conclusions about the behavior of subjects within pairs.

One of the ways of looking at this data is to see how the usage of fictive motion constructions spread through dialogue. For example, when one subject uses a novel fictive motion construction does it influence the other subject to use comparable fictive motion in their next utterance? This sort of "contagion effect" would show up as an epidemiological spread of FM usage in the flow of 
discourse. If this contagion effect was present, subjects within pairs would use equal amounts of FM. But this is not the case, in fact, across pairs only two pairs had comparable FM usage while the remaining pairs had uneven distribution of FM usage suggesting that high FM-producing subjects did not spread their FM usage to low FM-producing subjects.

Table 2.2 Between group differences (CNTRL)

$\begin{array}{ccc}\text { A, Priming } & \text { B, Priming } & \text { C, Priming } \\ \mathbf{8} \text { (Badger) - } \mathbf{1 1} \text { (Regina) } & 2 \text { (Carl) - } \mathbf{2} \text { (Holly) } & \mathbf{1 0} \text { (Herman) - } \mathbf{3} \text { (Eliza) } \\ \mathbf{1 5} \text { (Raleigh) - } \mathbf{6} \text { (Nicole) } & (\mathrm{n} / \mathrm{a}) & \mathbf{1 0} \text { (Polonius) - (n/a) }\end{array}$

Table 2.3 Between group differences (TEST)

$\begin{array}{ccc}\text { A, No Priming } & \text { B, No Priming } & \text { C, No Priming } \\ 13 \text { (Don) - } 1 \text { (Natasha) } & 0 \text { (Bob) - } 2 \text { (Ariane) } & \text { (n/a) - } 3 \text { (Marian) } \\ 11 \text { (Tripper) }-(\mathrm{n} / \mathrm{a}) & (\mathrm{n} / \mathrm{a}) & \text { (n/a) }\end{array}$

Because of this distribution of FM production seen between groups and across groups it is argued here that FM did not spread between subjects in the study.

\subsubsection{The three basic stimulus questions:}

Throughout the study each subject was asked a series of three statementquestions. Although not identically phrased in each case, the general questions were as follows: 1) Describe the map, 2) Describe the trail, 3) Describe the terrain. Note: The B-Trial subjects were not asked question \#1 because they did not receive a map during the experience. 
These questions elicited descriptive data that was then analyzed for FM usage and path and landmark language.

It is important to mention that the ambiguous word trail may have mislead some subjects. The original intent was to delineate the physical substrate of the trail through the woods (i.e., the linear "object" trail), however, some individuals may have understood the word trail to refer to an experiential matrix composed of the event, the actual path substrate, the scenery, flora and fauna, and the geophysical terrain. However, this is addressed with two of the B-Trial subjects in section (2.12) which outlines the perceived differences between the word "trial" and the word "path".

\subsubsection{Priming activity: matching contour lines to terrain profiles:}

Control group subjects were given a brief priming activity that was selected to prime subjects to look at elevation in the map and on the trail. Björn Kjellström's enduring guidebook Be Expert With Map and Compass $(1955,2010)$ contains many activities for orienteering practice. One of those activities is a matching game between thumbnails of contour lines and their respective silhouette profiles.

This game was chosen because it is educational (by introducing subjects with contour lines), and because it gives a more meaningful notion of the canonical 
orientation of the referents of the contour lines (by describing what they look like from a horizontal perspective). People routinely engage the world around them at eye level on a horizontal plane (with the exception of the vertical plane when flying above a region or looking out a window). The familiarity with the horizontal perspective and the unfamiliarity with the contour lines enabled subjects to begin to match up correspondences in shape. The priming activity matching game sheet is seen below:

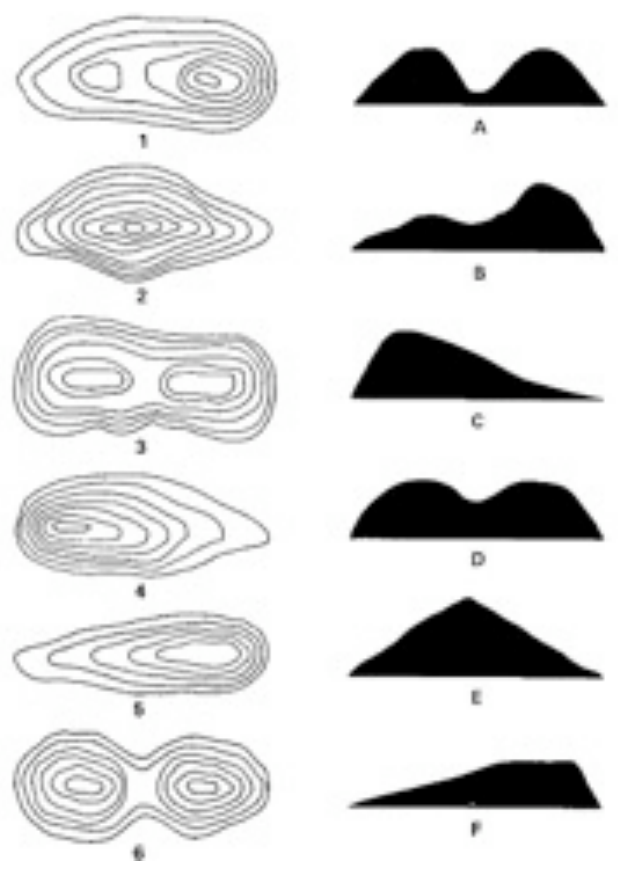

[Figure 2.1 - priming activity: matching contour lines to terrain profiles] (Kjellström, B. \& Kjellström Elgin, C. Be expert with map and compass: The complete orienteering handbook (third edition), John Wiley \& Sons (2010), page 38: reprinted with permission)

The correct matches are: \#1-B, \#2-E, \#3-D, \#4-C, \#5-F, and \#6-A. 
Only one subject made an error in the priming activity, crossing \#3 with \#6 by connecting \#3 \& A, and \#6 \& D. The error was made by Nicole, an A-Trial control subject, who produced $4 \mathrm{FM}$ sentences that related to the physical substrate of the path, $1 \mathrm{FM}$ sentence that related to a physical material on the path (stones), and only $1 \mathrm{FM}$ sentence that related to the path symbol as depicted on the map. The fact that only one utterance related to the map is interesting, but it is not sufficient information to determine whether or not it roughly reflects the error in the matching activity. In fact, the error was a simple error (the switched shapes D \& A resemble each other) and may have resulted from trying to complete the activity too quickly.

\subsubsection{The Stanford Trail map:}

A-Trial and C-Trial subjects were provided with this official topographical map of the Brandywine Falls Area. The map is printed in landscape orientation on white 8.5x11 sized paper (see Figure 2.2).

Subjects who received the map prior to the walking experience were asked to describe the map, the trail, and the terrain before beginning the walk. Subjects who did not receive the map began their walking experience without any such briefing experience. The control groups in trials A \& B completed their priming activity before embarking on the walking experience and the control group for C- 
Trial completed their priming activity before they were asked the questions at a table.

\section{Brandywine Falls Area \\ National Park Service \\ U.S. Department of the Interior \\ Cuyahoga Valley National Park}

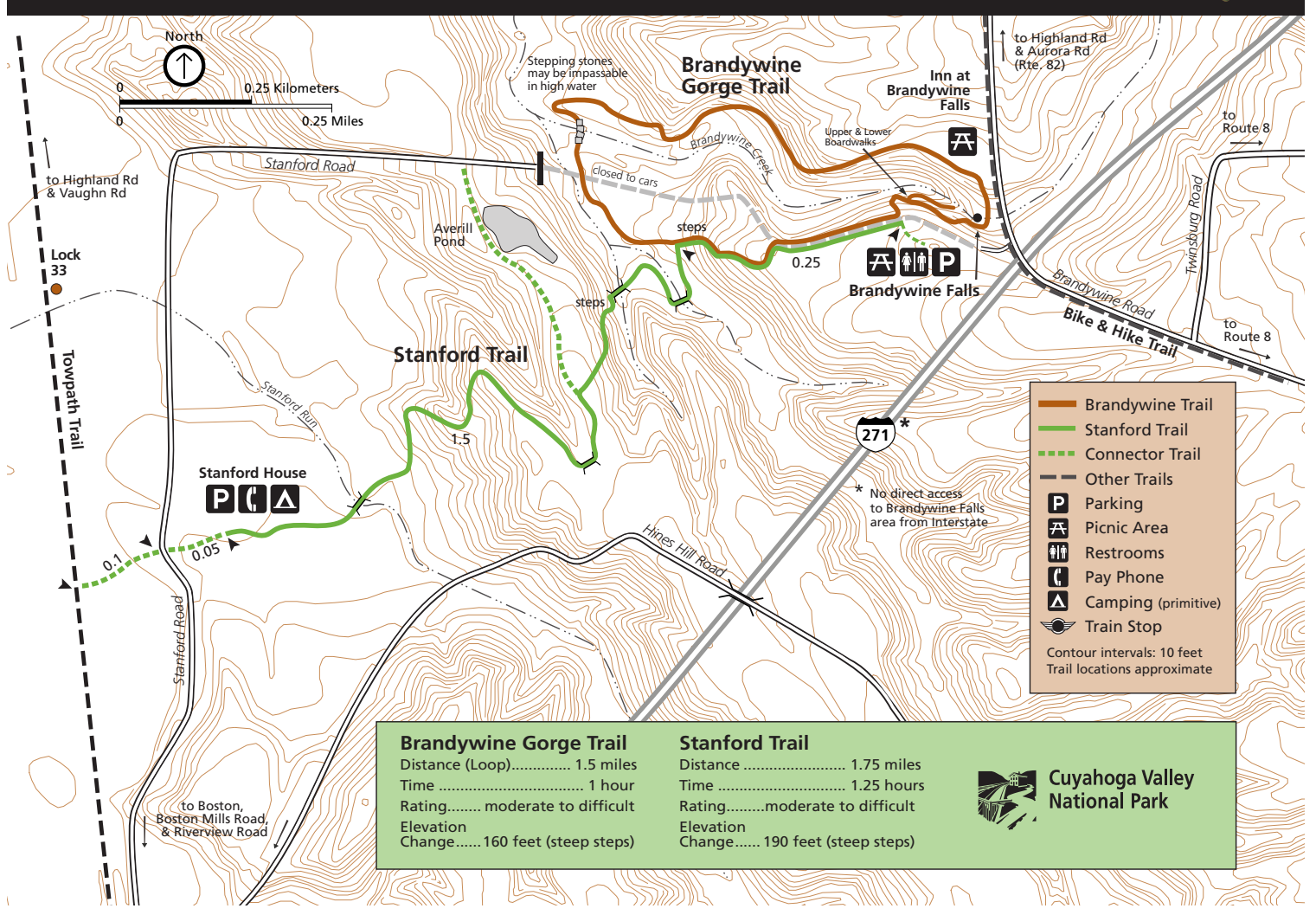

[Figure 2.2 Brandywine Falls Area Map featuring Stanford Trail (solid green line)]

\subsection{Semiotic characteristics of FM constructions}

\subsubsection{FM typology and the SYMBOL world:}

As mentioned, the main finding with the Stanford Trail is that subjects used FM to describe the physical trail more frequently when they were able to see the trail as a representational SYMBOL on the map. It put the trail at a scale that they could 
apprehend and it afforded easy visual and mental scanning. In 67 out of a total of 99 FM occurrences for all trials, the FM produced by subjects in this study was of this SYMBOL type. Not only did people use SYMBOL FM to describe the trail, but they used SUBSTRATE FM to describe the physical trail with a total of 26 FM verbs describing a SUBSTRATE (21 of those verbs came from subjects who had access to a map).

Talmy (2000) outlines a typology of fictive motion path types, noting the differences between emanation paths, pattern paths, frame-relative motion, advent paths, access paths, and coextension paths among others. These distinctions focus on geometrical variation and manner of motion information but they hardly address this physical-representational modality distinction (SYMBOLSUBSTRATE) as a categorical baseline. Consider the following FM types found in chapters 2 and 3 of the present document:

Table 2.4 Descriptions of select types of fictive motion with examples

\begin{tabular}{lll}
\multicolumn{1}{c}{ path type } & \multicolumn{1}{c}{ description } & \multicolumn{1}{c}{ example } \\
coextension & $\begin{array}{l}\text { a path is conceived as being located } \\
\text { along some spatially extended object } \\
\text { [the path itself is the fictively moving } \\
\text { entity] }\end{array}$ & $\begin{array}{l}\text { "the trail zigzags back and forth } \\
\text { through the woods" or "the road } \\
\text { runs along the shore" }\end{array}$ \\
advent & $\begin{array}{l}\text { location of stationary object with } \\
\text { respect to its manifestation in its } \\
\text { location [the appearing of the object in } \\
\text { that location is fictive] }\end{array}$ & $\begin{array}{l}\text { "look at all of the clay chimneys } \\
\text { dotting all over the place" }\end{array}$ \\
& $\begin{array}{l}\text { location of stationary object with } \\
\text { access } \\
\text { respect to a path that an agent could } \\
\text { take to reach that object [fictive } \\
\text { movement along path] }\end{array}$ & "the cafe is down around the corner \\
& &
\end{tabular}




\begin{tabular}{|lll}
\multicolumn{1}{c}{ path type } & \multicolumn{1}{c}{ description } & \multicolumn{1}{c}{ example } \\
prospect & $\begin{array}{l}\text { object with a front faces its } \\
\text { surroundings [fictive vision follows the } \\
\text { path determined by the front orientation } \\
\text { of object] }\end{array}$ & "the balcony looks out on the city" \\
line-of-sight & $\begin{array}{l}\text { intangible line emerges from visual } \\
\text { apparatus [line follows path set by } \\
\text { visual orientation] }\end{array}$ & $\begin{array}{l}\text { "I quietly turned my camera around } \\
\text { the room" }\end{array}$ \\
targeting & $\begin{array}{l}\text { an agent orients an object along a } \\
\text { desired path [fictive line travels that } \\
\text { path] }\end{array}$ & "I pointed my camera into the \\
& kitchen"
\end{tabular}

[roughly adapted from pages 107-138, Talmy: 2000]

Although these fictive motion types do not categorize along semiotic borders, Talmy does address the variation in experiencing the fictive motion in consciousness. Talmy's own "palpability parameters" address the concreteness of the conscious experience of the entity that is being construed with fictive motion, but otherwise, the semiotics of FM are left untouched. Talmy's original notion of palpability will be discussed throughout this work, and modifications to his notion of palpability will be explored to include not just the palpability of conscious experience of an entity, but also the palpability of the actual entity itself. However, that discussion of extended palpability is jumping ahead, and is beyond the current discussion of the categorization of fictive motion types.

A critical distinction that emerges from the findings of the present study is that fictive motion categorizes across another set of features, specifically scale and modality as they converge in experience of physical substrates, vistas, events, and symbolic representations of those experiences in imagery and map 
symbology. Perhaps the reason that this has been left untouched is because it does not reflect a qualitative difference in the overall geometry of the FM typology; a zigzagging line on a map that reflects a zigzagging trail on the ground still share the feature shape of a zigzag. But it is interesting to note that the presence of a symbol of a zigzagging trail on a map evokes more fictive motion construals than does the actual experiencing of that zigzagging on the actual trail. What accounts for this difference?

It will be argued that this difference results from an issue of scale and has a categorizing effect on the fictive motion present in this data.

\subsubsection{Four-category typology of FM:}

As mentioned, an experience that includes having a map with a symbolized trail seems to evoke more FM construals than having an identical experience without that map and symbol. This difference might result from issues of scale, which produces a categorizing effect in the FM present in this data. This categorizing effect suggests the specification of an ad hoc typology of FM that divides fictive motion along dimensions not previously considered in the study of FM. I have called this typology the semiotic typology of fictive motion since its primary distinction is across the relationships between the sign and its object (visual or linguistic). The main four category typology is: 


\section{SYMBOL - SUBSTRATE - SUBSTANCE - EXPERIENCE}

What follows in this section is an overview of the perceived dimensions of the FM data, a description of the FM distribution in the data, a treatment of scale and mental scanning, and a robust selection of examples that illustrate the semiotic typology of fictive motion in this data.

\subsubsection{Suggested dimensions of FM:}

The data covered in this study exhibit multiple categories for FM, including FM related to: the physical artifact of the map and its associated symbology (i.e, SYMBOL); the actual geographic features of the terrain (i.e., SUBSTRATE); salient objects present on the terrain (i.e., SUBSTANCE); and visual scenes, points of view, physically experienced scene, or abstract non-tangible FM (i.e, EXPERIENCE). These categories can be best represented in three pairs of binary distinctions:

- SUBSTRATE vs. SYMBOL [e.g., physical trail vs. trail on map]

- SUBSTRATE vs. EXPERIENCE [e.g., physical trail vs. overall hiking area \& event]

- SUBSTRATE vs. SUBSTANCE [e.g., physical trail vs. leaves or stones on trail $^{* 1}$

\footnotetext{
1 The SUBSTRATE vs. SUBSTANCE distinction is important whenever the substrate is recruited in FM without considering the substance, such as when a riverbed is construed in FM but the water in the river is not in focus. Similarly, sometimes the substance is construed as a trajector figure with FM and the substrate is the landmark ground. In those cases this distinction provides a useful way to think about the relationship between the substrate and the substance (i.e., the CONDUIT conceptual metaphor).
} 
This work addresses the SUBSTRATE and SYMBOL type in this chapter, and in chapter 3 EXPERIENCE will be considered, but SUBSTANCE (e.g., Nicole: "I see stones approaching." [2.179]) is left unexplored because of the limited examples in the data.

Talmy (115: 2000) addresses a distinction between the Experiencer as Source and the Experienced as Source in sensory path fictive motion. His discussion is centered around the directionality of the sensory path. The present Trail study focuses on physical path substrates that exhibit coextension path fictive motion, and Talmy's emanation distinction is further explored in the Paris study which focuses on the general mise en scene established through emanation path and access path FM. The emanation path types and the access path types are categorized as the EXPERIENCE type presented above. In fact, the EXPERIENCE distinction is not in competition with Talmy's model, it is used here to represent all vision-oriented FM that is not SYMBOL or SUBSTRATE FM.

Matlock (2004b) proposes two types of FM constructions: Type 1 has a metonymic link between the trajector of the FM construction and actual motion in the real world (i.e., the road runs toward the hills); Type 2 has no such metonymic link from referent to reality, in fact, despite being a linear extended object the referent is not typically viewed as being able to support motion (i.e., the clothesline runs from the house to the barn). This two-type distinction may appear similar to the SUBSTRATE-SYMBOL distinction presented here, but they 
are different. For instance, the SUBSTRATE and SYMBOL construction types can sustain both Type 1 and Type 2 elements, since the substrate is equal to the referent in real space and the symbol is equal to a representation of that substrate in representational space.

It seems like Matlock's Type 1 and Type 2 FM are best suited to distinguish differences among coextension path constructions, and that Talmy's emanation source distinction is best suited for the differences in visual fields. While Talmy and Matlock's distinctions elegantly categorize the range of fictive motion, the present study has data that suggests clustering around different features, along more semiotic lines between the SYMBOL and the SUBSTRATE.

\subsubsection{Examples of SYMBOL and SUBSTRATE FM:}

In the data collected from subjects who either walked the trail with a map or sat at a table and described the map, a robust collection of FM examples were found with distinctions drawn between SYMBOL and SUBSTRATE. The data is explored in subsequent sections, but a sample of SYMBOL and SUBSTRATE examples are presented below to help clarify the distinction.

\section{SYMBOL-oriented:}

(11) Regina: When the red lines are going down that means that you're going to have a decline in the "terrain"? [1.151]

(12) Polonius: it looks like it follows the low lying areas, mostly, it doesn't look like it goes over a peak necessarily, maybe here [8.019] (C-Trial: no walk experience) 
(13) Raleigh: It also looks like it, uh, intersects with another... [2.030]

Raleigh: ...intersects with another trail [2.032]

(14) Don: see so the lines are this way so that's the elevation climbing up, so we're going down so we're down [3.129]

(15) Eliza: It connects from the towpath, and you go past Stanford Road, it twists and winds a lot, and... [7.026] (C-Trial: no walk experience)

\section{SUBSTRATE-oriented:}

(16) Nicole: But so far, pretty even, as far as not going steeply up and down,... [2.090]

(17) Don: You know what is funny I didn't really see the ravine on the map, that we were walking along, so like right here, here's we're on this bridge, that ravine ran beside the trail, and I wouldn't have thought by looking at the map that that was a ravine. [3.102]

(18) Badger: I don't feel like you can really...outside of the fact that it looks like it's going uphill [1.072]

(19) Badger: Well, the trail got... [1.202]

Subjects who had the symbolic map available to them also had SYMBOL FM available as a construal option in addition to general SUBSTRATE FM. Subjects without the map had nothing to motivate any SYMBOL FM because there was nothing related to SYMBOL in their experience. It is not surprising that those subjects did not use SYMBOL FM. However, the SYMBOL-SUBSTRATE distinction makes it interesting to look at the reasons why a subject who has access to SYMBOL FM might construe some scenes with preference for SYMBOL-oriented FM, compared with reasons why the same subject might choose to construe other scenes with preference for SUBSTRATE-oriented FM. It is already clear that the having access to SYMBOL is the first factor. The ability to scan the path enables a path to achieve human scale. Whether that human scale occurs at the SYMBOL level (by having a pre-compressed bird's-eye view 
on a map) or the SUBSTRATE level (through online compression in traveler's perspective) is a matter of operating as a spectator and a participant (Hutchins 1995). A secondary factor might be the relative palpability (Talmy 2000) of one type of path (SYMBOL or SUBSTRATE) when compared to the other (i.e., if SYMBOL is perceived as more palpable than SUBSTRATE, then SYMBOL is the preferred FM construction) this seems to be related to attention phenomenon.

\subsubsection{Distinguishing between SYMBOL and SUBSTRATE:}

Oakley describes middle voice constructions as construing "spatially extended objects in terms of a traversed path that is coextensive with the object" (159, Oakley: 2009). These are typical examples of fictive motion, such as the general coextension path FM that is most frequently addressed in literature about FM. Considering the physicality of the path and its location on an extended object, one might question why SUBSTRATE is being distinguished from coextension path FM. What is gained from such a distinction? This is a valid question that can be answered with a mere glance at an utterance such as:

\footnotetext{
"Mayfield road runs up the hill into Cleveland Heights" [NB: fabricated utterance]
}

This sentence can be true in the context of standing on a street corner giving directions by pointing to the road and the hill. It can be equally true of a statement made while reading a map, or it can be true while describing the actual scene in discourse where neither the road or the map are present, such as in its 
representation above. The construction in (20) can describe the SUBSTRATE, the SYMBOL, or an abstraction of the two.

With this type of flexibility where an utterance can be felicitously used in three different contexts, one might ask why drawing a distinction between SUBSTRATE and SYMBOL is even necessary. In the present study it seems necessary because the people using the coextension path FM constructions seem to draw the same distinction by their patterns of FM usage. The frequency of FM seems to be dependent upon having a SYMBOL representation when the substrate scene is too complex to be visually scanned. The actual scene overloads the subject (either through protracted duration, confusing turns in the trail, reduced visibility from tree growth, or by distraction from a new environment), or, perhaps it is just an inability to take the spectator's view that limits the ability to scan in a way that permits higher frequency of FM usage. In cases where the spectator's view is provided through the map the subject is able to construe more FM paths (SUBSTRATE and SYMBOL) than they would have otherwise.

Maps do a good job at providing the spectator view.

Maps shrink space to a compressed scale that allows the user to blend the world of the map with the world of the geographic terrain described on the map. This shrinking effect gives users new strategies for thinking about space. Thinking 
about space in a symbolic way is one of those strategies. On the trail map, the map displays a symbol that represents the trail and a subject can see and scan this symbol and then connect the symbol to the surrounding terrain of the trail by a series of mental space mappings like identity, part-whole, and representation. Sometimes the SYMBOL is projected into the FM blend, other times the SUBSTRATE is projected into the FM blend.

This difference in projection of SYMBOL or SUBSTRATE correlates with access to the map in the first place. Subjects without access to the SYMBOL are less likely to construe the path in any FM terms (SUBSTRATE by default since SYMBOL is absent). Subjects with the SYMBOL not only use SYMBOL-related FM to describe the path, but they also now have SUBSTRATE-related FM available for description. Importantly, SYMBOL is a variable in the process of scene description, and with the presence of the map SYMBOL the map acts like a key to unlock other FM constructions for active use in discourse.

SYMBOL FM here refers to FM that features the sign of the trail as it exhibits iconic similarity to the shape of the trail (it zigzags on paper and on the ground), it exhibits indexical relations that are manifest in the reduction in scale where one increment of length on the map is connected to a calculable increment of length on the ground, and it exhibits symbolic relations whereby the sign of the trail on the map is understood to represent the coextensive path along the ground with a 
common SOURCE-PATH-GOAL image schema. SUBSTRATE FM here refers to the actual object of the trail, the compacted dirt worn underfoot over time.

While it might be the fact that subjects have access to the symbolic map which in turn enables them to use FM about the trail, and it might be that SYMBOL and SUBSTRATE are really the same type of FM (i.e., coextension path FM), this does not mean that the SYMBOL-SUBSTRATE distinction is structurally insignificant. In fact, it can be argued that the difference between the projection of SUBSTRATE or the projection of SYMBOL is tied to attention patterns of the subjects using the FM construction. This role of attention in FM construction usage is the view taken in this study. It is argued that the subjects exploit the symbolic map as an input space that anchors their attention patterns to select the SYMBOL FM, and in cases where the SUBSTRATE FM is found subjects have anchored attention in the substrate terrain. Attention and palpability might be linked in the decision to project SYMBOL or SUBSTRATE into the FM blend.

When the subject has access to both the SYMBOL and the SUBSTRATE, one of two types of FM blends ensues:

- Subject has SYMBOL and SUBSTRATE, attention is focused on the SYMBOL, attention scans along the SYMBOL, SYMBOL FM is produced.

- Subject has SYMBOL and SUBSTRATE, attention is focused on the SUBSTRATE, attention moves through the SUBSTRATE, SUBSTRATE FM is produced. 
This stands in contrast with the situation where no SYMBOL is available to achieve human scale. It is more common for subjects without SYMBOL to produce the following "blend":

- Subject only has SUBSTRATE, attention is focused on the SUBSTRATE, attention moves through SUBSTRATE, factive motion along SUBSTRATE is produced

On rare occasions a subject without the SYMBOL does produce fictive motion blends in the following pattern:

- Subject only has SUBSTRATE, attention is focused on the SUBSTRATE, attention moves through SUBSTRATE, SUBSTRATE FM is produced (rare)

It should be noted that while this semiotic distinction of FM is useful in explaining distinctions in the data within this study, further empirical exploration of its tractability as a theoretical structure will need to be done in order to test its broader usefulness and legitimate application. For instance, had the time frame for this study permitted, one such approach to testing this distinction would have involved running experiments requiring subjects to judge the faithfulness of a linguistic description to a scene, with gradient altering of palpability across the set of prompts. 


\subsection{Frequency of FM occurrence across trials:}

Although B-Trial had fewer subjects, the margin of difference between the FM usage in the two trials suggests that something about A-Trial facilitated FM usage. The variable between the two trials was whether or not a map was provided with the experience. A-Trial subjects all received maps for use during the walking experience but B-Trial subjects were not given maps during the walking experience. FM was certainly more frequent with walkers with maps.

An initial explanation for this variance is that the scale of the trail as represented on the map lends to mental scanning of the entire trail, whereas strict experience of the trail without any symbolic compression presents a scale that does not lend to mental scanning of the substrate (or at best only partial mental scanning). The ability to mentally scan the trail is critical for an FM construal of the environment.

Table 2.5 Distribution of fictive motion types across trial groups

\begin{tabular}{|c|c|c|c|c|c|}
\hline $\begin{array}{l}\text { Trial/ } \\
\text { Group }\end{array}$ & $\begin{array}{c}\text { Subject } \\
\mathrm{s}\end{array}$ & \# of FM verbs & SYMBOL & SUBSTRATE & OTHER \\
\hline A CNTRL & 4 & 40 & 23 & 13 & 4 \\
\hline A TEST & 3 & 26 & 18 & 8 & 0 \\
\hline B CNTRL & 2 & $5^{*}$ & $0^{*}$ & 4 & 1 \\
\hline B TEST & 2 & 2 & 0 & 2 & 0 \\
\hline C CNTRL & 3 & 23 & 23 & 0 & 0 \\
\hline C TEST & 1 & 3 & 3 & 0 & 0 \\
\hline
\end{tabular}


The differences between the A-Trial groups and the B-Trial groups seem significant in terms of the raw number of occurrences of FM, and indeed, interesting effects were observed which may relate to the primary variable between the groups. The primary variable was the presence or the absence of the map during the experience. Control groups also received a priming activity that involved matching contour lines to contour profiles. Whether or not this priming activity affected the frequency of FM is uncertain.

The raw number differences between the A-Trial groups, the B-Trial groups, and the C-Trial groups is also interesting. The difference seems to elevate the importance of the map in the production of the FM; the B-Trial groups did not have a map and their production of FM is insignificant compared with the FM used by the $\mathrm{A}$ and $\mathrm{C}$-Trial groups which both had maps.

However, in addition to not having the map, B-Trial groups did not have an initial interview at the trailhead like the A-Trial subjects, this is because there was nothing about the trail that B-Trial subjects could have known prior to beginning the walk. It should be noted that 14 out of 40 of the A-Trial (control \& test) SYMBOL type FM constructions occurred in the initial interview at the trailhead before A-Trial subjects had any exposure to the SUBSTRATE of the trail. This may introduce a bias into the data since the initial interview favored SYMBOL FM without subjects having the experiential knowledge necessary to choose SUBSTRATE FM. However, once the trail experience began and SUBSTRATE 
knowledge became available many subjects did oscillate between SYMBOL and SUBSTRATE FM.

Interestingly it seems that the actual experience of walking on the trail may not be as significant of an influence on the production of FM as was originally expected. C-Trial subjects produced FM with comparable consistency to the ATrial subjects, but without the same number of opportunities to answer the three basic stimulus questions.

All A-Trial subjects had extended interviews that were spread out over the length of the trail: at the trailhead, at each of the four bridges, at the final stop, and again at the trailhead. The overall walking and interviewing experience was nearly 2 hours in length.

All C-Trial subjects had shortened interviews because they lacked the protracted experience of the walk with intermittent stops at bridges for questioning. Instead, C-Trial subject interviews occurred at a table and lasted between 5 and 10 minutes. C-Trial subjects had only 1-2 iterations of the interview questions which stands in contrast to the 5-6 iterations of the interview questions for the A-Trial subjects. 
From the comparability of these raw numbers it seems that whether or not a subject walked on the trail was less significant than whether or not the subject had a map during the interviews.

This difference is attributed to the use of a map as a material anchor and the compression involved in the scale of the map which made the trail SUBSTRATE more salient and available for clear mental scanning. This argues that the B-Trial subjects (who did not have a map) were not able to mentally scan the SUBSTRATE as readily as the subjects who had the compressed SUBSTRATE on the map.

\subsection{Conceptual integration and compression in SYMBOL and SUBSTRATE FM:}

Fauconnier and Turner argue that cognition and language produce fictive motion constructions in order to achieve human scale (377, Fauconnier \& Turner: 2002). What happens when the symbolization of space achieves human scale from the beginning, such as through human scale trails on a map? Does this symbolization short-cut the need for achieving human scale through fictive motion during map use? Or does it increase the odds that fictive motion will be recruited in human-scale descriptions of graphically represented trails?

In the fictive motion blend, when fictive motion occurs, there is compression to human scale by projecting a static entity into the blend while projecting motion 
into the blend. In the map blend, when physical space is represented graphically on maps, the map scale reduces actual size to human scale by projecting gross path shape into the blend, but not gross path length (although, ratio of length is projected into the blend).

When fictive motion occurs without a map in a description of the terrain world, one input space contains the actual geophysical terrain of the trail at actual length. The second input space contains the SOURCE-PATH-GOAL schema with the trajector moving along that path. When the actual path space maps to the second space with the path schema and trajector, there is an identity relation between the two and it carries into the blended space. The terrain world input does not project gross path length into the blend, but only path shape, and path length ratio, these elements are compressed in the blend to achieve human scale. The second input space projects the schema, the path, and the trajector into the blended space and their Identity relation is manifest in the blend. In this blend, the compression of the terrain into the human scale of the fictive motion description occurs en route from the terrain input space to the fictive motion blend. 


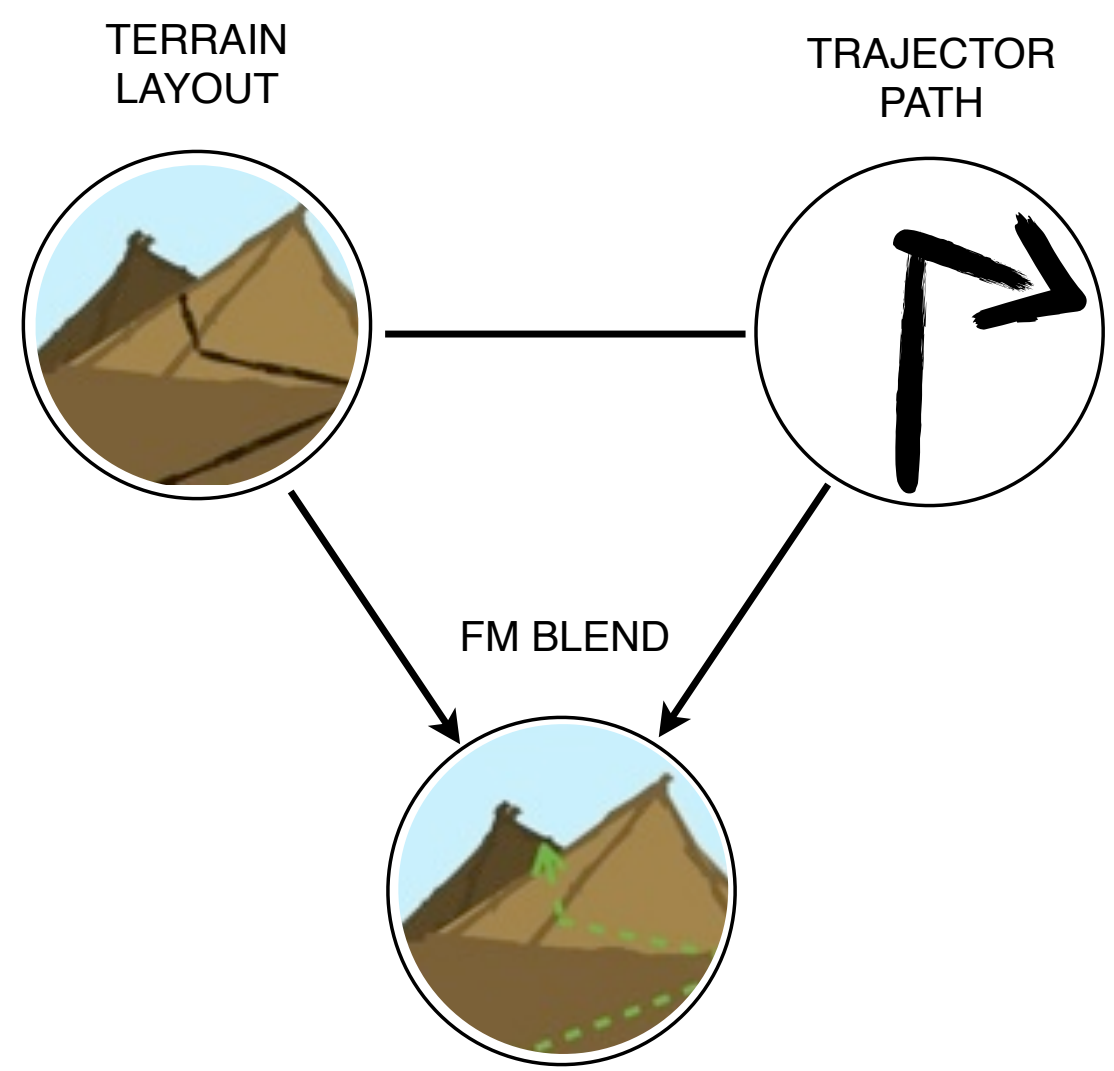

[Figure 2.3 Fictive Motion in Terrain World - path compressed in blend]

However, as shown in figure 2.4, the situation is different in fictive motion blends that take place in the map world; the trail comes pre-compressed as a graphical line in the map artifact, and the map artifact is one of the input spaces in the FM blend. The hard work of compression is already accomplished by the map. The map input space contains the static graphical representation of the trail (itself a blend of path shape and length ratio). Just like the blend in (figure 2.3) the second input space contains the SOURCE-PATH-GOAL schema with the trajector moving along that path. When the graphical path shape on the map artifact maps across to the path and trajector of the second input space, that identity relation carries into the blended space. That the compression happens 
prior to the map input space being activated in the integration network should make it easier to produce fictive motion construals. In this blend, the compression of the terrain does not happen in this immediate integration network, instead, the input contains the pre-compressed map-world graphical path shape. This blend does not need to compress in order to achieve human scale. Consequently, fictive motion should be facilitated by this type of blend.

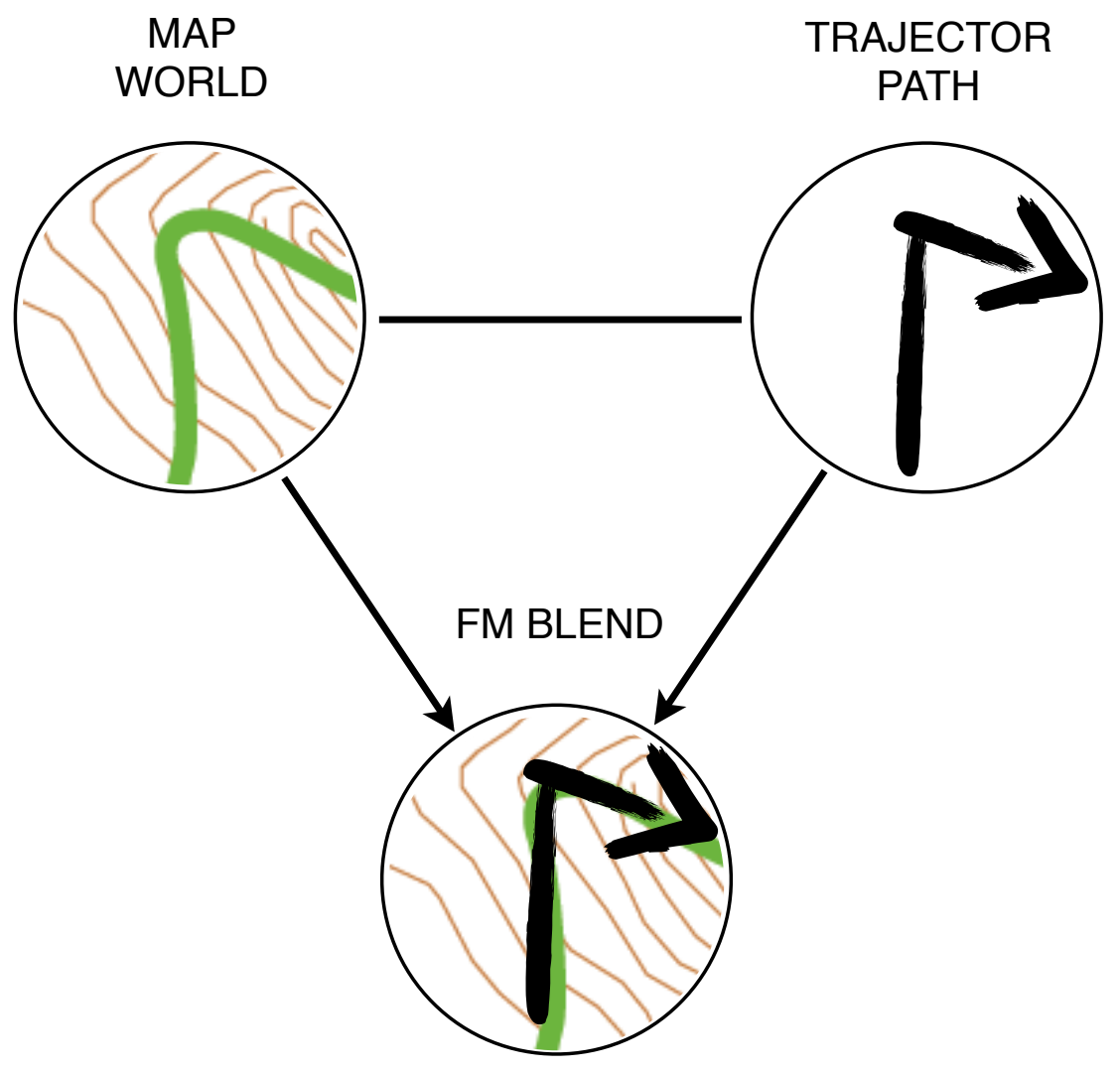

[Figure 2.4 Fictive Motion in the Map World - path pre-compressed in map]

The organizing frame of the Map World input space has already compressed the terrain world trail to a linear representation. Not only is it double-scope because it is an FM blend, but it uses another double-scope blend as an input. This 
makes the FM in this blend into fictive motion about a complex network of blends. It could be thought of as a compound blend that is stretched across two time frames: the time frame of the cartographer producing the map, and the time frame of the subject reading the map and producing the fictive motion utterance.

Fauconnier and Turner talk about how processing components of a human-scale action is more difficult than processing the entire action (379, Fauconnier \& Turner: 2002). It could be that processing blends like those in figure 2.4 are easier than those in figure 2.3 because the major compression to achieve human scale of the trajector path has already been achieved prior to attempting the fictive motion blend.

While Turner has argued that not all maps are blends (97, Turner: 1996), it is possible to specify this map compression as a blend, especially since it is recruited in the construction of fictive motion descriptions of the terrain depicted by the map.

\subsection{Data differences across trials}

\subsubsection{A-Trial data:}

The data from A-Trial subjects features a total of $66 \mathrm{FM}$ verb constructions, 41 of which are SYMBOL and 21 are SUBSTRATE with a remaining 4 other types. The fictive motion features rich descriptions of path shape such as winds, 
zigzags, weaves, twists, turns, intersects, crosses, circles, widens, breaks off.

These FM verb constructions come from the blends discussed above, which are summarized in the following table:

Table 2.6 A-Trial blending options

\section{Motion Blends Available to A-Trial Subjects:}

Input Space 1: SYMBOL \& SUBSTRATE

Input Space 2: PATH MOTION

Blended Space: SYMBOL FM

Projections: [S1: SYMBOL Elements] + [S2: SYMBOL as Trajector]

Input Space 1: SYMBOL \& SUBSTRATE

2 Input Space 2: PATH MOTION

Blended Space: SUBSTRATE FM

Projections: [S1: SUBSTRATE Elements] + [S2: SUBSTRATE as Trajector]

Input Space 1: SYMBOL \& SUBSTRATE

3 Input Space 2: PATH MOTION

Blended Space: FACTIVE MOTION along SUBSTRATE

Projections: [S1: SUBSTRATE Elements] + [S2: Subject as Trajector]

\subsubsection{Path shape:}

Path shape in the FM construction reflects either the notion of the representational path on the map or the geophysical path. Path shape is a feature of Talmy's (2000) coextension path fictive motion, in that a schematic path shape is coextensive with the terrain feature. Paths in this sense are manifestations of the conceptual metaphor schema: SOURCE-PATH-GOAL, and the movement of the trajector along that schema contours to the geometric and directional variation that is present in the terrain feature. 
If the terrain feature is rounded on one side and a linear path is placed down upon the edges of that rounded feature, then the path schema takes the schema of the terrain feature and is ostensibly a curving path. If the terrain feature is straight and a linear path is centrally placed along that terrain feature, the path is a straight path. Several straight paths and several curving paths could combine to form a path that weaves or winds its way through the terrain. Several straight paths alternating with several angled paths would produce a path that zigzags back and forth through the terrain. What follows are examples from the data that manifest these path shape characteristics, and then a treatment of how path shape intersects with directionality.

\section{TURNING \& CHANGING ELEVATION}

Tripper describes an access path to a "...point beyond his field of vision..." and then describes two articulations of the path's behavior: it turns, and it changes elevation: than one might like, less populated than it was a few minutes ago, and at some point the trail beyond my field of vision, is going to take a sharp turn to what would be my right, this trail is going to ascend or descend, and uh, there we are." [4.090]

Not all turns are fictive motion, consider Natasha's nominal response in the following example:

(2) RD: And, uh, do you want to describe the trail? [3.230] Natasha: sharp turns. [ADJ + NOUN] [3.231] 


\section{INTERSECTS \& CROSSES}

Another path shape that is common is the intersection, or path crossing.

Consider the following FM constructions:

(3) Raleigh: It also looks like it, uh, intersects with another [SYMBOL] [2.030]

(4) Raleigh: It crosses several uh... [2.035]

(5) Tripper: Um, still going straight and flat, crossing a river, and then we're going to have some elevation change, with some back and forth, maybe to compensate for the elevation change. [subject is "the trail"] [4.062]

Intersections can also be described as splits in the path. Stanford Trail trail features multiple points of this kind of division described as the path breaking in a verb construal:

(6) Nicole: It breaks off and its three paths. [SUBSTRATE] [2.188]

Compare this FM verb construction with the same schematic structure conveyed with a noun in Natasha's comment about "the splits":

(7) Natasha: So we need to be...pay attention for the splits so we remember to go to the right instead of the left. [NOUN] [3.085]

Like Natasha's example shows, not all of the descriptions that feature path shape are fictive motion verbs. Many path descriptions are strictly adjectival roles. Consider the following: 
(8) Raleigh: Um, we came downhill quite a bit, down the side of a ridge and then flattened out at the base. And windy. [SUBSTRATE] [ADJ] [2.162]

(9) Tripper: And uh, we're going to be going down some sort of relatively winding trail...with alternate trails we're not taking, to get here. [SYMBOL] [ADJ] [4.023]

Natasha: I would call it windy. [ADJ] [3.006]

These types of adjectives are not considered in the FM data because they are not primarily movement oriented. Just because a path is described with a seemingly dynamic path shape does not mean that it contains fictive motion, as seen in Natasha's noun examples above.

These examples have been fairly straightforward and simple. However, more complex situations do occur in the data that show the intersection of the SYMBOL world and the SUBSTRATE world as well as the interface between path shape and directionality. For example, SYMBOL organization reflects the complexity of the SUBSTRATE world. Regina uses a description of the contour lines that features a curving shape, the way that contour lines curve out around the spine of a ridge, or curve in towards the trough of a valley forming down the side of a hill. This is interesting because it is not a linear path that is curving, but a continuous geographic surface that is curving, displayed through contour interval lines.

(11) Regina: And I, I'm obviously reading this wrong, which I didn't really know about this anyway, but I thought if it, if it curves up like this that means you're going up, if it curves down like this that means you're going down, if it curves like this, then I, this is where I got confused. [SYMBOL] [1.294] 
Raleigh's around example offers a more prototypical case of curving because it refers to the linear path arcing around, expressing the changing position of the path as it moves through the terrain.

(12) Raleigh: Well, it looks like it kind of zigzags through some...short, uh, well for Ohio, moderate like ridges, kind of uh weaves its way through, goes around one, goes kinda through another... [2.026]

Notice that Raleigh's utterance contains a number of FM verb constructions that all have slightly different path shapes. Each one of the changes in path shape outline a continuation of the forward moving trajector, but along separate vectors. Each verb is constrained to specifying one vector, according to Bohnemeyer's (2003) Unique Vector Constraint (UVC). He argues that path shape do not specify direction, and so the multiple back-and-forth vectors typically thought of in a verb like zigzags, the in-and-out vectors of weaves, and all of the angle rotation vectors in going around the perimeter of a circle, are merely the preservation of direction. So rather than a mathematical breakdown of the angles and rotations, a functional preservation of the intended path is a single vector (108, Bohnemeyer: 2003). This notion of the term vector is adopted in the remainder of this document. Raleigh's changes in vectors between the three verbs are marked by clause changes, satisfying the UVC, but the actual verbs themselves already satisfy the UVC and are seen as continuous motion.

Looking at these individual FM verbs might yield an interesting perspective on the role of vectors in SYMBOL FM constructions. Raleigh's complex FM 
utterance is an interesting example of a distinction drawn by Zwarts (59: 2003) between centered paths and tail-head paths. Zigzagging and weaving seem at first to be articulated directions in which a series of direction changes specify the journey of the path, these direction changes are thought of as tail-head paths, where the tail of one directional path becomes the head of another directional path when the direction changes. However, another conceptualization is feasible, that of the centered path, which holds that the overall direction in space is a single direction. So, if the path from $X$ and $Y$ zigzags erratically between the two points, it is still centered on the trajector path from $\mathrm{X}$ to $\mathrm{Y}$, and so it is a single vector.

When a path weaves its way through, goes around one, goes kinda through another, it could be conceived of as traveling along a centered path, but it could also be traveling along a tail-head path. However, it seems like Raleigh is using the tail-head path with this sequence because with each FM verb there is a clause change, and the clause changes likely indicate a new vector per the UVC.

At this point in the study Raleigh is sitting at the picnic table describing the map before he embarks on the hike. He introduces the general trajectory of the trail with "...it looks like it kinda zigzags through..." this is the centered path between the starting point of the trail and the end point of the trail. It acts as a summary of the general trail path shape; the path shape is zigzagging. He then specifies the actual segments of the trail in three descriptions: one that weaves, one that goes 
around, and one that goes through. This is an adoption of the tail-head path. $\mathrm{He}$ uses both of Zwarts' path distinctions in his description to give a broad global overview with an episodic play-by-play of the different segments of the trail. This acknowledges the simplicity of the whole without ignoring the actual complexity of how that whole is achieved.

Other aspects of the complexity of path shape are spelled out in the descriptions of the symbol world which evoke a number of path shapes that graphically describe the complexities of the geospatial substrate. For instance, the spaces between the contour lines of a topographic map have topology that is visually underspecified and describing these spaces is difficult. Natasha views the symbol world as a flattened world and describes the space width in this next example. Notice that this comes in the form of a question, indicating that she is trying to negotiate the meaning of the contour line space width that she is describing. This is a clear example of the referential relationship between SYMBOL and SUBSTRATE in the subject's focus:

(13) Natasha: and as they widen out it get's lower? [3.203]

Natasha's guess is interesting to consider because it reflects a mistaken understanding of the texture described by the map; in reality the widening of the spaces actually flatten the terrain. 
Overall the A-Trial data contains rich path shape descriptions, and fictive motion that crosses between the SYMBOL world and the SUBSTRATE world. Some of those situations will be explored in the remainder of this document.

\subsubsection{B-Trial data:}

The data from B-Trial subjects features a total of 7 FM verbs, 6 of which are SUBSTRATE with a remaining 1 other type. After completing the trail exercise two of the B-Trial subjects drew maps of their route and then looked at an official trail map, during this post-trail segment they produced an additional 3 FM constructions which are not counted in the total listed above, since B-Trail subjects did not use maps in the actual exercise. This additional FM constructions were all of the SYMBOL type and are discussed in this section after the official data are considered. The B-Trial data is largely factive motion descriptions and other non-motion descriptions of the substrate. However, there are a few fictive motion examples that will be addressed in this section. Consider the following table of available motion blends for B-Trial subjects:

Table 2.7 B-Trial blending options

\section{Motion Blends Available to B-Trial Subjects:}

Input Space 1: SUBSTRATE (NO SYMBOL)

1 Input Space 2: PATH MOTION

Blended Space: FACTIVE MOTION along SUBSTRATE

Projections: [S1: SUBSTRATE Elements] + [S2: Subject as Trajector] 


\section{Motion Blends Available to B-Trial Subjects:}

Input Space 1: SUBSTRATE (NO SYMBOL)

2

Input Space 2: PATH MOTION

Blended Space: SUBSTRATE FM (rare)

Projections: [S1: SUBSTRATE Elements] + [S2: SUBSTRATE as Trajector]

The bulk of the apparent FM constructions in the B-Trial data seem to be adjectival constructions that describe the quality of the trail or the terrain. For example, consider this utterance:

(14) Carl: The path, um, kinda curvy, you know there's uh, there's twists, turns uh, [indistinct] [5.202]

Despite giving the sensation of fictive motion, this utterance actually features an adjective construction (kinda curvy) and two motion nouns (twists, turns).

Several utterances appear at first to have this fictive motion quality, but on closer examination they use either adjectives or nouns, and are not really fictive motion in a prototypical sense. Some of the other motion-associated adjectival descriptions ascribed to the trail include: windy, uphill, downhill, level, steep, smooth, mostly downhill, semi-steep, not too steep, and winding. The motionassociated noun descriptions ascribed to the trail include: uphill-downhills, and twists and turns.

(15) Carl: Um, Like I said it was less muddy, but um, it was, you know it was windy, there was uphill-downhills, you know, twists and turns, but, you know, for the most part it was, it was uh, kind of, I don't know, winterish. [laughs] [5.151]

Holly: I liked this trail a lot better because it was downhill. [laughs] [5.059] 
(17) Carl: It was just kind of windy from the last bridge, it was windy, um, it kind of sl...sloped I guess a little bit. [5.119]

It is acknowledged that these adjectival motion-associated adjectives imbue a highly dynamic quality to their noun referent, but it does not construe them in terms of moving along any path (emanation or coextension). Notice that the last utterance builds a sort of fictivity by expressing a source-path-goal schema: "It was just kind of windy from the last bridge..." It is this full path specification that makes it as dynamic as it is, but it is still not an FM construction. Perhaps if Carl had said "The path wound its way from the last bridge" it could be argued to be true fictive motion, but the fact that it merely adjectival prevents reading the trail as a trajector that follows a motion path that is coextensive with the path itself. However, the last part of the utterance "...it kind of sl...sloped I guess..." is certainly a fictive motion construction as will be shown below, after other ambiguous examples are cleared up.

This next example is ambiguous without additional context. The subjects have been asked to describe the trail. Carl describes the geophysical trail and surrounding environment. Holly describes the experience of the trail. Carl seems to be dissatisfied with Holly's response and he clarifies what was meant by the request to describe the trail:

(18) Carl: ...the path coming up, like coming up here, how was that? [5.037] 
On other occasions Carl tries to get Holly to give descriptions that he feels are more on target to the question. For example at another point he comments about Holly's answer with an amused response: "That's not the trail, but anyways," [5.082 MK]. Given that (38) is an attempt by Carl to elicit a better response from Holly, rather than a direct response to the request to describe the trail, it seems like "the path" is not the trajector of "...coming up the hill...", a better analysis construes Carl and Holly as trajectors factively in motion coming up the hill, and "the path" serves to orient Holly's attention to the substrate during their actual ascent. Seeing this context renders (38) as factive motion description rather than a case of fictive motion.

There are some valid fictive constructions in the B-Trial data, a few of these constructions address fictive agency rather than fictive motion (i.e., Holly: "nature gives you a break" [ LK], and Ariane: “...it wasn't very clear where the trail was taking us...” [RR], and Ariane: “...where the path leads...” [6.120 RR]), but other constructions ascribed fictive motion to the veridically static elements of the substrate. Consider the following B-Trial fictive motion constructions:

(19) Carl: kind of windy, this this part of it was anyways, kind of did a lot of uh, winding.[participle] [5.086]

(20) Carl: ...enough time to rest during it, because you're just on like level ground and you know it just twines and turns here and there... [5.137]

(21) Carl: It was just kind of windy from the last bridge, it was windy, um, it kind of sl...sloped I guess a little bit. [5.119]

(22) Ariane: The trail began to descend, it was still muddy, and... [6.075] 
And a slightly ambiguous example of fictive motion:

(23) Carl: It was uh, you know, basically level ground though for the most part, other than the the winding hills, [laughs], [might just be adjectival] [5.090]

This example is ambiguous because winding might just be an adjective, rather than a fictive motion verb. While "winding" would certainly be a verb in a written genre, it is less clear that the verb reading is absolute in the spoken genre.

Interestingly, three SYMBOL FM constructions occurs in the B-Trial data, but only after the subjects have drawn a sketch-map of the trail and have seen the official topographic map.

(24) Carl: That's where it split, that's where I was talking about the split. [5.231]

(25) Holly: Ok. This is where we started off, walking, then we come to the first bridge, there's a little bit of an incline and a curve, then we come, um, uphill, to the second bridge, then we came down, to the next bridge, then we went back uphill where it kind of veered around, to another bridge, and then we walked uh, well kind of flat here, and then it split. [5.191]

These utterances are atypical B-Trial FM utterances. Carl and Holly's usage of the "split" FM construction is designed to direct attention on the SYMBOL of the trail splitting in two directions. Holly's use of “...veered around" occurs while she is describing her sketch-map and is designed to orient attention to the curving of the trail substrate through representation in symbolic space. Considering that these three examples were produced after exposure to the SYMBOL it 
contributes to the evidence of the co-occurrence of FM usage and the scalability that comes through symbolic representation of physical referents.

A careful observer will notice that the bulk of these actual FM constructions (presymbol exposure) are produced by the same subject, Carl. Holly produces a fictive agency construction, and two symbol types during her sketch-map symbolic representation. Ariane uses one actual fictive motion construction, but her other fictive constructions are the fictive agency constructions mentioned above. Since Ariane never encountered a map during the study she did not make any SYMBOL type FM. Bob only makes one utterance that resembles anything near fictive motion:

(26) Bob: Um. It was kind of, what would you say, winding? [6.168]

But this seems like it is just an adjectival description.

All of these B-Trial fictive motion exceptions feature fictive motion even though the subjects did not have the map with the scale appropriate for scanning the trail SUBSTRATE. Does this harm the hypothesis that access to a map (i.e., SYMBOL) increases the usage of FM by making scanning of the SUBSTRATE easier? It has not been argued that FM cannot be produced without a scannable symbolic representation of the trail, just that the symbolic representation facilitates FM construal. These exceptions do not disrupt the line of argument, 
they only illustrate that despite the limited visibility of the entire trail subjects were still able to use FM in meaningful ways.

It might be interesting to consider that the B-Trial subjects did have the ability to mentally scan portions of the trail. The trail walking experience was broken up into segments by the bridges scattered along the way. Subjects could see the ascending hills and descending trails, they could see the trail weaving back and forth, splitting in different directions. So why was there not more FM in the data they produced? It might be that the ability to scan the trail end-to-end through the map representation is the key to unlocking the FM descriptive capacity. Clearly subjects could use motion-associated descriptions, but actually doing the work of moving attention along a static path in a way that construed the static path as moving through the terrain is another story. Consider the following examples of factive motion construal that is more typical of the B-Trial subject utterances:

Holly: Um, I know, I mean, I don't necessarily think it was any easier cause there was still a lot of uphill, but, um, just kind of knowing the points of how far we were going and how far we had to come back was a lot easier. [5.148]

(28) Carl: But it's more, uh, it's more relaxed, its more, I mean it's got its, its got, you know, hills and peaks... [5.196]

(29) Holly: I'm happy that the ground is level, because now I can breathe again. [Laughs] [5.030]

(30) Carl: Yeah, and then like you'll gradually go downhill for a little bit and then you're again on, you know, levelish ground...and then you'll hit them steep hill, you know, that last steep, down-hill marker. [5.139]

(31) Bob: Ok. Make a note, when we're going to the falls it seems like we're going on a decline and walking down a hill. [6.059] 
(32) Ariane: The terrain continues to have leaves, mud, wet spots, and... I s, continue to see roots of trees that are growing in the trail. [6.110]

(33) Bob: A lot more secure, right, cause that incline was pretty steep this time around too, when we were going down the hill towards the falls. [6.080]

These examples are taken as the effect of scanning portions of the trails and construing the scanned portion with veridical motion language. This is interesting because simple changes render many of these examples as fictive motion constructions. Consider how the schematic structure of the trail was construed with a noun phrase rather than motion verbs in the following example:

(34) Ariane: But we did have direction, we did have some direction because there was a point of intersection, [6.089]

A fictive example could have been "...we did have some direction because the trails intersected at one point..." In A-Trial subjects this point of intersection was construed with fictive motion: Raleigh: "It also looks like it, uh, intersects with another..."

Instead of finding robust motion descriptions that are associated with the trail substrate, most of the data focuses on the actual motion of the actual subjects as they move along the path. In a way this makes sense. It is an ego-centric perspective that does not have access to the outside perspective of the thirdperson view afforded by the symbolization of cartographic representation. In fact, this perspective is a difficult one for most people to attain. Hutchins aptly describes the differences between the bird's eye view and the traveler 
perspective, it is presented here in full and will be referenced throughout the study:

"Finally, charts introduce a perspective on the local space and on the position and motion of the vessel that is almost never achieved directly by any person. Standing over a chart, one has a "bird's-eye" view that, depending on the scale of the chart, could be duplicated with respect to the real space only from an aircraft or a satellite. Furthermore, the perspective is that of a spectator rather than that of a participant. This is one reason why establishing the correspondences between the features on a chart and the features in the local space is so difficult. In order to reconcile the chart to the territory, one must imagine how the world that is seen from a location on the surface would appear from a point of view from which it is never seen. The chart depiction assumes a very different perspective than that of the observer on the vessel. The experience of motion for the observer on the vessel is of moving through a surrounding space, while the depiction of motion on a chart is that of an objet moving across a space. This other perspective created by the chart is so compelling that a navigator may have difficulty imagining his movements, especially over large spaces, from the traveler's perspective. Conversely, people who have had no experience with maps and charts may find them completely baffling." [62: Hutchins: 1995]

Despite being able to mentally scan portions of the trail that were in their visual

field, based on Hutchin's argument above, subjects might not have been able to benefit from the clarity that the spectator role provided by a bird's-eye view.

Merely operating as a participant without the additional perspective did not facilitate the production of FM in B-Trial subjects.

\subsubsection{Consciousness of the need for a map in B-Trial subjects:}

In a final note, the relation of the priming activity and FM distribution in B-Trial subjects needs to be mentioned. The two B-Trial subjects (Carl and Holly) who had the priming activity which exposed them to SYMBOL (topographic) renderings of spatial topology produced more FM than the two B-Trial subjects (Bob and Ariane) who did not receive the priming activity. However, due to the 
limited number of subjects in this trial, the only conclusive statement that can be made is that in this data set the priming activity variable between the B-Trial subjects correlates with an increase in FM. Whether there is a causal link is uncertain. However, this is an area for further investigation to provide evidence to confirm or disconfirm the role of the topographic priming activity on subjects without access to the symbolic map artifact.

\subsubsection{C-Trial data:}

The data from C-Trial subjects features a total of $26 \mathrm{FM}$ verbs, all of which are SYMBOL type. Since C-Trial subjects did not have a walking experience, it is not surprising that SUBSTRATE FM did not occur in this data set. This FM-dense data is interesting because the amount of time that C-Trial subjects spent with the map and the number of questions they answered was a fraction of the time and questions experienced by the A-Trial subjects. Diversity in path shape is a notable characteristic of this data set, including most of the path shapes that occurred with A-Trial subjects, with a few additions: follows, goes over, contours, crosses, to hit, connects, twists, winds, runs, goes around in circles, levels out, starts, comes down, goes back over, et cetera. Consider the following table of available motion blends for C-Trial subjects: 


\section{Motion Blends Available to C-Trial Subjects:}

1

Input Space 1: SYMBOL (NO SUBSTRATE)

Input Space 2: PATH MOTION

Blended Space: SYMBOL FM

Projections: [S1: SYMBOL Elements ] + [S2: SYMBOL as Trajector]

Input Space 1: SYMBOL (NO SUBSTRATE)

2

Input Space 2: PATH MOTION

Blended Space: STATIC SCENE DESCRIPTION

Projections: [S1: Semiotic Objects of SYMBOLS] + [S2: Static FIGURE Objects]

Because of the small data set for C-Trial subjects all of the FM verb constructions are presented in this section. Most of the FM constructions in the C-Trial data describe clearly linear movement of the trail as a trajector through the terrain environment. The following examples show the trail (and a road in one case) progressing through the environment:

(35) Polonius: it looks like it follows the low lying areas, mostly, it doesn't look like it goes over a peak necessarily, maybe here [8.019]

(36) Herman: Uh, Brandywine Gorge Trail is more of a leisure walk because it contours to the topographical map, the trail does, like the, the the going around hills and going through the valleys I guess, there's not mo, they aren't mountains, but, I guess you could consider them valleys. [7.059]

(38) Eliza: It connects from the towpath, and you go past Stanford Road, it twists and winds a lot, and... [7.026]

(39) Marian: It's a map of, what?, the Brandywine Falls area, um, it shows major, you know, um, highways, intersecting roads, um, I forget what the, like uh, topography I guess is showing to you [9.016]

(40) Herman: So that's not, I mean, [clears throat]. They both have "steep steps" and they're both "moderate to difficult" so, where the Stanford Trail [clears throat] is, looks longer the Brandywine Gorge Trail goes around in circles. [7.081] 
The clarity of those descriptions causes other less clear utterances to stand out. Some subjects use negative FM expressions to describe the actual shape of the trail:

(41) Polonius: it looks like it follows the low lying areas, mostly, it doesn't look like it goes over a peak necessarily, maybe here [8.019]

(42) Polonius: it doesn't complete a loop or anything, its just,...whereas the Brandywine Trail does [8.018]

Both of these negative assertions have positive counterparts that describe actual trail shape: the trail stays off of the peaks, and it is a linear trail. These assertions might reflect Polonius attending to the feature that is being negated. In the first utterance Polonius attends to the ridges and hills of the terrain and notices that the trail does not cross those high points. In the second utterance Polonius attends to the contrast between the Stanford Trail and the Brandywine Trail noting that the Brandywine Trail is a closed loop, this contrast draws out the comment about the Stanford Trail not being in a loop configuration. Interestingly, both of these negative statements are somewhat speculative, as Polonius grapples with negotiating the discrete discontinuities in the texture of the continuous terrain. Other similar negotiations of texture do not feature the negative assertion, but they do include speculative reasoning:

(43) Herman: Uh, Brandywine Gorge Trail is more of a leisure walk because it contours to the topographical map, the trail does, like the, the the going around hills and going through the valleys I guess, there's not mo, they aren't mountains, but, I guess you could consider them valleys. [7.059]

(44) Herman: Uh, it looks like its, based on the topography...I'm not sure, l'm trying to decide if it's going around the large.., the steepest parts of the hills, or, 
making a purpose to, uh, um,...uh, hit the steepest parts of the hills based on, you know, if its a harder trail or an easier trail. [7.027]

(45) Marian: Um, because just, um, and this is an assumption, that the topography that's shown on here, I would imagine that these go upward [9.031]

Other instances include uncertainty about elements of the trial such as route articulation:

(46) Herman: Uh, it looks like its, based on the topography...I'm not sure, I'm trying to decide if it's going around the large.., the steepest parts of the hills, or, making a purpose to, uh, um,...uh, hit the steepest parts of the hills based on, you know, if its a harder trail or an easier trail. [7.027]

(47) Marian: Um, because just, um, and this is an assumption, that the topography that's shown on here, I would imagine that these go upward [9.031] *[note that Marian was the C-TEST subject who did not have the topography priming activity, but she still addresses the directionality of the contour lines.]

These negotiation strategies for reconciling uncertainties about terrain are most similar to the uncertainties expressed by Tripper, the A-Trial test subject who used the terrain to help him learn how to read the contour lines on the map, and to Don, the B-Trial test subject who negotiated the shape of a ravine on the map as his conceptualizations oscillated between the lines marking a valley or a ridge. Other A-Trial and B-Trial subjects speculated about terrain texture, but the degree to which speculation was featured in their terrain negotiation was not as intense as Tripper and Don who were exceptionally tenacious and curious about establishing equitable correspondences between the contours on the map and the shape of the terrain. It seems that C-Trial subjects had a similar curiosity to Tripper and Don about making sense out of the representations on the map, perhaps that is why there are so many FM constructions in the C-Trial subjects. 
Given their limited time spent with the map and the reduced number of interview questions asked to C-Trial subjects, the number of FM constructions used is considered higher than expected. This is high frequency is attributed to the curiosity of the subjects.

Part of this uncertainty stems from the inherent difficulty of imagining the surface of an unseen terrain based on the map. This is similar to the problem Hutchins elucidated when describing the difficult of reconciling a chart to a territory when the navigator does not have access to the point of view displayed on the chart [62: Hutchins: 1995]. The map reader never has access to the terrain surface perspective, but remarkably, the map readers are able to make accurate statements about the terrain textures and route paths by reading the contour lines and imagining the texture as they describe it.

Other route articulations do not have the elements of uncertainty seen in the last two examples, instead, they make qualitative judgments about the relative difficulty of particular articulatory legs of the trail using FM constructions. Herman speaks to the trail becoming less difficult when the terrain levels out, while Polonius addresses the same section of the trail with the description of it starting off "pretty easy".

(48) Herman: The Stanford Trail, is, um, well, it uh, looks steeper than the [clears throat] Brandywine Gorge Trail, because, um, based on the topographical map, it um, does, it does go around some of the hills but I can see in some parts it is um going up the hills, down the hills, and, in, in one portion it levels out over here by uh Stanford House, um and obviously it becomes less difficult, 
but um, over by the Averill Pond this is where the most of the, probably the heavy-duty hiking will uh, be taking place. [7.086]

(49) Polonius: It starts pretty easy, but I guess it does go over some hills here, and it looks like it comes down...and it winds around, um, it looks like it goes back over some ridges here, and... [8.023]

Lastly, some subjects mention the general trajectory of the trail in absolute terms:

Polonius: uh, it goes from, it goes east-west, uh, [8.014]

(51) Marian: Um, well, I guess it runs, um, from West to East, or East to West, more so than North to South, um. I'm trying to think what else can I tell you about it [laughs], I don't know. [9.021]

Not surprisingly, this C-Trial data shows a clear preference for SYMBOL FM. Because the subjects only interacted with the map (and did not interact with the terrain) their FM was confined to SYMBOL descriptions. This may have been facilitated by the spectator view afforded by the third-person bird's-eye view of the map.

\subsection{Comparing the three trials:}

It could be that being a spectator and a participant (A-Trial) has a facilitating effect on the production of FM, since being a participant alone (B-Trial) yields insignificant amounts of true FM - especially when compared to the production of FM that resulted from being a spectator alone (C-Trial). 


\subsection{Scale \& FM construal in SYMBOL:}

Some real life elements that exhibit veridical motion (such as a river) are not usually available to be trajectors in an fictive motion construal. But when those same elements are viewed in the symbolic world of a map, they become available for fictive construal. The detached bird's-eye view of a veridically moving entity as represented on a map permits veridically moving objects to be construed with fictive motion (see p. 10-11, Matlock: 2004b). Consider how a blue line that bisects a map could be seen as "running across the page", even though it symbolizes a river that factively runs in real life. This "running" is used without respect to the actual direction of the river's flow. The blue line could be perceived as running from right to left when in reality the water moves from left to right. It is important to note that a symbol may be construed as moving in one particular direction when in reality it might move in opposite directions.

Notice that the first-person perspective of a veridically moving entity (the actual river) cannot felicitously use FM to describe the trajector; only the third-person perspective (the blue line graphic river) can use moving trajectors in FM. The map seems to facilitate FM construals of entities which otherwise might not be available for FM construal.

In addition to maps permitting moving entities to be available for FM construal, a symbol for a trail that does not specify directionality may be imbued with a sense 
of directionality based on the forward movement of the subject along the trail. The trail goes in the direction that the subject is hiking. If the subject turns around, the direction of the trail follows the subject so that the trail always goes in the direction of hiking. This is a kind of ego-centric view of directionality. It carries into the map world, a line that represents the trail is progressing in the same direction as the subject is moving. It is important to note that a symbol may be construed as moving in one particular direction when in reality it might not specify directionality and may permit bi-directional travel.

That the map seems to facilitate FM construals of entities which otherwise might not be available for FM construal (both directionally moving and bi-directional static entities) suggests a general tendency of symbolization to increase the availability FM construals to non-prototypical object referents.

With this insight, in the current study of the trail language, it makes more sense that subjects who had a physical map used more fictive motion, since in addition to their physical experience of the trail substrate, they were able to visualize the trail through the third-person perspective that afforded an FM construal. The graphic line of the bi-directional trail took a specific direction, leading forward, almost as if it were the body of an arrow that pointed toward a destination. It is that linear directionality that acts as a vector path for the trajector to move along, so that the path directionality is coextensive with the substrate of the path itself. The SYMBOL reifies that coextensive marriage of schema to SUBSTRATE. 
Once the subject found their location on the map, the situated use of FM placed the origo-locus of the FM construal in the SYMBOLIC domain rather than the geophysical SUBSTRATE domain. The SYMBOLIC instances of FM are seen as separate from the immediate context of veridical motion through the terrain since the experience of that motion is abstracted into FM in the symbolic world in its representation as a line on paper and schematically marking the motion as a vector.

In this case, the line is more representative of the experience than the actual experience itself, because the subject has acquired the experience and has placed it in the "black-box" of the symbolic line, moving upwards to the next level of abstraction after an embodied mastery of the one level of complexity.

This is a blend which compresses the physical input with the symbolic presentation, and produces the emergent structure necessary for input into the FM conceptual blend of the stable trajector and a dynamic motion construal. The compressed symbolic trajector is recruited into the FM because it is at a scale that permits its integration with a dynamic motion state (either suppressing veridical motion status in the case of the river, or orienting directional status of the trail as a vector). Without being reduced (abstracted) to such a manipulable state as SYMBOL, the blend is not possible, and therefore fictive motion itself is 
more difficult to achieve. This explains the disproportionate number of SYMBOL FM constructions compared to SUBSTRATE FM constructions.

This is seen to bear out in contrastive evidence of subject's construal of their veridical motion through the terrain in the first-person perspective as factive motion. Conceptualization that features a veridically moving entity, like a subject walking along a path, cannot be construed with FM. This is why the factive motion descriptions that subjects provide about their movement (as trajectors) through the terrain features veridical motion language, and why the movement of the stable elements like the trail are construed with fictive motion language. But in order to see the stable trail element like a trajector moving through the terrain it needs to be conceptualized symbolically, which is made possible by the map. The ability to see the trail as a sign on a map renders a SYMBOL FM construal possible, all other descriptions of the trail feature the more prominent trajector: the subject doing the actual walking.

\subsection{Palpability of map SYMBOL and trail SUBSTRATE:}

In line with the argument for SYMBOL reifying the vector of the trail making it available for FM construal, the SYMBOL also acts to compound the palpability of the trail, doubly increasing the availability for FM construal. 
Talmy (2000) outlines an array of parameters of cognitive functioning that are used to measure the general palpability of an element of perception or conceptualization. He argues that these parameters are on a gradient scale that moves from concreteness to abstractness. In his treatment Talmy indicates that the experience of elements which feature concreteness for these parameters typically results in factive descriptions:

"With respect to general fictivity, a representation ceived at the concrete level of palpability is generally experienced as factive and veridical. It can function as the background foil against which a discrepant representation at a lower level of palpability is compared." (144, Talmy: 2000).

Talmy's argument is that concretely experienced elements typically produce factive construals, and that they are not often used for fictive motion construals. Palpability, according to Talmy, is a feature of the subjective experience of an entity rather than a feature of the objective entity itself. In this sense of palpability, the relative concreteness of an objective entity would not determine a fictive construal, only the palpability of the experience of an entity could influence construal.

At first it seems that the opposite is seen in this study: that objectively concrete elements might facilitate fictive motion descriptions. For instance, along a simple presence/absence continuum, the presence of the concrete artifact of the map actually seems to facilitate the production of fictive motion whereas the absence of the concrete artifact of the map seemingly interferes with the production of 
fictive motion. That tangible features of the map as an objective entity (and not just an experience of that entity) might affect palpability in consciousness runs counter to Talmy's original claims when an entity with concrete physical palpability prompts for a fictive (rather than factive) construal. One possible reconciliation of the concretely palpable map apparently facilitating fictive motion is that perhaps the presence of the concrete map actually increases accessibility to conscious experience of the fictively moving entity (in this case the trail symbol). This would seem to harmonize with Talmy's notion of palpability in consciousness without neglecting the role of the tangible palpability features of the physical artifact of the map.

Notice that Talmy argues for concreteness of experience acting as a "background foil" for some more abstract element of experience, in this case it is argued that the "discrepant representation at a lower level of palpability" is the consciousness of the SUBSTRATE of the incompletely experienced trail that is compared against the concretely palpable SYMBOL artifact of the map. The map SYMBOL as a concrete object is also ceived at a concrete level, but it opens conscious experience to include the entire end-to-end trail SUBSTRATE through the SYMBOL representation. Because of this SYMBOL representation of the SUBSTRATE, the map user is able to experience the fictive movement of trail at a lower level of palpability; the trail symbol allows the map user to see the complete trail and facilitates FM by providing a visual path that attention can scan along on the physically concrete map. This complete visual path is absent in the 
SUBSTRATE world which does not provide an end-to-end perspective of the trail SUBSTRATE; only the SYMBOL world provides that perspective, and the concrete SYMBOL world affords the user an abstract trajectory path that facilitates the FM production.

While the SUBSTRATE trail is a physically tangible element that holds a level of concrete palpability for terra firma, it is only so to the extent of the length of the trail that subject can apprehend in the visual field. Since the subject cannot see the entirety of the trail from the starting point to finish, the only segment of the trail that can be perceived with concreteness is that segment which can be immediately seen by the subject. This is why the map has a compounding effect in facilitating FM production, because the subject experiences their location in the concrete SUBSTRATE trail along some segment of the entire trail and also experiences the concrete SYMBOL of the trail that enables the subject to see the trail representation in its entirety. It could be argued that the participant view afforded by traveling along the SUBSTRATE results in less FM production since there is less of a path for attention to abstractly scan along; trees, hills, bends and forks in the path all occlude apprehension of the path as a complete entity. The spectator view provided through the SYMBOL affords a clear path that can be scanned as a complete entity - imbuing the saccade along the path on the map with an abstract palpability, and hence, facilitating FM production. 
Stjernfelt (278: 2007) argues that in our interaction with all maps is the idea that there is correspondence between a route on the map and a route on the actual area represented by the map. The map artifact used by the subjects in this study is no different, the route on the map describes the route on the terrain. The difference between the two routes is that subjects who can see the route on the map are able to apprehend the totality of the route, whereas subjects without the map are left with a notion of incompleteness and non-totality.

Earlier, Stjernfelt presents Peirce's claim that diagrams are "in the middle part of our reasoning", and argues that this occurrence of operating on an icon as if it were the object is a "moment of fiction" (112, Stjernfelt: 2007). This moment of fiction is what may have prompted subjects to use the concrete map with its concretely visible trail to describe the concrete (but incomplete) trail with fictive motion construals. This moment of fiction seems to heighten the concreteness of the trail SYMBOL and mesh it with the presence of the concrete trail by providing pattern completion to the trail SUBSTRATE and thus operating as Talmy's background foil for the more visually abstract notion of the complete trail at the traveler's perspective. It may be that the tight relationship between the SYMBOL and the SUBSTRATE interact as a unified whole that provides a multi-faceted view on the experience, amplifying the traveler's perspective as participant by providing a glimpse of the outside view of the spectator. Subjects without the map had no such relationship of unified perspectives, leading to a more abstract 
notion of the entirety of the trail with a concrete understanding of the segment of the trail along which they found themselves.

It seems as though the situation is this: having a map (concrete artifact) leads to an abstractly palpable experience of the geophysical trail when the map provides a trajectory for intangible abstract motion in attentional scanning, facilitating the FM construal. On the other hand, not having a map also provides an abstractly palpable experience of the geophysical trail, but leaves the participant without a trajectory for attentional scanning, resulting in more construals of actual motion and less FM construals.

The entirety of the trail for the subjects without the map had a lower palpability in consciousness than it did for the subjects with the map. Not only was the crisp line of the trail a palpable concrete figure on the map (thereby increasing the palpability of the trail substrate), but map users also compounded the palpability of the trail substrate by lining up the map with the terrain. This palpability was not available to the subjects without the map.

The subjects who walked along the trail without the map had some interesting comments about the ambiguity of the path. Consider the following comments that B-Trial subjects made that reflect their understanding of the palpability of the trail: 
(52) Ariane: It wasn't very clear where we were going, but somehow we managed to find our way, based off of the worn leaves and mud. [6.172]

Bob: And I think Ariane was a little more like, she knew a little bit more where to go, whereas I had to sometimes second guess myself. And Ariane kind of pointed she's like well I know its right there, and I was like are you sure? you know, so, I think you had a better sense of the trail even though it was not clear in some parts. In some parts like we mentioned, it was more pretty defined, like there was gravel, stone, and there was less trees so it was drier so we kinda knew where we were going. [6.173-6.176]

At the beginning of their experience Bob and Ariane encounter the a partially obscured trail going up the first hill between the first bridge and the second bridge. Fallen leaves hide the worn path of the trail. This is a source of initial uncertainty about the path as reflected in Bob's comments:

(53) Bob: The trail is kind of, you can't really see it, especially because of the leaves, that's a big distraction, but Ariane has a pretty good sense of direction [indistinct] [6.020 - 6.021]

(54) Bob: Bigger incline, a lot more leaves and a lot of fallen trees, at one point, many points, we don't really know where we are going. Um, so we kinda had to just guess a little bit, cause the leaves were all over the place and we had to like figure out, um where we were going, but then eventually we found the path back on to where I think we are going. [clears throat] [6.028 JR - 6.029]

Later Bob has become more comfortable with how to see the trail and attributes

this to other people having walked the trail before:

(55) Bob: it looks like you know that trail, which we probably didn't mention initially, its natural, there's no like concrete, it, it, its like, its almost like the folks that walked it, thats how you find it. That's how we know how to walk, um, the trail, um, a lot of, ok, that's the trail, alright? [6.123 - 6.124]

Bob admits to second-guessing himself and Ariane's sense of direction, conceding that some parts of the trail were more defined than others: 
(56) Bob: And I think Ariane was a little more like, she knew a little bit more where to go, whereas I had to sometimes second guess myself. And Ariane kind of pointed she's like well I know its right there, and I was like are you sure? you know, so, I think you had a better sense of the trail even though it was not clear in some parts. In some parts like we mentioned, it was more pretty defined, like there was gravel, stone, and there was less trees so it was drier so we kinda knew where we were going. [6.173 - 6.176]

Ariane describes how the worn leaves and the absence of leaves defined the trail:

(57) Ariane: It wasn't very clear where we were going, but somehow we managed to find our way, based off of the worn leaves and mud. [6.172]

(58) Ariane: And it's more defined. So you know where you're going...because there's no leaves. [6.156 \& 6.158]

(59) Ariane: And, I think like we said, it wasn't very clear where the terrain was taking us, but, we managed to find our way. [laughs] [6.181]

Interestingly that same day, A-Trial subjects (Don and Natasha) walked the trail and did not have the same difficulty in knowing where the trail substrate was. If the leaves hid the trail, it was not clear in their descriptions, in fact, Don and Natasha only mentioned the leaves three times:

(60) Natasha: Lots of roots and leaves... [3.088]

(61) Don: there was one spot where it was covered with the leaves pretty good and yeah and I wanted to confirm that we were on the trail, but she could tell by looking up ahead that the trail continued. [3.092]

(62) Don: Yeah it was, uh, it was a little muddy, but the leaves, you know, for the most part took up the mud, sometimes it was slick, [3.254]

Considering that Bob and Ariane walked the trail without a map on the same day that Don and Natasha walked the trail with a map, and only Bob and Ariane had difficulty in seeing the trail, it might be that the trail was less palpable to Bob and 
Ariane than it was to the subjects with the map who experienced a concretely palpable trail. While there is not necessarily a causal link between not having a map and experiencing the trail as abstractly palpable, it is interesting that the only subjects who had difficulty seeing the trail also did not have a map. Later in the year the other B-Trial subjects (Carl and Holly) would walk the same trail without a map and describe it as "very visible":

(63) Holly: Also the path was very visible, so if you do have, um, if you tell them "just follow the path", they can actually just follow the path, they don't necessarily need a map or anything to go on it. [5.205]

The exact role of trail palpability in the B-Trial data is unclear, but even within the B-Trial data, the subjects who were able to make the most FM utterances (5 out of the B-Trial total of 7) were also the subjects who felt that the trail was very visible. The subjects who felt that the trail was indistinct because of the fallen leaves had a lower sense of the palpability of the trail and they only produced a total of $2 \mathrm{FM}$ utterances.

Perhaps there is a causal relation between the palpability of the trail and the general ability to construe the trail with fictive motion descriptions, as mentioned, this relation is likely that the map increases the abstract palpability of the trail via an increased accessibility to consciousness of the end-to-end shape of the SUBSTRATE. This accords with the general notion that scale facilitates FM construal (as noted above), and explains the role that scale has in increasing the accessibility of the path to consciousness, and how that accessibility to 
consciousness permits the abstract palpability necessary for attentional scanning along the now accessible path. Being able to see the trail on a map reduces the life-scale trail (which has varying levels of palpability in consciousness across subjects) to a concretely palpable SYMBOL, which does not have cross-subject variability in terms of objective concreteness. Either subjects have the map or they do not have the map. Subjects without the concretely palpable map and spectator perspective can only rely on their subjective experience of the varying palpability of the trail as taken in by participant perspective.

It is interesting to take this a step further and to see whether or not subjects who did not have access to the map are able to reproduce the shape of the trail in a sketch-map.

\subsection{Mental scanning without a map in B-Trial sketch-maps:}

Because of the difference in the raw number of FM utterances in B-Trial subjects it appears that not having a map diminished the ability to mentally scan the SUBSTRATE trail. However, out of impromptu curiosity the last two B-Trial subjects (Carl \& Holly) were asked during their debriefing session to draw a map of the trail that they had just completed walking. Surprisingly the maps produced by these two subjects (see image 2.1) reflected a roughly accurate path shape when compared to the official topographical map. It would have been ideal to have all four of the B-Trial subjects draw a sketch-map of the trail during their 
debriefing. Unfortunately, however, Carl and Holly were the last B-Trial subjects to walk the trail and the research permit expired later that week before any other subjects were identified to take part in the study. Further studies could be conducted to see how this perceived trail shape is represented in sketch-maps, and subjects could be questioned about their sketch-maps to see if their personal symbolic representation of the trail also leads to higher usage of FM in descriptions of that symbolic sketch-map.

Earlier it was reported that B-Trial control subjects (Carl and Holly) made a total of $5 \mathrm{FM}$ utterances during their trail experience, none of them being SYMBOL type FM. In addition to these 5 FM constructions, Carl and Holly used 4 FM verb constructions during their descriptions of their sketch-maps, but they were not included in the initial table since they reflect decisions made outside of the original protocol and only occurred after Carl and Holly interacted with the SYMBOL world in their sketch-maps.

Only 3 of those 4 FM utterances actually discussed the path shape or trail SUBSTRATE. Consider the two constructions in Holly's description of her sketch-map:

(64) Holly: "Ok. This is where we started off, walking, then we come to the first bridge, there's a little bit of an incline and a curve, then we come, um, uphill, to the second bridge, then we came down, to the next bridge, then we went back uphill where it kind of veered around, to another bridge, and then we walked uh, well kind of flat here, and then it split." [5.191] 
The third FM utterance described atmospheric conditions and is irrelevant to the trail SUBSTRATE description:

Carl: “...the dew had lifted.” [5.204]

Carl also described his sketch-map, using mainly veridical motion constructions to outline the path with the exception of a single dynamic predicate element:

(66) Carl: "It'd be us going into the woods, and then us kinda going up that uh, kinda going up uphill towards the top and then um we kinda walked straight for a minute, and then we started walking I would say up a little more, this way, and then uh, I would, uh, you know we kinda walked straight for a minute and then we kinda made another like left, and then here, I guess, I guess there would be a little more cause this is like where it kinda split off, like you could either go straight or this way, and, uh, we kinda went more this way, and then there was another, oh I guess this was a, you know, the first bridge here, and then there was another small bridge over here, and then there was another bridge here, and the last bridge was around over here." [5.186]

Carl's use of "...it kinda split off..." occurs with the main verb "is", making the "splif" element into a predicate and not a prototypical FM construction, although it is counted in the tally of FM constructions because it contains a notion of fictivity.

The sketch-maps produced by Carl and Holly reflect a defined back-and-forth pattern of the trail which resembles the general schema of the trail as represented on the official map. This demonstrates that they were aware of the overall shape of the trail and could give a general sense of the morphological structure of the trail. 
It would not be surprising for this awareness to be related to the palpability of the trail as a linear winding figure against a continuous planar ground. As noted in the last section, palpability of the trail for those not having a map has to be considered subjective because of the variance in how subjects see the trail and what they pay attention to. This is in contrast to the trail on the map that is concretely palpable for all map users, opening the trail to abstractly palpable experience of the trail as a trajectory for attention. Given the subjective palpability of the trail, in the case of Carl and Holly it is safe to argue that their sense of the trail was concretely palpable as evidenced in the sketch-maps and their higher use of FM constructions when compared to Bob and Ariane who were also B-Trial subjects. Consider Carl and Holly's sketch-maps:

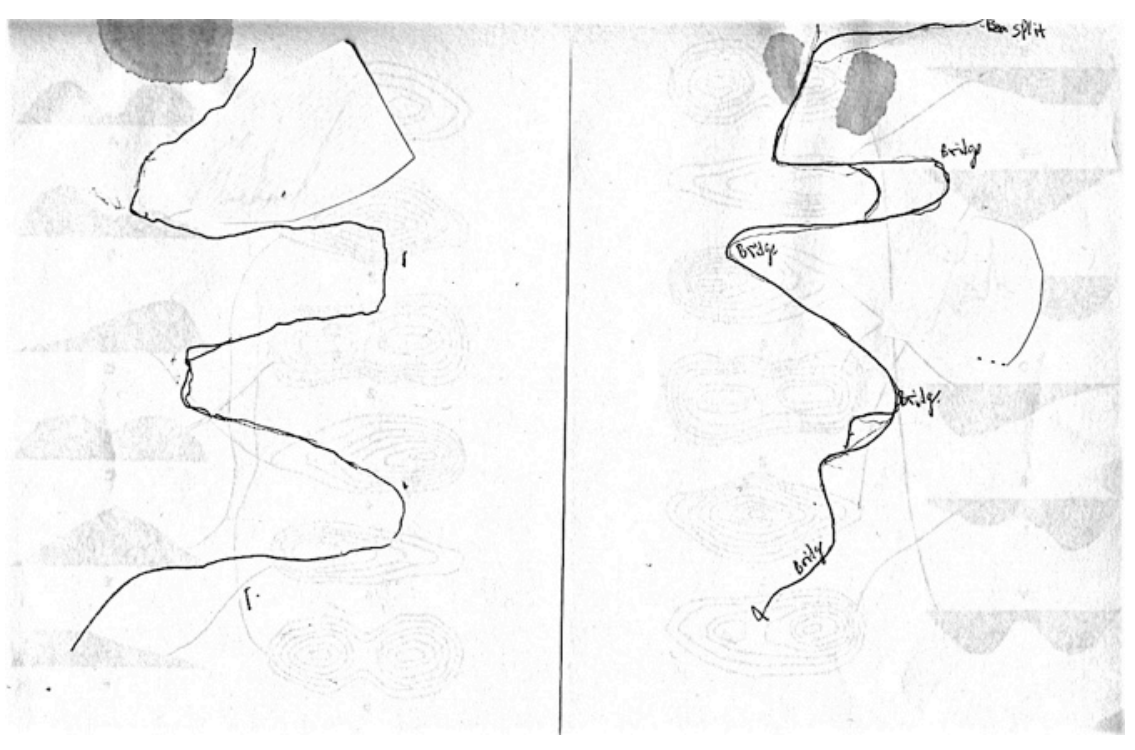

[Image 2.1 Sketch-Maps 1 (left) Holly \& 2 (right) Carl]

Sketch-Map \#1 was produced by Holly and was later corrected after seeing the actual topographic map. Sketch-Map \#2 was produced by Carl and was not 
significantly corrected. Although over-exaggerated in their execution, both of these sketch-maps capture the salient zigzag feature of the trail, suggesting that at least the zigzag linear schema was accessible for mental scanning. This overexaggeration is akin to what Stjernfelt (325: 2007) would judge as the sketch's semiotic purpose, it relates the subject's conceptualization of the salient features of the trail and records what the subject felt was important information about the path shape. These are approximations of path shape to communicate rough generalities of the geometry of the trail as perceived by the subject drawing the sketch-map; precision is not part of the semiotic purpose of the sketch.

Stjernfelt would further argue that scarcity in sketch detail comes from a sense of indeterminacy, and that this indeterminacy may hold for the perceived object and the perceiving entity's understanding of the perceived object (325, Stjernfelt: 2007). The subjective indeterminacy present in these images is a reflection of the subject's conceptualization of the trail, and the drafting of the sketch-map takes place after the subject has walked along the trail. These sketch-maps are not cartographically precise, the incomplete rendering of the trail, the disproportionate contours of the trail shape, and the general cartesian imprecision of these sketch-maps speak to a sense of objective indeterminacy where the object (i.e., the referent trail) is not fully known. But cartographic precision is not the intended aim of the sketch-map. Additionally, constraints on precision prohibit complete accuracy; checking the accuracy of their memories or of sketch is not possible, so the subjects make estimations based on their 
memory of the experience. These approximations and estimations emerge from the relative instability of the subjects and their encounter with the space they experienced and the resulting shape they represent in the sketch-map.

All of this points to the fact that the subjects have some idea of the trail shape (although imprecise), and they have some communicative intent in the sketchmap which is not hampered by their generalities of path shape. Since the sketch-maps were produced after the experience and the subjects were not made aware of the task ahead of time, these facts suggest that the subjects were able to mentally scan the terrain as they walked and to apprehend elements of path shape along the way which enabled them to draft a roughly accurate sketchmap.

Because of their ability to draw from memory a roughly accurate map of their walk experience of the trail, it cannot be argued that B-Trial subjects did not produce the mental scans necessary to produce FM. Instead, a more reasonable argument is that their lack of FM usage is an indicator of the absence of attentional scanning along both the map SYMBOL path and the actual SUBSTRATE path and that this co-occurred with the absence of a reified abstraction of the path on a map. The two B-Trial subjects who drew sketchmaps obviously had some linear path schema that they acquired during the walk experience, but this was not enough to prompt for FM at the same level of raw 
frequency as the palpable linear path schema of the trail on the map was able to prompt for FM usage in A-Trial and C-Trial subjects.

\subsection{PATH vs. TRAIL distinctions in B-Trial subjects:}

In addition to collecting sketch-maps from the two B-Trial control subjects they were also asked about the differences between the word path and trail since it was suspected that the word trail might not have adequately focused on the SUBSTRATE construal that was intended. Consider the following responses:

(67) Carl: "A trail is something you follow, I think, you could kind of follow something that's already guided out where a path you can kinda make your own." [5.210]

(68) Holly: "Um, I kinda feel like they're both pretty much the same. When I think of "path" I think of something that's visible, visible to me. Um, the trail I kinda find feel is the same way." [5.213]

Carl's response clearly draws a distinction between the two terms, whereas Holly sees the two terms as nearly synonymous. However, it would have been interesting to extend this same question to each of the subjects in the study to see if Path and Trail evoked different responses. One hypothesis on the differences is that "path" might more accurately reflect the SUBSTRATE and "trail" might reflect EXPERIENCE, which would lead to distinctions in the type of FM produced. The reason for this hypothesis is that trail evokes a larger and more global scale than path, which seems to evoke a more local scale. For instance, hiking the Appalachian Trail evokes not only the trail SUBSTRATE schema, but also the region that the trail goes through: the Appalachian 
mountains (which is EXPERIENCE in the semiotic typology of FM). The word "path" might have focused subjects more on the immediate trail SUBSTRATE, and less on the contextual description of the environment surrounding the trail, and the landscape through which the trail passed. Future studies along the lines of this study should consider a norming procedure to disambiguate the two words, or alternatively, consider including "path" and "trail" in the stimulus questions to work out the nuances of word meaning to individual speakers.

\subsection{Demonstrative path fictive motion and perceptual wholes [SYMBOL domain]:}

Talmy (2000) outlines demonstrative path FM as paths that point in order to direct attention. They are linear objects that end in a point.

(69) Regina: "And I, I'm obviously reading this wrong, which I didn't really know about this anyway, but I thought if it, if it curves up like this that means you're going up, if it curves down like this that means you're going down, if it curves like this, then I, this is where I got confused." [1.294]

This curving is similar to the demonstrative purposes of the demonstrative path, except that Talmy $(109,2000)$ states that demonstrative paths are linear objects with point-type fronts, and it is at first uncertain how this curving satisfies that requirement, since it is the contour lines that curve, and they have no end points (they are all contorted closed loops). However, contour lines do pull the gaze along the length of a portion of the line as it curves to define the plan view contours of the terrain. But even though having no endpoints makes them less 
likely to be demonstrative path candidates, they still can satisfy Talmy's specifications. Contour lines are nested sequences of loops that stretch around the protrusions and depressions of the landscape to express the landscape's topological content in topographical terms, and while they are loops they often are elongated into pointed shapes that point up along a ridge or down a valley, down a moraine or up a spur (see figure 2.5).

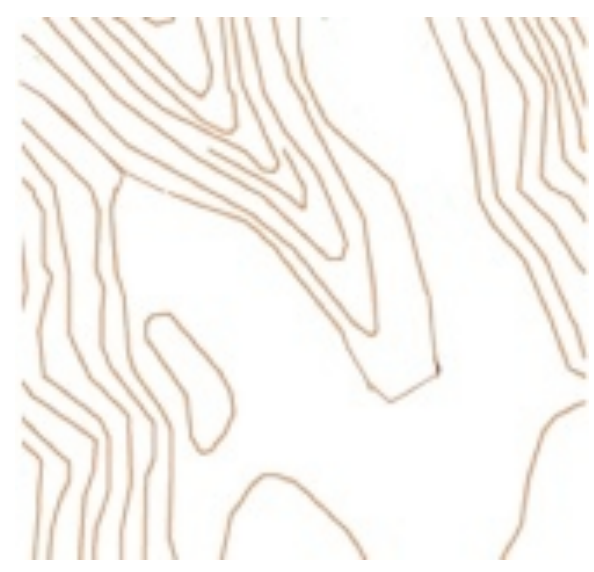

[Figure 2.5 Stacked contour lines forming a perceptual whole]

Although in the present FM construction it is unclear which precise contour line the subject is referencing, this type of curving pattern is pervasive on a topographic map and is precisely what is giving shape to the "going up" or "going down" mentioned by the subject. Since it is easy to see in figure 2.5 how the stack of contour lines produces imagery that lends to a conceptualization as a linear object with a point-type front, considering this an example of demonstrative path fictive motion is hardly a stretch (however, it could be analyzed as a coextension path without the sense of directionality). 
Interestingly, this raises the issue of how the graphic representation of contour lines expresses directionality by way of the interval slices on a horizontal level. Several subjects had difficulty in determining if the landform represented by a set of contour lines was a ridge or a valley. This is reflected in the uncertainty they use to describe the map, and captured in the mistakes that they made in thinking about the terrain shape based on the map symbology. A stack of contour lines could be "pointing" up to a hill, or they could be "pointing" down into a valley. Because contour lines are ambiguous with regards to how they represent vertical elevation, typical topographic maps indicate the direction of elevation through a number system where every fifth contour line reads the elevation of that contour line with respect to sea level. This Brandywine Falls Area topographic map does not have those index contour lines, so naturally, readers have increased difficulty with determining which way the contours "point". This partially explains Regina's problem with sensing the pointing of the curved lines.

Several subjects made sense out of the map and the terrain by mutual alignment of known features on the map and the terrain, this behavior was an attempt to coordinate the symbol world with the substrate world. Other subjects exploited the fixed natural terrain as material anchors that enabled them to orient themselves and their map to the surrounding terrain, however, these activities are beyond the scope of this study. 


\section{TOURIST WAYFINDING}

Wayfinding is not restricted to hiking trails zigzagging through the woods, people engage in wayfinding around the world in all types of settings in both small-scale indoor space and large-scale outdoor space. Among this ubiquity of wayfinding scenarios is the common experience of wayfinding as a tourist. Processes similar to the hiking trail wayfinding are involved in traveling in cities like Paris. This second study is a product of an ethnographic approach to understanding tourist wayfinding by interviewing a couple who had recently returned from Paris. This document only contains the fictive motion portions of the study, other navigational blends were analyzed but they are beyond the scope of this study. The interviews were conducted in two stages, the first involved viewing a slideshow of over 600 photos and transcribing the descriptions of the photos. The second stage involved eliciting directions from the subjects through a series of sketch-map exercises. The two sets of data were compared, first looking at the emanation path fictive motion employed in the descriptions, and secondly looking at the role of vision in the conceptual blends featured in the sketch-maps (not included here).

While similar path construals were found in the Paris data, this report largely focuses on the role of emanation path fictive motion since sight and intangible vision paths proved to be essential in the wayfinding activities of the sight-seeing tourists. Additionally, this focus on emanation path fictive motion roughly rounds 
out this study's coverage of Talmy's (2000) main fictive motion structures (emanation path and coextension path).

\subsection{Layout of the chapter:}

The chapter began by describing the ethnographic study of tourist wayfinding in Paris through the reconstruction of memories while looking at photographs and through memories conveyed during sketch-map drawings of memorable routes between memorable landmarks across the city. The next section begins to explore the role of seeing and vision in their relationship to scale and scanning. The Paris data mainly featured emanation path fictive motion, whereas the Trail data featured more coextension path fictive motion of the SYMBOL and SUBSTRATE type. While those types occurred in the Paris data, this study focuses on the emanation type which in the semiotic typology falls under EXPERIENCE FM (although EXPERIENCE is more than just emanation). Additionally, access paths are explored in detail in this study.

The structure of photographs is important in this study, the accompanying fictive motion in some images corresponds to the general palpability of landmarks in the photographs. Since the photographs were taken while walking around, a path is implied by the sequential order of the images. Some sequences are interesting because of the general description of the path as it unfolds with new features in the subsequent images. The early part of the chapter explores the subjects 
moving towards I.M. Pei's Louvre Pyramid, by looking at the nesting of figureground relations in the use of an access path.

Moving away from the glass pyramid, the study begins a path down the Axe Historique, one of the axial organizations of the city which features ample line of sight and targeting path fictive motion examples. Next explores the sighting between landmarks such as Luxor Obelisk on the Place de la Concorde and the Arc de Triomphe along the Axe, and then the Obelisk to the Eiffel Tower not located on the Axe, with a discussion of targeting paths. More emanation paths are discussed, with focus on the role that figure-ground organization plays in disambiguating between line of sight and access path FM. Simple description of the occurrence of FM constructions during the drawing of a sketch-map get the reader ready for a richer description of sketch-maps in chapter 5 .

At this point, the study turns to looking out windows in Paris to compare how views as activities in the verb sense differ from views as objects in the noun sense. Talmy's (2000) notion of palpability is seen to feature largely in this discussion. The question being addressed at this section is whether or not there is a reason that a subject would construe a view with FM in one case and use a noun instead of FM in another case. Grammatical differences are explored, but it is the functional differences that seem to be most useful in determining the differences. Functional differences like type of building (institution vs. dwelling), 
extent of agency, and the role of attention converge in a semiotic description of the different views out different windows.

\subsection{Walking around looking at things - scale \& scanning:}

Busy and complex grounds (like a forest, or a city) preclude views that can comprehend the full scope of a path. This produces a discontinuous experience of something like a trail that might otherwise be expected to be described with coextension path FM in a continuous view. These interrupted grounds might preclude an FM construal because the scope of the trajector cannot be perceived in one visual scan. As seen in the Trail study, when a view-interrupted trail is rendered at a different scale on a map (which affords a single visual scan) the trail becomes available for a FM construal. In these cases SYMBOL affords an FM construal more than a non-symbolic experience.

Simple grounds that are not busy, but which have sharp and distinct figureground organization afford FM construals that do not require the experienced figure to be reduced to a manageable SYMBOL. A simple visual scan of the SUBSTRATE, SUBSTANCE, or other physical referent can afford an FM construal.

Photographs delimit the scope of a view of an area. For instance, you cannot scroll left or right on a photo to see what surrounds the image, and you cannot 
look up or down or behind the camera. Photographs inherently reduce enormously complex visual scenes to a narrow focal channel. This reduction of complexity focuses on what the photographer perceives as salient in the complete visual scene. It could be argued that a photograph (such as the kind taken as mementos of travel) is a relatively simple relationship between a figure and a ground. Poorly composed photographs may be less clear, but even in that case, the frame of the photograph can be thought of as the figure with the unseen surrounding as the less salient ground. Finely composed photographs employ strategies such as the rule of thirds which places salient features in areas of the image that draw the eye to perceive them as more prominent. The salient feature in focus places the non-salient elements into the background.

While Steve is not a professional photographer, he does take photographs that are thoughtfully composed with some attention to the location of salient objects. He was the primary photographer during their trip to Paris. In his photos there is usually a clear figure-ground distinction between some figural salient element and the ground against which it stands in contrast.

These figure-ground relationships provide for fictive motion descriptions in many cases. The main types of FM constructions that Steve and Joanna use are emanation path descriptions and access path descriptions. These will be investigated in the following sections. It is important to note that their use of both of these types strongly features vision as opposed to featuring the physical 
structure of the trajector of the FM path (such as with coextension path); even a number of the access paths focus on visual access (although some do focus on physical access).

The role of trajector palpability and landmark palpability are considered in the various vision-related FM constructions collected during the slide show. Since the medium of photography preserves details that might have gone unnoticed as the photographer captured the image, it is important to consider what element in the image is described as the trajector in case the trajector is not the intended figure in the image.

\subsubsection{Access path: approaching I.M. Pei's Louvre Pyramid:}

In the following example of an access path FM construction that outlines the path a visitor would take to reach the pyramid at the Louvre, none of the salient concretely palpable elements of the two photographs that are being described act as the trajector in the FM construction.

(1) Steve: um, this is the Louvre, and we entered from the one side and went through like a courtyard, or a little interior part, and then we wal, yeah, we walked through here and there's this big fountain in the middle, and beyond that was the I. M. Pei glass pyramid in the middle that is now the entrance into the museum. [Image 117] [1.0412]

(2) Steve: um yeah, you can see it there [indistinct] [Image 118] [1.0413] 

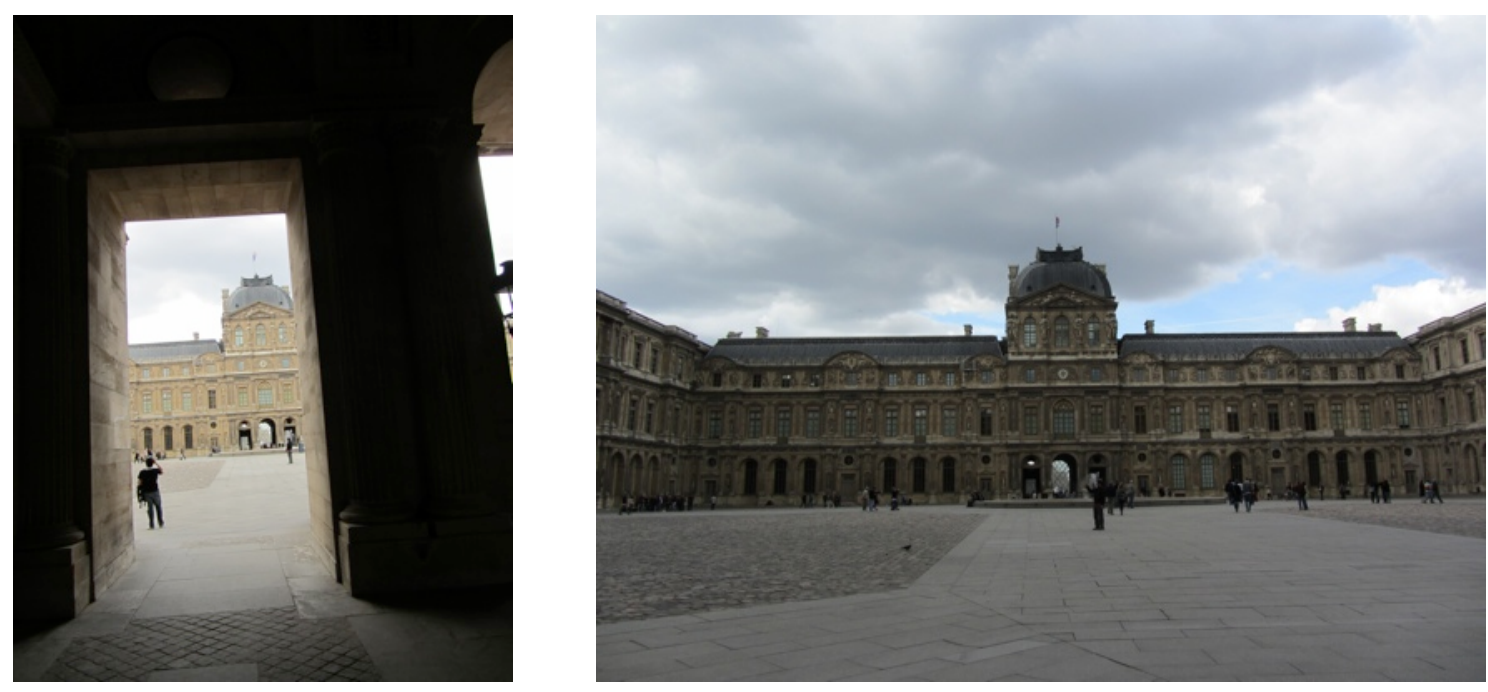

[Image 3.1 The Louvre (pyramid visible through far archway) Photographs: 117 \& 118]

In this case, it is argued that the glass pyramid was such a concretely palpable element in Steve's memory of the Louvre that it is available to be the trajector in an FM description that accompanies an image even when that image does not have a prototypical figure-ground distinction in which the FM trajector is equal to the image figure. However, once you focus on the contents of the far archway and once the glass pyramid is recognized, it does become a primary object set against the secondary object of the structure of the Louvre. Talmy (2000) outlines a primary object as having unknown spatial properties, being more movable, smaller, geometrically simpler, newer or more recent in awareness, having greater relevance, being less immediately perceivable, and being more dependent on a secondary object (183, Talmy: 2000). In these terms then the glass pyramid can be seen as a primary object which renders it roughly equal to the role of figure (183, Talmy: 2000). 
However, this pyramid as figure should be read as nested in a larger figureground distinction between immediately salient perceptual elements such as the figure of the Louvre with respect to the Ground of the doorframe in the foreground for photograph 117, and the Louvre as the figure with respect to the courtyard in foreground for photograph 118. Only after acknowledging these two more salient $F-G$ relationships is it possible to argue that the glass pyramid is a nested figure. In both cases the less salient figure is nested in the more salient figure. This nesting has the effect of making the initial salient figure into part of the ground as the less salient pyramid becomes the focal feature. Contrast this description of the pyramid as a nested figure with it's role as a more salient feature of photograph 119 (image 3.2):

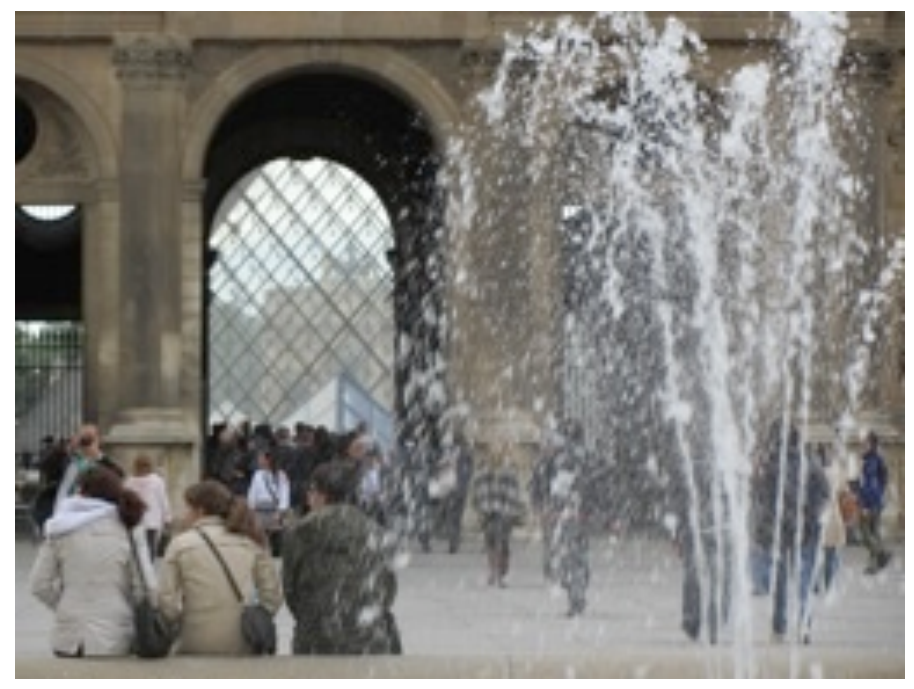

[Image 3.2 The glass pyramid through arch: Photograph: 119] 
The pyramid as shown in photograph 119 occupies one of the prime locations for a salient object according to the photographer's rule of thirds. It can be argued that this rendering of the pyramid has the pyramid as the figure. Interestingly, having just been described in photographs 117 and 118, the pyramid is not described in this image (the entire image goes by unremarked). Perhaps this is because it's subject has already been disclosed in the preceding utterance.

When Steve and Joanna have finally made it through the archway to the location of the pyramid in photograph 123 (image 3.3), the pyramid's active status as topic is reflected in Steve's third person pronominal reference in the following non-FM utterance:

(3) Steve: There it is. [1.0416]

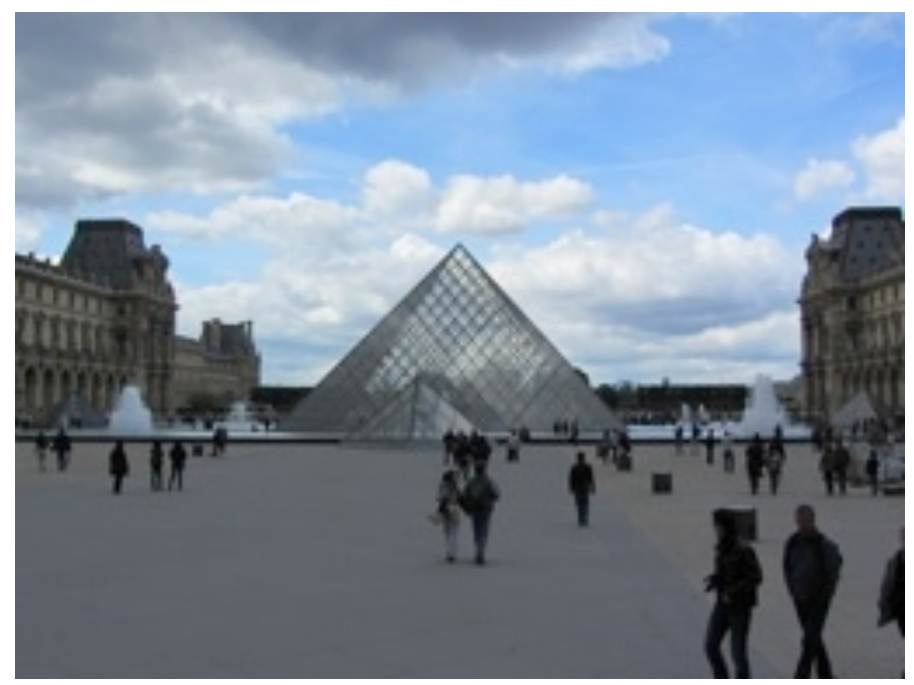

[Image 3.3 I.M. Pei's glass and steel Louvre Pyramid: Photograph: 123] 
As seen by the palpable pyramid, the description may feature elements that are less focal in the image, but which capture a distant and concretely palpable landmark and that landmark may be recruited into an FM description.

The palpability of the pyramid at the Louvre is clearly established in the descriptions provided during the slide show and during the sketch-map collection sessions. In fact, during the sketch-map session, the Louvre is iconically represented by a triangle, a metonymic extension of part of the Louvre standing for the whole of the Louvre.

This palpability of the pyramid identifies it as a significant place in the Paris landscape, in fact, the pyramid and the Louvre are at the starting point of one of the most significant features of the Paris landscape, the Axe Historique, a boulevard of monuments in near perfect alignment. Interesting blends of the layout of this Axe were discovered as the subjects gave route descriptions between landmark elements, these are not covered in the present study. At this point focus turns toward the Axe to understand its significance and the views that it affords, with a look at several FM constructions that accompany its description.

It is impossible to appreciate the scope of the Axe Historique without understanding the intentionality behind its linearity; the Axe Historique has been a work in process since the seventeenth century, and is under extension and 
development to this day as it continually creeps westward. This is a triumphant work, aptly receiving the alternate name La Voie Triomphale; the triumphal way.

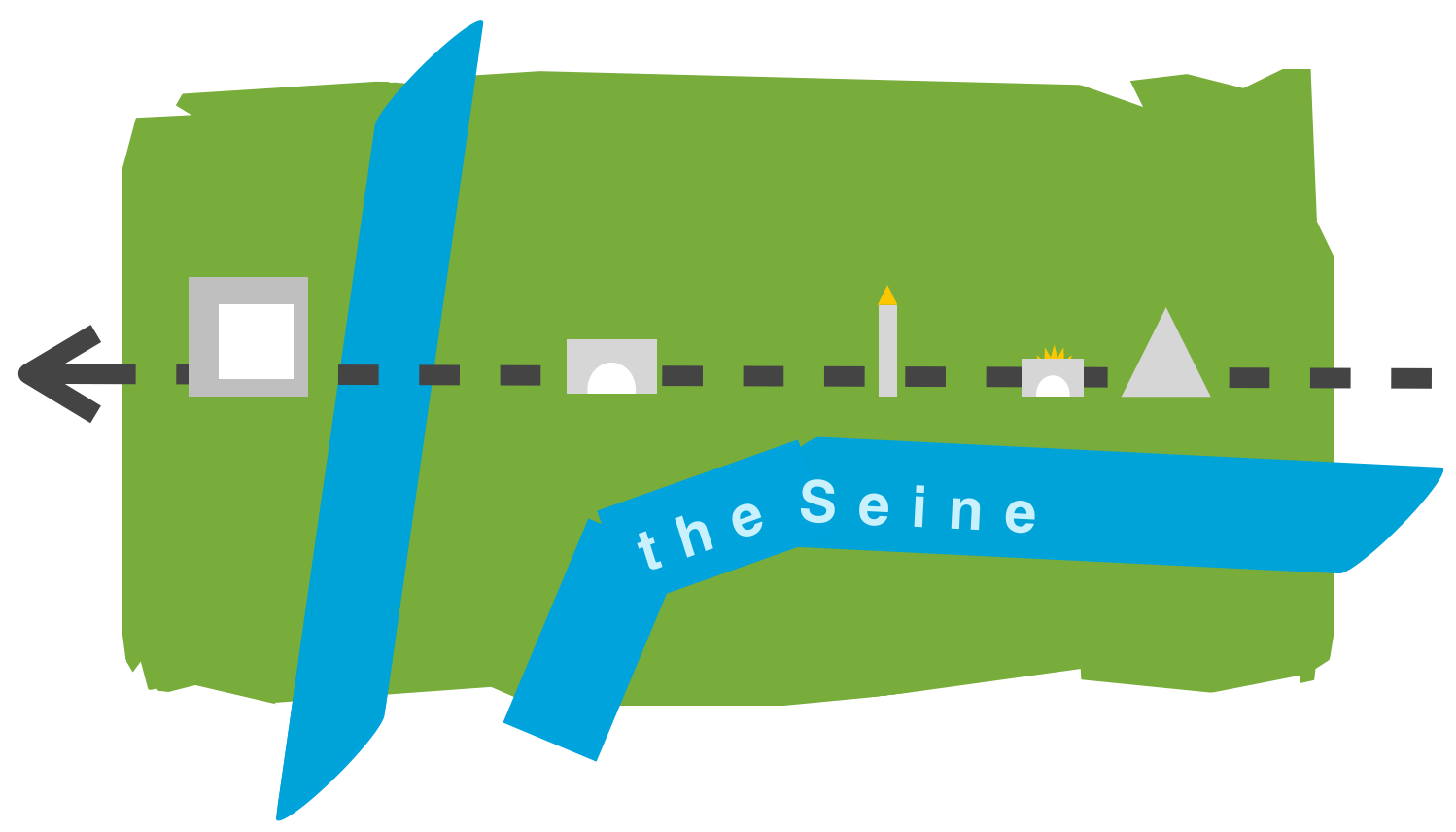

[Figure 3.1 The Axe Historique (not to scale)]

There is direct line of sight along the Axe Historique running from the Louvre, through the Arc de Triomphe du Carrousel, past the Luxor Obelisk on the Place de la Concorde, through the Arc de Triomphe on the Charles de Gaulle Étoile, out of Old Paris and across a switch-back of the Seine into La Défense where it passes through the Grande Arche to make its way toward one of the western switch-backs of the Seine. 
For readers unfamiliar with the layout of Paris, it should be noted that the Eiffel Tower is not along this Axe, as it was intended to be a temporary structure for the Exposition Universelle (the World's Fair of 1889). The main fairgrounds were located across the Seine on the Champ de Mars where the Eiffel Tower still sits today. Despite the ubiquity of the Eiffel Tower in images of Paris, many images and films do feature some portion of the Axe Historique. It is in fact this imagery of the Axe that lead Steve and Joanna to believe that Paris had more grand boulevards than they actually encountered; most streets in their experience were small and windy in comparison. However, this wide and straight boulevard is a powerful image of the structure of Paris.

In the sketch-map sessions explicit focus was placed on the linear relationship of some of the landmarks along the Axe Historique with the intent of eliciting different emanation path FM expressions so that argument structure differences between image descriptions and sketch-map descriptions could be looked at, but a peculiar feature of their descriptions of these aligned landmarks stood out as oddly significant. Instead of describing the linearity of the Axe, their descriptions had an obtuse angle at a vertex on Luxor Obelisk in the Place de la Concorde. The Axe had a bend, in their descriptions and their sketch-maps. This mysterious bend is outside the scope of this work, but is discussed in a companion paper (in preparation). For now, other visual emanation FM examples are explored to attempt an understanding of the role of visual experiences in the formation of knowledge of a place. 
Since line of sight is such a strong feature of the approach to many landmarks in Paris (including landmarks not along the Axe Historique) it is not surprising that many of these approaches and views are described with fictive motion featuring strong emanation path structure. Talmy describes emanation as "basically the fictive motion of something intangible emerging from a source." (105, Talmy: 2000). It follows that the source of emanation can be either the entity having the experience (such as the case of having a sight path that reaches a destination) or the entity creating the experience (such as the case of something projecting the intangible element away from itself and toward the entity having the experience).

For instance, Steve encountered the Louvre Pyramid and took an image which he described with: "I like this picture, the way the building reflects off the pyramid." In this example the reflection is the intangible entity projecting from the surface of the pyramid - this is emanation in which the entity is creating the experience, the experienced element produces the emanation. For the opposite situation in which the experiencer produces the emanation consider this utterance where Steve's line of sight is the intangible entity emanating to the experienced object: "That's looking down into the pyramid". This case has Steve's line of sight as the emanating entity which reaches down and apprehends the view of what is down inside of the pyramid. This distinction of 
experiencer/experienced will be drawn into analysis of the emanation paths in the following section.

In addition to the emanation paths, access paths describe some of the paths to landmarks. Access paths are not emanation paths because they outline the path that an entity might travel to reach the entity being accessed, this differs from the emanation path type by primarily drawing attention to the physical path instead of the visual path.

\subsubsection{Access path: Arc de Triomphe from Place de la Concorde:}

Consider the following access path fictive motion utterance:

(4) Steve: "Oh, there's there's the Arc de Triomphe, we're down at the other end of the, its way off in the distance there." [image 343] [1.0776]

This provides an access path that directs the hearer and viewer of the photograph to look in the distance represented by the horizon line in the image to see the Arc de Triomphe positioned on the horizon. This produces the effect of an access path that is easily apprehended by line of sight, but precludes a lineof-sight FM reading since the sight is not construed as being in emanating motion. Instead of line-of-sight emanation, this is more like an advent path in which the Arc is in the distance. But most likely this represents an access path that the viewer is directed to move their gaze along the perspective of the 
camera angle to the distant location of the Arc on the horizon. In fact, Steve leaves a lexical element out of the utterance that would clarify this as an access path: "...we're down at the other end of the..., its way off in the distance there." The path to access the Arc de Triomphe from Steve and Joanna's position is across the unspecified stretch of space that sits between them and the landmark; this is the Avenue des Champs-Élysées, a stretch of boulevard along the Grand Axe. It is the road that is the access path, and it is deprofiled by ellipsis.

\subsubsection{Emanation path (targeting path type): sighting between landmarks:}

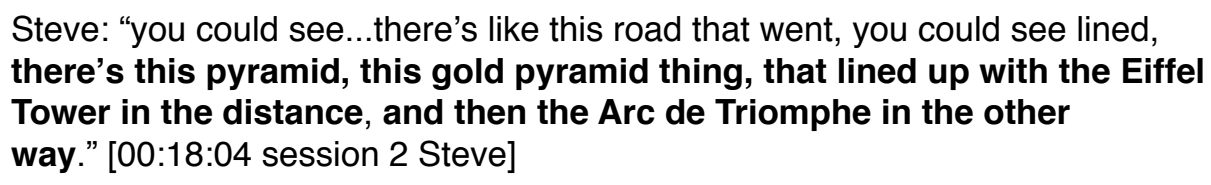
there's this pyramid, this gold pyramid thing, that lined up with the Eiffel Tower in the distance, and then the Arc de Triomphe in the other way." [00:18:04 session 2 Steve]

During the second session, the subject was emphasizing the ability to see two landmarks from the vertex of an angle that converged on a third landmark. In the sketch-map this angle is made clear, but the landmarks themselves are in the wrong locations. Because of this mistake, the sketch-map is not included, although the important element (the line of sight angle) is reproduced with the dashed arrows on the map below. The subject's placement of the landmarks is not important in understanding the sentence, since it is the line of sight that is linguistically represented in the FM. This confers with the images from the slide show included below the map. (The incorrect sketch-map is available in the archived data). 


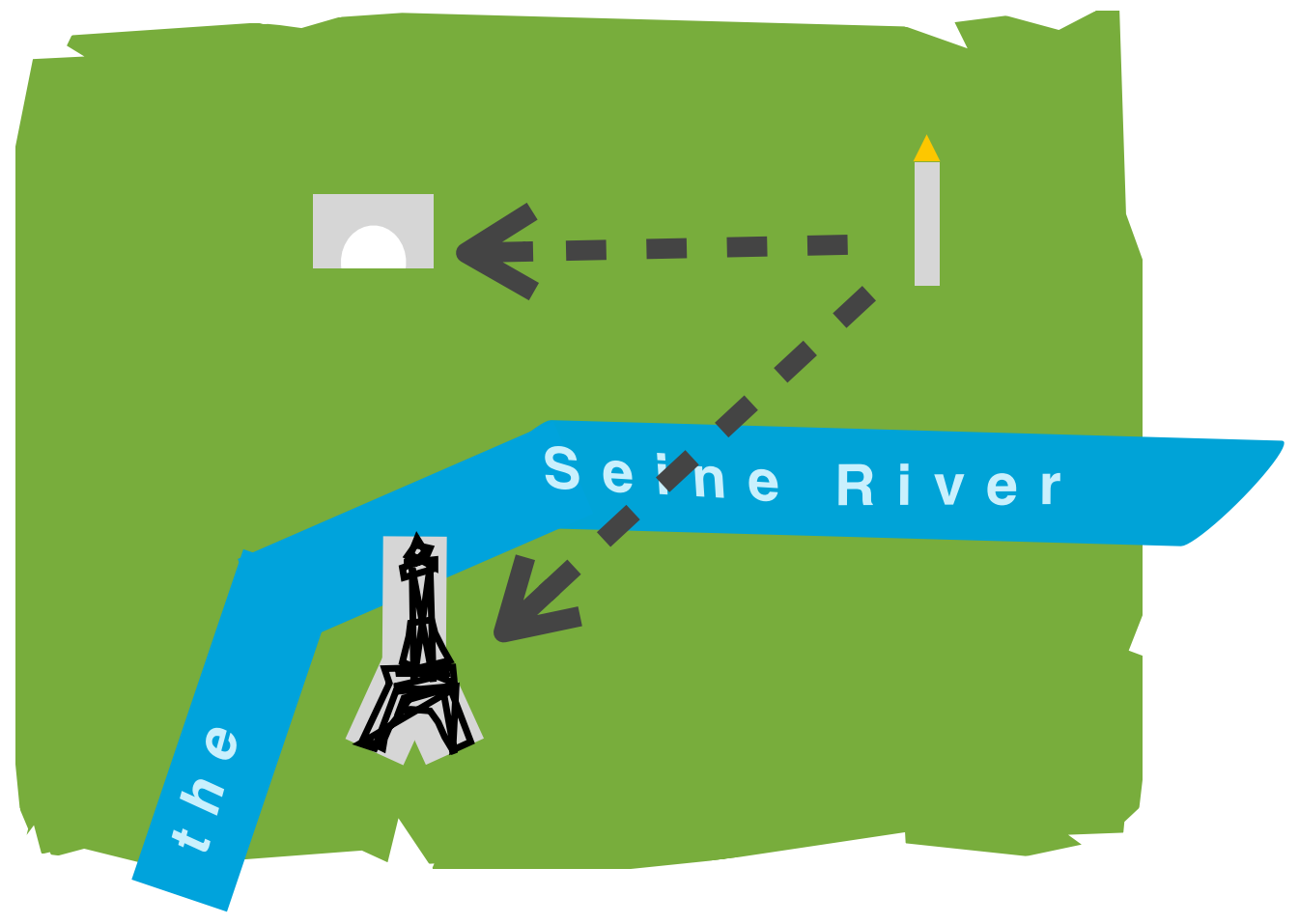

[Figure 3.2 Line of sight: Place de la Concorde - Arc de Triomphe - Eiffel]

It should be noted that this is not the mysterious bend in the Axe Historique mentioned above, this is just a shift in gaze direction from the vantage point of the Place de la Concorde toward the Arc de Triomphe along the Axe to the Eiffel Tower across the Seine.

During the first session this scene showed up in the slide show (see images below); clearly the line of sight is a salient feature of his experience of Luxor Obelisk at the Place de la Concorde. In this session Steve draws the location of Luxor Obelisk on his sketch-map and then proceeds to draw the line of sight from 
the Obelisk to the Eiffel Tower, and then from the Obelisk to the Arc de Triomphe. In both cases the line begins at the obelisk and extends away from it.
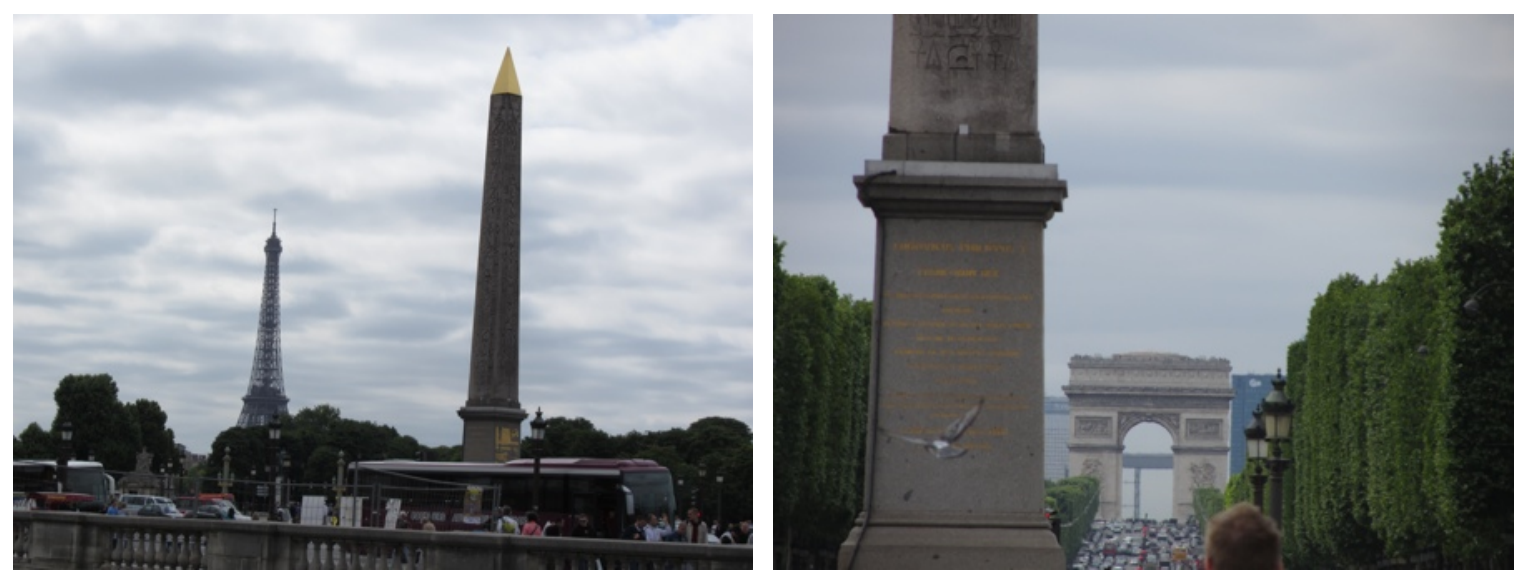

[Image 3.3 Place de la Concorde to Eiffel (left) and Arc (right): Photographs: 341 \& 344]

The palpability of the Eiffel Tower and the Arc de Triomphe as landmarks is concrete. Both landmarks are mentioned in the FM construction (over two clauses) and both are at a great distance from the vantage point. It is this distance that solidifies the concreteness of the landmarks in consciousness; had they not been so prominent in the field of view and so palpable with their presence either some other more salient landmark would have taken their place, or more likely, this view would have gone unnoticed as unremarkable. Instead these landmarks anchored the eye with the weight necessary to make them focal elements, and this comes through linguistically as the objects of the alignment path in the retelling of the experience in (5). Also, as endpoints the Eiffel Tower and the Arc de Triomphe draw the eye down the alignment path with 
intentionality; the landmark is something that the subject wants the listener to attend to as a fact of the scene.

At first (5) might be thought of as an alignment path because the FM construction describes how landmarks are aligned with respect to the view that is available from the vantage point. However, Talmy discusses alignment paths as orientation paths for linear objects that have point-type fronts (108: 2000). The only possible linear object could be the road between the obelisk and the Arc de Triomphe, but it lacks a point type front other than the "directional point" of the subject's direction of travel along the road.

More likely this is a hybrid between a demonstrative path a targeting path. The demonstrative path again requires a linear object with a point type front but this time with an intangible line emerging from that front that line directs attention along the line's path (109, Talmy: 2000). Certainly the directing of attention is achieved in this FM construction, because the landmarks are salient, in this act of drawing salience to a distant object this FM is like the demonstrative path. However, it is also very much like a targeting path, which Talmy states requires an agent to intentionally orient an object so that it suggests an emerging line along the intended path (109, Talmy: 2000). This act of targeting is very much like the act of sighting a gun, which requires lining up the sight posts on the breech of the gun with the sight post at the end of the barrel of the gun. When both sight elements are in line, then the bullet will follow a trajectory to the 
element that is in front of the aligned sight posts. In sighting a gun the marksman has a vantage point that is behind both sight elements. Similarly, in (5), the subject has a vantage point that is behind the obelisk and the Eiffel Tower in the first clause, and behind the obelisk and the Arc de Triomphe in the second clause.

Considering Talmy's (2000) palpability parameters, in this situation there is a concrete type-of-geometry, the view between the obelisk and the landmarks in both instances is unimpeded and linear; this is a straight line. This unimpeded view invites the listener to attend to the end point landmark object, and in so doing produces a concrete level of actionability. However, this actionability is concretely dependent upon the concretely palpable landmarks and the alignment suggested by "lined up" as the stimulus for understanding this targeting path.

In both clauses the subject has targeted down a desired line of sight that is fixed on the two landmarks, and the palpability of the landmark has secured the intent that attention is being guided to the landmark targeted in sight. The very act of placing the foreground landmark (obelisk) in line with the background landmark (Eiffel Tower or the Arc de Triomphe) is an act of sighting along an axis with the intent that the end point landmark will be attended to as it relates to the foreground landmark. This draws the linear orientation of their axis into salience; they are lined up. 


\subsubsection{Emanation path (prospect path \& access path type): Grande Arche facing the Arc de Triomphe:}

Consider the path in the following interaction:

(6) Steve: That's the, um, the um, they made the modern version of the Arc de Triomphe, down in their main town, it's supposed to be facing it, but when they built it, it's slightly off-skew so its a little bit crooked, but it's supposed to be facing it. [laughs] [1.0749]

Steve: Modern technology and they can't even align two buildings [laughs] [1.0750]

Joanna: But yet the Arc de Triomphe is lined up with, there's another Arc... [1.0751]

Cross-talk Steve: It's perfectly lined up with another [1.0752]

Joanna: its like by the Louvre [1.0753]

Steve: by the Louvre [1.0754]

Joanna: Yeah [1.0755]

This access path is intended to follow a perceptual path of attention toward the focal subject of this image (i.e., the centrally located Grande Arche that is compositionally aligned at one of the focal points in the photographic space linguistically marked as "the modern version of the Arc de Triomphe") and its immediate surroundings (linguistically marked as "their main town") In addition to the access path in this example is a prospect path that has a contextually dependent pronominal construction: “...it's supposed to be facing it...”. This "facing" contributes to the linear path between the vantage point of the photograph and the captured image along the access path implied by the alignment of the two points. Without this prospect path the overall palpability of the access path would be semi-abstract, and without the accompanying photo the access path would be completely abstract as "down in their main town" does 
not establish any directionality in the mental map of the path between the two landmarks.

\subsubsection{Subject denial and speculative analysis of an access path:}

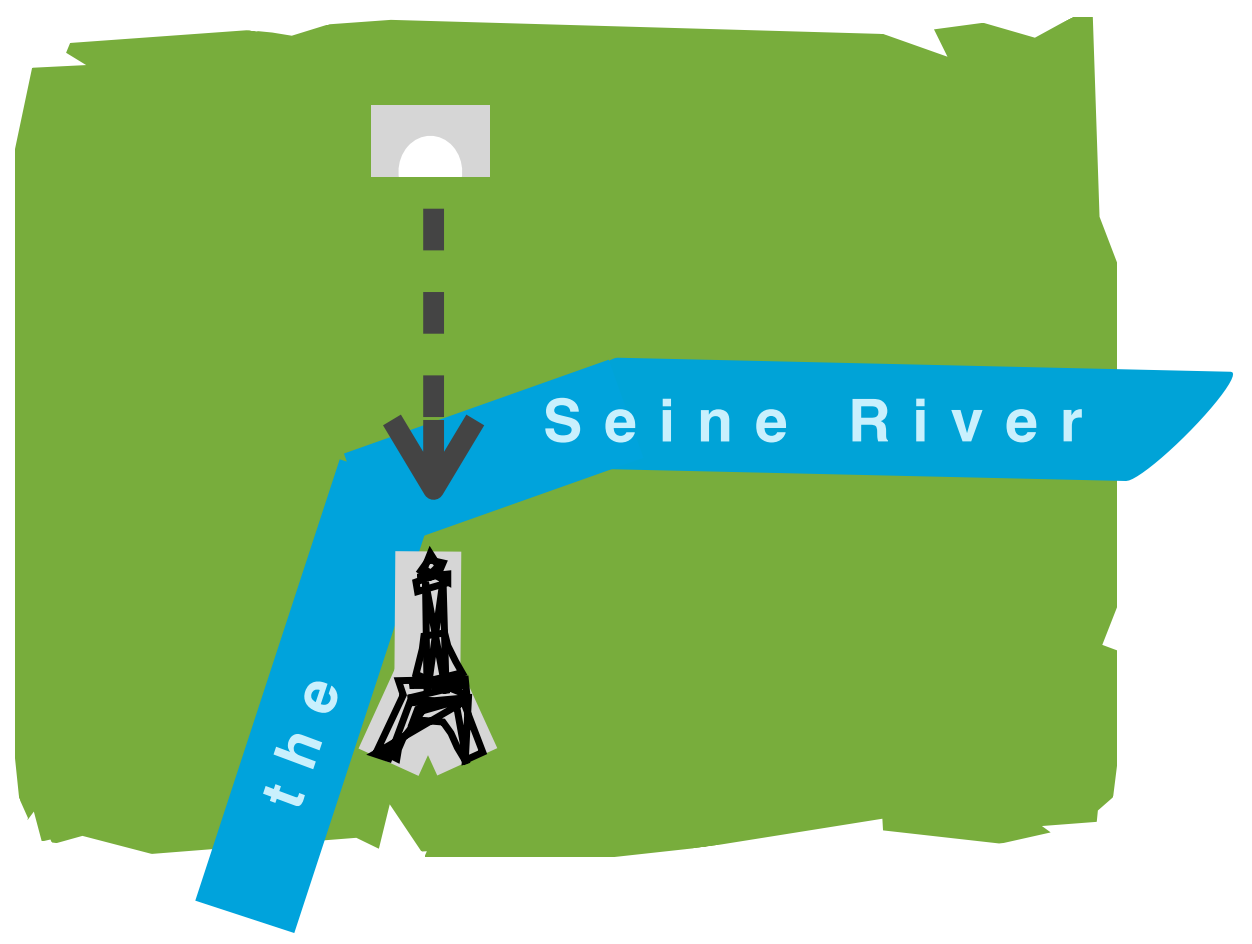

[Figure 3.3 Line of sight from Arc de Triomphe to Eiffel Tower]

While drawing a sketch-map between the Arc de Triomphe and the Louvre, Steve described the roads that radiate away from the Arc. One of those roads pointed toward the Eiffel Tower on his map. He begins to make a statement about the line of sight relationship between the Arc and the Eiffel Tower and traces the length of the road with the marker pen as he says: 
At this point he realizes he is making a mistake, that the Eiffel Tower is not at the end of the road as he is indicating and so he interrupts himself and immediately follows up to correct himself:

"um, I guess you couldn't see the Eiffel Tower, the Eiffel Tower was kind of between roads" [00:24:43 session 2 Steve]

What is left is a fragment of the FM utterance (7) which reflects the subject's conceptualization of space, mistakes and all.

It might be tempting to look at this utterance as a Line of Sight FM construction because it uses the words "this line of sight", but that would be a wrong analysis since there is nothing about "this line of sight" that conveys an emanating trajector, and having an emanating trajector is one of the requirements of Line of Sight FM. Instead, the speaker is describing the actual path (i.e., the road) as indicated by his tracing gesture with the marker pen along the road he has drawn, and "this line of sight" is incidental as a visual path afforded by the gestured road. Because it is about the actual path this FM fragment is more likely an access path. It is a path that another entity might follow in order to have the experience alluded to by "this line of sight". 
Unfortunately this FM utterance has a fragmented predicate and the speaker did not specify the path referent that affords the line of sight. However, the predicate is recoverable from the context and so it is possible to use the context of this sentence to construct two speculative options as to how this access path might have been completed. It is important to explore these access path speculations because the context makes it clear that this utterance was intended to be an access path. What follows is this speculative analysis.

Talmy argues that access paths depict stationary objects with respect to the path taken to reach that stationary object $(136$, Talmy: 2000$)$. Because this is spoken speech it reflects the effects of flow, and the speaker has interrupted a description and preempted an incorrect statement by not completing the incorrect sentence. For the first speculative analysis we look at the likely completed sentence. The subject's completed sentence might have been: "But there's this line of sight all the way down this road to the Eiffel Tower", which would have clearly contained an access path to the Eiffel Tower (i.e., this road) and rendered the Eiffel Tower as the stationary object.

However, a slightly different access path can be read even in this fragment FM utterance. As a second speculative analysis, since we already know that "this line of sight' is not a Line of Sight FM construction, perhaps this fragment FM utterance could be read to have "this line of sight" as the access path itself (that is, instead of a road). Perhaps "this line of sight" is metonymically referring to the 
road via the pedestrian's perspective from the road. In other words, the path to access or encounter the unstated stationary object is the same path that affords the view of that stationary object. The subject's completed sentence might have then been: "But there's this line of sight all the way down this direction to the Eiffel Tower", which would have turned the phrase "this line of sight' into the path and rendered the Eiffel Tower as the stationary object.

What we have in (8) is the subject's denial of the unstated predicate in (7), this denial rejects the probable completion of (7), rendering (8) as sufficient information to reconstruct that predicate for the speculative analysis above. The subject's own rejection utterance confirms that the speculative predicate is highly probable and makes it available for analysis.

It is interesting to look at this fragment from the speculative analysis to see how this access path was the result of interaction with the sketch-map through a suggestion of the road as the unstated predicate. It is also interesting to see that the path itself might not need to be a physical path, but can be an ephemeral path that results from a perspective of someone on that physical path.

Again, even without full specification of the predicate, this FM fragment is clearly an access path FM construction, since it does not have an emanating element as the trajector, but instead construes the path that an emanating element would need to follow. In this sense, by analogy, "this line of sight" relates to the 
emanation of sight as "blood vessel" relates to the flow of blood, a sort of CONDUIT conceptual metaphor. When placed in concrete terms it is easier to see that "this line of sight" is actually a ground/path and that the figure/trajector "sight" is absent from the utterance in (7).

\subsubsection{FM while drawing a sketch-map of the Champ de Mars:}

At one point Steve draws a map of the area that leads up to the Eiffel Tower, the Champ de Mars. Roughly, it is positioned as shown in the illustration below:

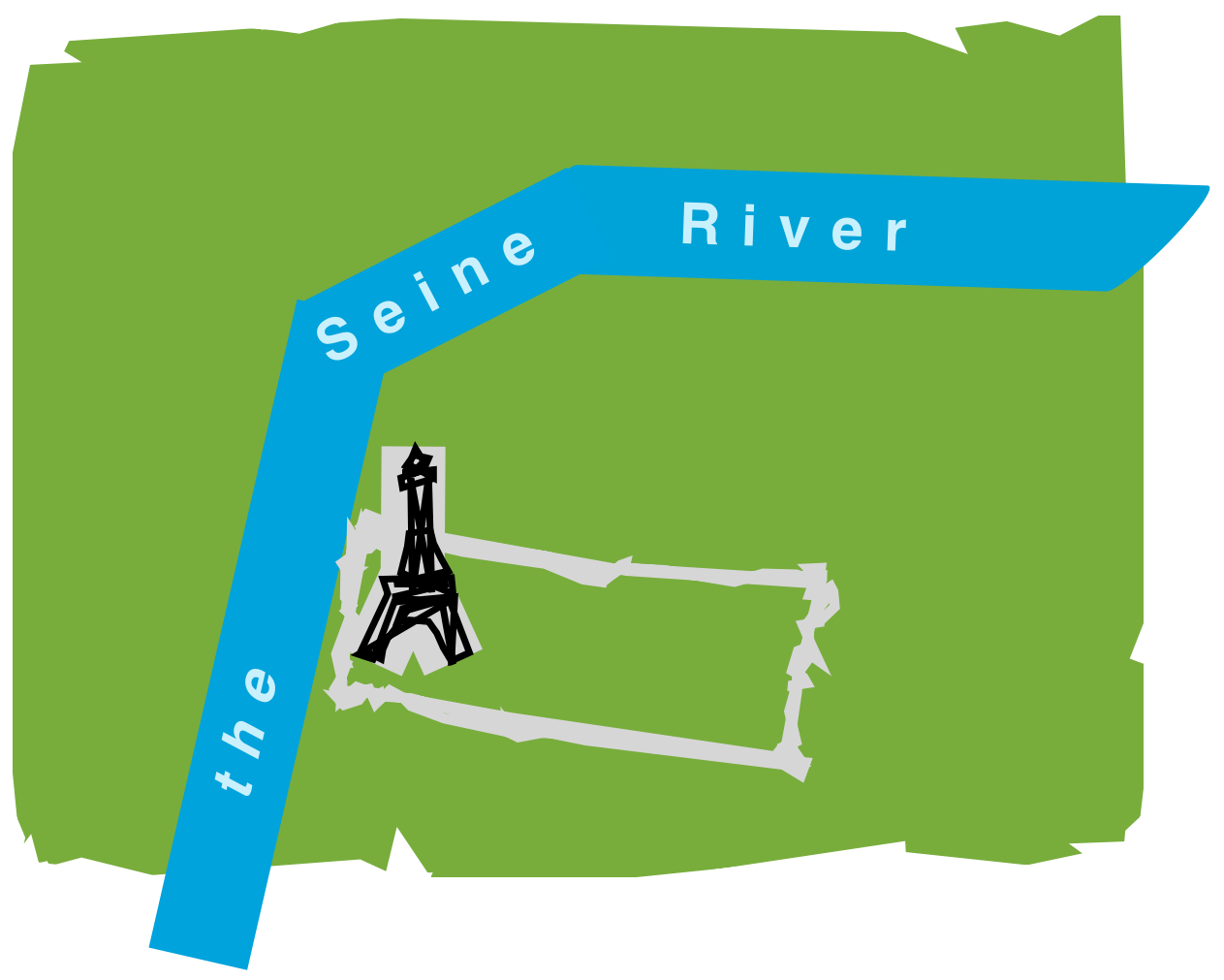

[Figure 3.4 The Eiffel Tower and the Champ de Mars] 
As Steve draws a sketch-map of the Champ de Mars and the Eiffel Tower he produced several sentences that appear to be fictive motion constructions. However, the data has inherent ambiguities; it might be a) that his language is meant to correspond with his drawing activity in which case it narrates the drawing motion (not FM); b) that his language is relating his memory of the space (FM); or $\mathrm{c}$ ) that his language corresponds to the drawing activity but is still fictive motion. Consider the following fictive motion constructions:

(9) "There's a bridge that comes across the river..." [00:29:00 session 2 Steve] (on start) [TR: bridge]

(10) “...there's a road that went through it...” [00:29:24 session 2 Steve] (not drawn) [TR: road]

(11) “...I don't remember if it connected through, I don't think it did, I think it just went like that..." [00:29:37 session 2 Steve] (after drawn as not connecting) [TR: it (road)]

(12) “...the lawn went like this..." [00:29:41 session 2 Steve] (on start) [TR: lawn]

(13) “...like a road went this way...”[00:29:54 session 2 Steve] (on start) [TR: road]

(14) “....and then the grass, the grass continued this way at a distance..."[00:30:20 session 2 Steve] (on start) [TR: grass]

Importantly, he was using this FM to narrate his drawing of the map. Four of these six FM constructions co-occur with the initiation of the drawing of what is being described by the FM. For instance, when he says "There's a bridge..." he begins marking the line that becomes the bridge on the sketch-map. If (a) were the case, this physical act of drawing would be the motion denoted by the motion verbs in the constructions above. But it seems that it is also reasonable to argue 
that since the general past tense of the motion verbs occurs with the start of marking the line that describes the trajector of the motion verb (b). For instance: [t1]“...like a road went this way..." [t2](starts drawing). His act of drawing follows the past tense description of the scene, which makes it likely that the motion verb describes the actual scene and not the drawing that he has not yet produced. This makes the first line problematic, since Steve uses the simple present tense "There's a bridge that comes across the river..." However, this present tense can be explained by viewing this as contributing to the building of a mental space (38, Fauconnier: 1997) that establishes the scene and places the listener in the location that is about to be described from a past tense perspective.

The middle road perspective (c) is that his motion verbs correspond to the act of drawing, but they are still seen as fictive motion. This fictive motion construal is possible since the trajector in each statement is not the symbolic line being drawn, but the actual referent in the location that is being mapped. This is a palatable option because \#3 shows Steve's uncertainty about the physical space “...I don't remember if it connected through, I don't think that it did...". Steve acknowledges that his drawing is representational of a scene, and he is trying to think within the space of the scene being represented, almost like he is channeling the scene in order to represent it with his drawing. His presence in the scene and in the sketch-map world enable a reading of the motion verbs as representing the actual trajectors while he calls them into being with the marker pen on the sketch-map. Using his memory he spans two domains: the Champ 
de Mars and the sketch-map; his language relating the two worlds together in a kind of reflective and generative dynamism.

A word about verb choice and manner of motion: it could have been significant that the subject said "...the road went this way..." instead of "...the road ran this way..." since the duration of the subject's drawing of the road element was protracted and unhurried. His drawing speed might have been reflecting his FM motion verb choice of the slower verb went, compared to a faster verb like ran. The reason might have been similar to Matlock's (2004a \& 2004b) findings about the relationship between processing differences for fast and slow motion in her reading experiments, where faster motion was processed faster. Perhaps in the present case slower verb choice accompanied by slower drawing motions resulted from a similar processing connection, since there was no experimental component to this study it is only speculation. But in reviewing the videos of the other drawings, it appears that most of his drawings are unhurried and methodical. In retrospect, this is most likely a reflection of his professional practice; the subject is a professional designer with over a decade of drafting experience as well as being an urban planning graduate student.

Instead of the manner of motion and verb choice hypothesis, it is better to see his use of FM concurrent with his actual drawing of the sketch-map depicting the FM trajectors as a computation about the configuration of the space. Despite the ambiguities, it is possible to see his fictive motion utterances as helping him walk 
through the space in his memory as he lays down one map element after another.

\subsection{Looking out windows in Paris:}

In the following investigation, the descriptions of four different images are compared because of their similar visual content. It is interesting to note that despite their similar content load, the speaker chooses different patterns of construal for each image. Two of the images are described with emanation path fictive motion constructions while the other two receive hypostatic descriptions, or at best something like access path fictive motion. What accounts for this difference? As predicted by Talmy (144: 2000), a brief comparison of the palpability parameters finds a correlation between the concrete palpability of two of the images and their accompanying veridical descriptions. But this is a surprising correlation given the role of concretely palpable elements in the facilitation of FM in the first half of this study, where a concretely palpable map afforded an abstractly palpable view of the FM trajectory path in section 2.10 , and concretely palpable landmarks afforded an abstractly palpable route for attentional scanning in 3.2.2. Since palpability as a feature of an objective element does not always translate into abstract palpability in conscious experience (as needed in FM construal), objective palpability cannot be enough of a motivating factor in fictive motion construal. Accordingly, two other factors are considered: grammatical motivation and semiotic motivation. The 
comparison of the grammatical structure finds no motivation for different construals, so the semiotic structure of the scene is investigated to find a possible functional motivation. This final semiotic approach confirms Talmy's notion of the preference for dynamism (172, Talmy: 2000) and shows that a dynamic construal is contingent on attentional expectations and the construal of agency in the concretely palpable objective elements.

Before presenting the four images and their accompanying utterances (sections 3.3.2 and following), Talmy's notions of general fictivity are presented and the palpability parameters are outlined as they relate to visual fictive motion.

\subsubsection{Relations between views and visual FM:}

Talmy argues that images can contain general fictivity as readily as does language:

"General fictivity can serve as the superordinate framework because, among other reasons, its concepts and terms can apply as readily to visual representation as to linguistic ones, whereas metaphor theory is cast in concepts and terms more suitable for language alone." [103, Talmy: 2000]

This opens up the possibility of considering the imagistic qualities of views in the analysis of corresponding linguistic fictive motion under the assumption that there is a correlation between the view in the image and the trajectory path in the description. This means that palpability of linguistic elements and palpability of visual elements are equally available for analysis in the process of discerning trajectors and trajectory paths. The visual perceptual domain is considered 
alongside the linguistic conceptual domain under Talmy's umbrella of “ception” (139, Talmy: 2000).

In this study, visual path fictive motion and structural elements in the images they describe are considered alongside of Talmy's thirteen palpability parameters (141, Talmy: 2000). These parameters provide a benchmark for analysis by enabling a gradient scale of concreteness to apply to the fictive motion elements in the linguistic and visual scenes. In section 2.10 it was seen that a concretely palpable object (e.g. a map) rendered a trajectory path available at an abstract level of palpability for the attentional scanning necessary for a fictive motion construal. In light of that link between objects with palpable features and conscious experiences with palpable characteristics, the view of palpability taken in this study has consistently extended Talmy's original notion of palpability to include palpable features of elements in the physical realm as well as palpability of experiences in consciousness.

Palpability is measured on a gradient scale that moves from abstract, to semiabstract, to semi-concrete, to concrete. Talmy argues that an entity of "ception" (such as visual figure, or a linguistic trajector) tends to rank comparably across these palpability parameters in terms of general concreteness (140, Talmy: 2000). The parameters are palpability, clarity, intensity, ostension, objectivity, localizability, identifiability, content/structure, type-of-geometry, accessibility to consciousness, certainty, actionability, and stimulus dependence 
(see 141-143, Talmy: 2000 for a complete description of these parameters).

These gradient parameter scales provide a framework for evaluating how visual perception intersects with linguistic conceptualization of fictive motion.

Talmy's original work describes concretely ceived entities as being more factive and veridical (144, Talmy: 2000) and argues that fictivity becomes available at the semi-concrete to abstract levels in experienced consciousness. As seen in the Stanford Trail study, the presence of the concretely palpable element of the objective map facilitated the production of linguistic fictive motion by making available an abstractly palpable experience of the end-to-end trail. The view sustained here is that the palpability parameters apply to the overall unit of the FM construction and its context, maintaining conceptual abstraction of the fictive movement, but permitting concrete elements (like maps and physical referents) to play a stronger role in the production of fictive motion utterances as the affordances of concrete elements enable abstract experiences of palpability in consciousness.

At this point the four comparable images and their accompanying utterances will be considered, first looking at the two images that prompted fictive motion in section 3.3.2, and then looking at the two images that did not prompt fictive motion in section 3.3.3. In section 3.3.4, a chart compares the four images according to their concreteness rankings for each of Talmy's thirteen palpability 
parameters, and sections 3.3.5 and 3.3.6 explore alternate explanations for the variation in fictive/factive construal.

\subsubsection{View-related FM: views in verbal construal:}

In the entire data set for this study, there are many instances of static visual paths being described with fictive motion where an element of the static visual scene is viewed as a moving trajector along some trajectory path. The next two examples are of this visual type of fictive motion, where the actual viewing descriptor is a trajector fictively moving along a trajectory through some visual field. These examples are explicitly verbal construals of vision, they take vision to be an action that involves a moving probing element that reaches out to apprehend an element in the visual ground. What follows is the treatment of two of those instances.

\subsubsection{Emanation path (prospect path type): cooking classes and the Unique Vector Constraint:}

Emanation path fictive motion describes an intangible element emerging from some source (105, Talmy: 2000), within the category of emanation path fictive motion are a series of subcategories of fictive motion including the type presented in this utterance, prospect path fictive motion. Prospect path fictive motion occurs when an object with a "front" is oriented in such a way that it "faces" its surrounding environment, and looks out in the direction of it's gaze 
toward that surrounding environment. Talmy's example is "The cliff wall faces toward/away from/into/past the valley." (108, Talmy: 2000).

The prospect path in the following utterance is established by the subject element (the kitchen) that is facing the surroundings, and the act of prospecting is accomplished in the high-content participle (overlooking), and the surrounding environment is filled by the ground element (the Seine across the street).

(15) Steve: It was a really cool studio, like the kitchen was on the second floor overlooking the Seine across the street [1.0986]

Overall this image (image 3.5) and the accompanying utterance rank semiconcrete in terms of the palpability parameters. Three noteworthy parameters for this image are discussed below.

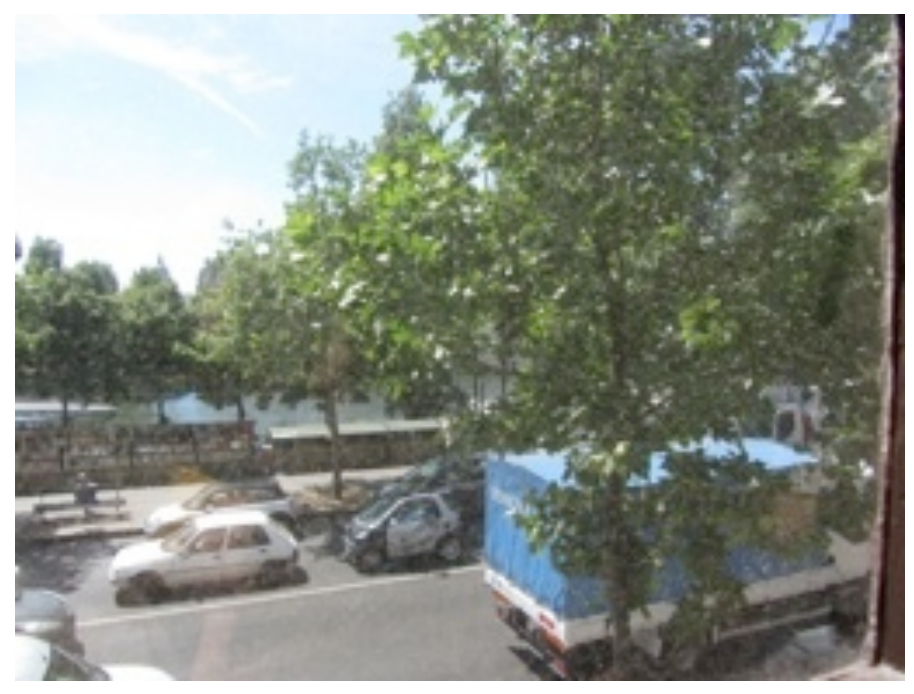

[Image 3.5 Looking out window of cooking school: Photograph: 458 (contrast adjusted)] 
In terms of content/structure this image is semi-concrete, since the content portion of this image (the street and the river) and the structure of the low angle of view over the street and the river is structurally abstract. This does not mean that the elevation of the vantage point and the street level do not suggest or display an angle, in fact the orientation angle is very clear because it is determined with respect to the two fields, the figure of the street level and the ground of the window frame. It is abstract because it is intangible even though it is geometrically present. Type-of-geometry is also semi-concrete, the view is displayed as pan-like rather than as a deeper shaft or boxy container. The street and the river across the street define the area that is being viewed (i.e., overlooked). By maintaining the low field of view, the use of overlook is felicitous because the gaze moves over rather than into such as when Steve looks down into the Louvre Pyramid (which was shaft-like).

In terms of stimulus dependence this image is semi-concrete, the notion of the kitchen/studio overlooking the Seine river can be understood without the visual stimulus of the image, but the inclusion of the prepositional phrase "across the street" is a complicating structure that would probably not be necessary in a strictly verbal description. However, since the street is visible in this image and takes up almost half of the composition, the use of the prepositional phrase is required to guide the viewer past the dominant street to the focal Seine. In other words, the stimulus of the image directs the descriptive language, creating the 
need for further elaboration of the object of the FM construction. Notice the object is not "the street and the Seine", but rather "the Seine across the street" creating a further fictive progression in the gaze that follows the overlooking view. This visual stimuli provides a heightened sense of path structure.

\subsubsection{Emanation path (prospect path type): Le musée Carnavalet:}

A similar prospect path situation occurred in the description of the Le musée Carnavalet in Le Marais:

(16) Steve: so we went up inside and there was, a museum that overlooked this courtyard. [1.0338]

This prospect path FM utterance occurs after a sequence of images that describe the courtyard, the courtyard is visually in focus during their progression through the courtyard on their way into the building. The image (image 3.6) that cooccurs with the FM construction is a view that looks down into the courtyard, but the subject matter of the image is a choir which is also active in the preceding discourse but unmentioned in Steve's utterance describing this image. The vantage point is situated inside the museum looking out onto the courtyard from above. In terms of the palpability parameters, this situation is primarily semiconcrete to semi-abstract in quality. Three noteworthy parameters for this image are discussed below. 


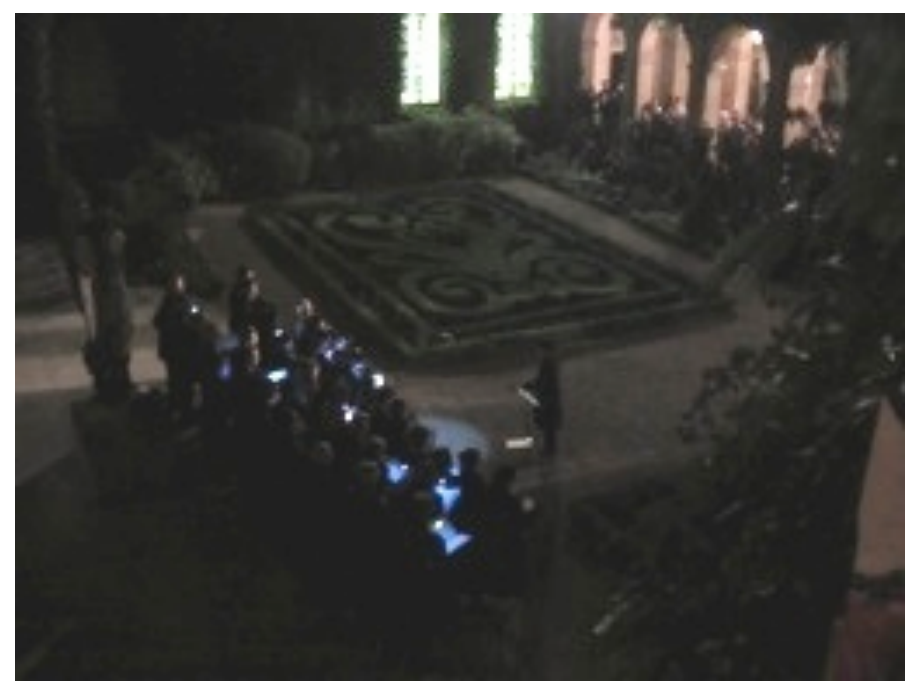

[Image 3.6 Hotel Carnavalet: Photograph: 078 (brightness, contrast, \& exposure adjusted)]

The visual content and structure of this image are semi-concrete: the courtyard is the content portion of this image (content being concrete), and the shallow acute angle of perspective is the structure portion that permits "overlooked" to be used (structure being abstract). Furthermore, the view is displayed as pan-like rather than as a deeper shaft or boxy container rendering a semi-concrete typeof-geometry. This linear boundary of the courtyard defines it as a space, but the pan-like field of view resulting from the shallow acute angle of perspective contributes to the effect of a shallow basin. Since the walls around the courtyard constrain the size of the courtyard to a relatively small space, in order for the verb "overlooked" to be used in a felicitous manner, the courtyard has to consume the bulk of the visual field for a person situated within the overlooking 
part of the museum. This pan-like splay of the courtyard is a result of the shallow acute perspective intrinsic in an overlooking viewpoint.

In terms of stimulus dependence this is semi-abstract, the notion of the museum overlooking the courtyard can be understood without the visual stimulus of the image, since understanding that views can be taken out of windows of multi-story buildings is part of encyclopedic knowledge and the affordances of windows. The idea of a building overlooking a defined space like a courtyard is at a scale that can be understood without symbolization or imagery. Without the stimulus of the view down into the courtyard presented in the images this FM utterance is still concrete enough for comprehension of the fictive path. In other words, the stimulus of the image does not need to be present for "overlook" to evoke a sense of fictive motion.

\subsubsection{Almost FM: views as nouns:}

In the slideshow data lots of things that could be construed with FM are not. For example, it some cases scenes that lend themselves to FM descriptions with emanation paths are linguistically objectified as nouns which preempted their usefulness as motion descriptions: instead of being a motion path for trajectors they became trajectors themselves. This is most clearly seen in cases which construe "view" as a noun (indicated by the presence of articles) rather than as a path for visual probing that emanates from the Experiencer as source and moves 
toward the Experienced entity. However, many situations are described with fictive verbs and participles such as overlooked, overlooking, looked, looking, zoomed. What follows is an exploration of two static scenes that afford highly dynamic descriptions but which are described as static nouns instead. Following this exploration the two "overlook" examples are compared with the two static "view" examples in sections 3.3.5 and 3.3.6 to attempt to answer what differences might prompt for fictive motion construals.

\subsubsection{The view (vision construed as a noun): the apartment:}

In the beginning of the slideshow Steve encounters a string of images taken at the apartment that he and Joanna rented in Le Marais. He describes the apartment and describes the view out the window:

(17) Steve: Um, this is the view, there was the, the courtyard on the interior, we were up on the fourth floor, so you'd have a view out to the alleyway and the streets on one side, and on the other side you'd have the courtyard. [1.0135]

The image (image 3.7, below) could certainly lend itself to a prospect path description, but instead Steve uses a static description. Notably the utterance refers to alleyways, streets, and courtyards which are not immediately visible in this image. However, the following photograph (007) in the slideshow (not included here) shows a view of the alleyway mentioned in this utterance, this utterance cataphorically introduces the content of other images that do not cooccur with this FM utterance (also, photograph 010 shows the alleyway on the 
opposite side of the building). Perhaps in the absence of a visible alleyway and street the subject fills in the visually absent details for the viewer, linguistically orienting the attention of the hearer to attend to visually absent details. This description is within the common ground understanding of this scene as focused on a view from a window. Three noteworthy parameters for this image are discussed below.

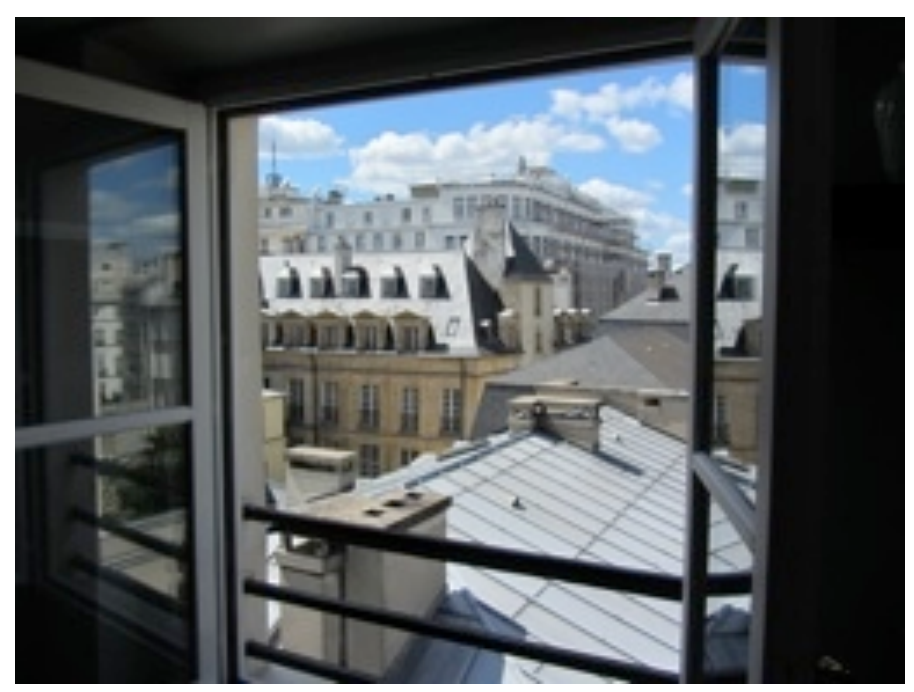

[Image 3.7 View out of apartment onto rooftops and toward streets: Photograph: 006]

Content-wise this is a semi-concrete view, the viewer of the image knows that it is a general view of something, likewise the structure is semi-concrete directing the viewer to "view out" by the dark interior of the room and the daylight out in the structure of the view. The view is afforded by the absence of impediments, such as the presence of an adjacent building blocking the view or window treatments occluding the view. This has a clear view which renders both content and structure as semi-concrete. Being an unimpeded linear view, this view is 
classified as having a concrete type-of-geometry. The presence of streets is marked by the rectilinear facades of buildings aligned and spaced to allow a linear path along their sides.

Overall, this image has a concreteness in terms of stimulus dependence; the notion that this is a "view out" is dependent upon the framing of the window, otherwise, this would be a view across, or some other image schematic perspective. The presence of the window stimulates the experience of the container metaphor in play in the noun + preposition construction in which the observer is located INSIDE the container.

\subsubsection{Another view: the apartment:}

This image is out the same window as image 3.7, but from a closer position and with a different targeting angle out the window. This image elaborates on the aforementioned courtyards visible in the view.

(19) Steve: "This is like a view into the ni, into the neighboring building's courtyard, and there was kids running around, and we'd watch the kids running around playing tag in that area." [1.0142]

Like image 3.7, this image (image 3.8) lends itself to a prospect path description, but instead it is described with a static construal. Three noteworthy parameters for this image are discussed below. 


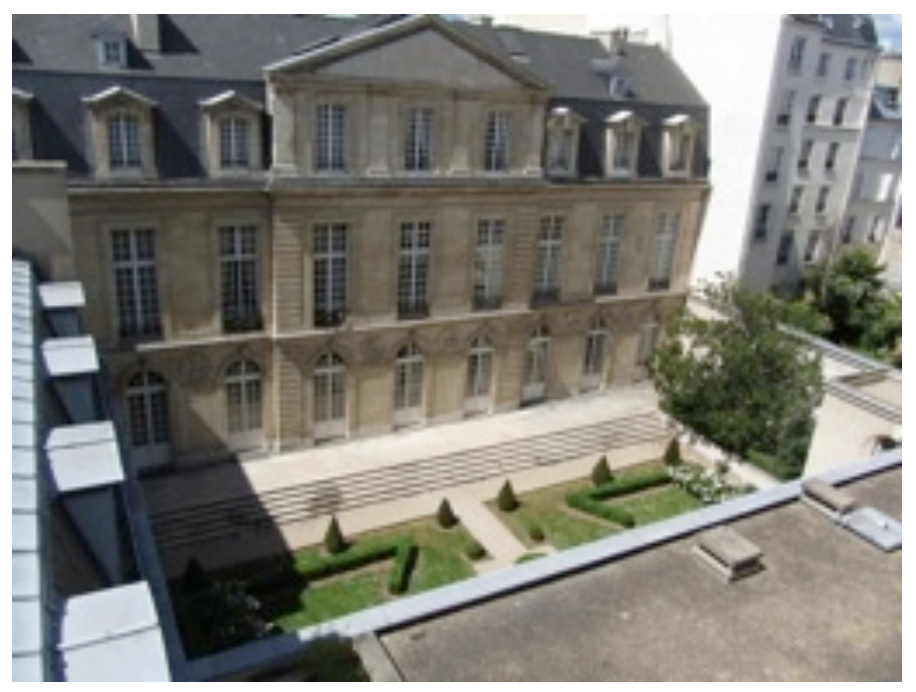

[Image 3.8 View from apartment out other window onto courtyard: Photograph: 009]

For this image Content/Structure is semi-concrete, The "view into" the courtyard is directed by the cliff-like edge in the foreground and the four enclosing walls. The floor of the courtyard is partially visible (possibly completed by the Gestalt principle of pattern completion) suggesting the actual SUBSTRATE content of the courtyard is as important as the spatial content of the contained space. The cascading view that descends over the edge of the foreground wall, and down the face of the neighboring building gives the type-of-geometry a concrete feel. Additionally, the view is also a shaft-like view that is directed downward by the boxing-effect of the four walls to the courtyard. The courtyard in this sense is a cube of negative space, or, the substance contained within the four surrounding walls.

Finally, stimulus dependence is concrete, the notion that this image is a "view into" is afforded by the four walls of the courtyard, making the courtyard into a 
container. Without the four containing walls, this would be a view "onto" or some other schematic perspective. The boxing presence of the walls stimulates the experience of the container metaphor in play in the noun + preposition construction in which the observer is located OUTSIDE the container. (contrasted with image 006)

\subsubsection{Comparing palpability parameters across images:}

In summary, it is useful to compare the overall consistency of the values of concreteness for the palpability parameters over the four images presented.

Table 3.1 Palpability parameters across the four images

\begin{tabular}{|c|c|c|c|c|}
\hline & Image $\mathbf{3 . 5}$ & Image 3.6 & Image 3.7 & Image 3.8 \\
\hline Palpability & concrete & semi-abstract & concrete & concrete \\
\hline Clarity & $\begin{array}{l}\text { semi- } \\
\text { concrete }\end{array}$ & semi-abstract & semi-concrete & $\begin{array}{l}\text { semi- } \\
\text { concrete }\end{array}$ \\
\hline Intensity & $\begin{array}{l}\text { semi- } \\
\text { concrete }\end{array}$ & semi-abstract & concrete & concrete \\
\hline Ostension & $\begin{array}{l}\text { semi- } \\
\text { concrete }\end{array}$ & $\begin{array}{l}\text { semi- } \\
\text { concrete }\end{array}$ & concrete & concrete \\
\hline Objectivity & concrete & $\begin{array}{l}\text { semi- } \\
\text { concrete }\end{array}$ & semi-concrete & concrete \\
\hline Localizability & concrete & $\begin{array}{l}\text { semi- } \\
\text { concrete }\end{array}$ & concrete & concrete \\
\hline Identifiability & concrete & concrete & concrete & concrete \\
\hline Content/Structure & $\begin{array}{l}\text { semi- } \\
\text { concrete }\end{array}$ & $\begin{array}{l}\text { semi- } \\
\text { concrete }\end{array}$ & semi-abstract & $\begin{array}{l}\text { semi- } \\
\text { concrete }\end{array}$ \\
\hline Type-of-Geometry & $\begin{array}{l}\text { semi- } \\
\text { concrete }\end{array}$ & $\begin{array}{l}\text { semi- } \\
\text { concrete }\end{array}$ & concrete & concrete \\
\hline
\end{tabular}




\begin{tabular}{lllll|} 
& Image 3.5 & Image 3.6 & Image 3.7 & Image 3.8 \\
\hline $\begin{array}{lllll}\text { Accessibility to } \\
\text { Consciousness }\end{array}$ & concrete & concrete & concrete & concrete \\
\hline Certainty & $\begin{array}{l}\text { semi- } \\
\text { concrete }\end{array}$ & concrete & semi-concrete & concrete \\
\hline Actionability & concrete & concrete & concrete & concrete \\
\hline Stimulus Dependence & $\begin{array}{l}\text { semi- } \\
\text { concrete }\end{array}$ & semi-abstract & concrete & concrete \\
\hline
\end{tabular}

Talmy argues that the values tend to correlate over the entire set of parameters (140, Talmy: 2000), that typically any given scenario will not have extremes in the values such as abstract for one parameter and concrete for another. This is evidenced in the comparative table, although image 3.6 displays a range from semi-abstract to concrete. However, given the darkness of the image it is not surprising that the semi-abstract values are for the parameters most concerned with the quality of scene presentation. Notice that the consistency of parameter values in image 3.6 pattern in a way that is largely comparable with the other images aside from those four semi-abstract values.

The only wholesale categorical differences between the FM described images and the non-FM described images occur with the FM images ranking semiconcrete in terms of intensity, ostension, and type-of-geometry, with the non-FM images having a concrete ranking.

Looking at the palpability parameters for these four images, it is clear that the elements in the last two images are arguably more concrete than in the first two 
images. This corresponds with the distribution of the fictive motion construals in the accompanying utterances and accords with Talmy's claim that concretely palpable elements are generally factive. Ordinarily, this concreteness would be enough to explain why image 3.7 and image 3.8 are not described with fictive motion. But, as demonstrated with the concretely palpable map in the Stanford Trail study, and as seen earlier in the Paris study with the concretely palpable salient cultural landmarks, fictive motion is actually often facilitated by concretely palpable elements in the visual scene when they provide a perspective that affords an abstractly palpable experience of those concretely palpable elements in the visual scene. Since element concreteness does not unilaterally determine the fitness of a scene for FM construal in general terms, it is important to determine what further factors help to account for these specific linguistic differences in FM construal between the four images/utterances.

Since the converging evidence in this study prevents palpability from making a categorical distinction in the present images, perhaps the fictive/factive construals can be explained by grammatical differences. The next section explores these differences to see if they motivate the variation in construal.

\subsubsection{Grammatical differences (seeing differences):}

Looking at the linguistic examples (15), (17), (18), and (19), it is easy to see that (15) and (17) convey their approach to vision as an activity, marked by the 
present participle overlooking or the past participle overlooked. Examples (18) and (19) convey their approach to vision as something that can be experienced, as an object of sorts, marked by an article and a noun the view (18), and a view (19).

The participles in (15) and (17) clearly portray the vision feature as an activity, but it is an activity that the architectural entity is engaged in, a more permanent characteristic of physical alignment. The kitchen overlooks, the museum overlooks, notice that it is not a person that is conducting this activity, even though people benefit from the architectural configuration that affords the activity of overlooking.

The nouns in (18) and (19) clearly objectify the vision feature in focus, it is something that can be experienced by an agent in the room with the view. The use of the definite article in (18) is interesting since it is a new element in the discourse; prior to this point the window has not been mentioned. The use of the definite article indicates that it is the primary view out of the apartment, or at least the view that is the most salient to Steve and Joanna during their stay in the apartment. The apartment had windows on the other side of the unit, but the views out of those windows are not captured in the images.

The use of the indefinite article in (19) identifies its arrival as an element in the discourse, suggesting that the particular view in focus is unique and is a 
particular referent that is different from the view in (18). Note that this is not a view out of a different window; this view is through the same window but at a different angle. The use of the indefinite article might suggest that this view is less encompassing than the view in (18). In fact, (18) is the view with the farther scope whereas (19) is the more immediate foreground view.

All four examples occur at comparable locations in the discourse structure, each occurs after the location has been activated, and after several images of the location have been viewed. They also share a situational commonality: the photos were all taken by Steve as he engaged in the activity of looking out a window. Perhaps something less grammatical and more functional accounts for the variation.

\subsubsection{A functional difference?:}

It is interesting to consider what caused the description to be different for the activity oriented description and the description that objectified the activity. Given that they share similar structural qualities (discourse location, architectural configuration) it might be fruitful to consider a content-based approach to the variation. It may be that the variation in dynamism can be traced to a functional difference of the vantage points between the four images. 
Of course it could be argued that in (15) and (17) Steve decided to be more poetic, or to use a richer description than in (18) and (19). However, that seems unsatisfactory, especially given Talmy's assertion that we have cognitive preferences toward cognizing dynamism and that cognizing staticism in a scene is highly marked behavior (172, Talmy: 2000). Although, such a view would certainly avoid the complex requirement of needing to explain behavioral patterns.

Looking at the functional evidence of variation across the four images could provide insight into the way that Steve conceptualizes the utility of space and how it space was recruited as conceptual grounds for specific figures like tasks and activities. With this in mind, what follows is a comparison of the semiotic domains of space and works toward drawing a clear motivation for the choice of fictive emanation construal for cases like (15) and (17), versus the less fictive construals in (18) and (19).

In what follows, three factors will be considered in the creation of the differences in construals. Considering first the nature of the spaces which provided the vantage points, an immediately striking difference presents itself. There are two types of buildings in this data: institution and dwelling. These types of buildings house different types of activities which occur with different frequencies and mean different things to the agents engaged in those activities. Interestingly the construal difference divides cleanly along this bifurcation of building type. 
Secondly, agency is an interesting difference in these utterances. It seems as if the examples which use the emanation fictive motion involve non-living entities engaged in the activity (...a museum that overlooked...), whereas the nonemanation non-fictive motion examples which construe the view as an object do not specify an agent taking part in the activity (...this is the view...). This is significant because in each of the four utterances, the vantage point of the photographer is within the body of the architectural structure. It seems reasonable to expect the vantage point to equalize these images and prompt for comparable description, but it does not. This makes the agent an important element to consider in the equation, why is the building construed as an agent in the verbal view, but a null agent assumed for the nominal view? Third, understanding the role that attention plays in these differences provides insight into the choices that Steve makes in presenting the descriptions.

Addressing first the nature of the spaces, it seems that the bifurcation of institution and dwelling brings intuitive distinctions about the nature of presence in the two types of buildings. The institution is for all, whereas dwellings are for private subsets of all. The institution exists for exchange on a social level, this is the semiotic domain of polis. The dwelling exists as a function of intimate relationship in the semiotic domain of oikos. Polis is an occasional place, the outside world, a place where people interact with structured attention. Oikos is a habitual place, a place of rest and a durative experience returned to after venturing in the polis. For Steve and Joanna, oikos is the apartment, and polis is 
manifest in their interactions in museums, tours, restaurants, and activities like wine tastings and cooking classes. The dwelling in this sense is Hendon's (2010) "semiotic house", an active background that grounds repetitive and routine life in ways that nonconceptually structure life through a series of figureground distinctions (pp 94-99, Hendon: 2010).

This is not a simple private/public dichotomy. In fact, there are strong attentional differences between the two domains. For Steve and Joanna, the apartment is the durative and unstructured background element of their trip which they return to each night. Over the course of their trip they spend more time in the apartment than they spend in any one museum or cooking classes. Thus, Steve and Joanna experienced the apartment as a more constant and stable element of the trip. Because the apartment is something that is seen to be experientially stable over the course of the trip it can be thought of as a ground in a figureground distinction between the various experiential loci of their Paris experience. The apartment is the ground and the cooking school kitchen and the museums are locational figures forming the texture of the ad hoc category Steve \& Joanna's Paris Experience.

The durative and habitual encounter of place in the apartment corresponds to the secondary reference object, or a stable ground. The temporary and infrequent encounters of place out and about in Paris correspond to the primary reference objects that form oscillating figures against the stable ground. The apartment is 
more permanent as an element of the daily routine of the tourists in Paris, whereas the intermittent experiences are fleeting, always giving way to a return to the stability of the apartment.

Turning now to the role of agency, it might be that this figure-ground distinction brings out different construals of agency. Importantly, it might be that the institutions (temporarily visited by Steve and Joanna) are themselves construed as agents, while the dwelling place continually inhabited by Steve and Joanna is not an agent. It is suggested that Steve and Joanna are the assumed agents who act on the visual experience of having a view out the window. The kitchen in the cooking school and the museum are institutional agents that habitually occupy the buildings, and so it is those agents that act on the visual experience of overlooking, it is a perpetual act of the structures rather than an ego-centric assessment of the view by the tourists.

How does attention play into these differences in construal? This can be approached from two directions: the way that attention is used in Steve's utterances, and the way that habitual attention is experienced in polis and oikos in the formation of Steve and Joanna's experience that is encoded in the situated utterances.

Attention is something that can be manipulated actively (when we solicit the attention of others) or passively (when our attention is directed by an external 
stimuli). When Steve explains the images of the views he is actively directing the attention of the audience. On the other hand, at certain points in Paris Steve experienced his attention being directed, in some of those moments Steve took a picture of the object of his attention. Both of these types of attention factor into the descriptions in (15), (17), (18), and (19).

Additionally, the quality of attention is something that varies. For instance, attention within a dwelling is usually unstructured, compared with attention in the institution. A feature of institutions is that attention is structured around a defining element of the institution, for instance, education institutions structure attention around learning often in a classroom; museums might structure attention around the configuration of the exhibition space, curatorial practice, and thematic display patterns. For the purposes of this analysis, institutions will be thought of as places of structured attention whereas dwellings will be thought of as places of unstructured attention.

The layout of dwellings (and other places habitually occupied for extended periods of time by the same individual) often includes a window. Since people spend much of their time in their dwelling places, it is important to have a view, in fact, views are essentials and default assumptions for many people. Consider the room with a view out onto the Arno in Forster's novel, the window seat on an airplane, a balcony on a cruise ship or a hotel room, or anywhere else that a person will be spending extended periods of time that features unstructured 
attention patterns. The presence of windows with views is not surprising in a dwelling.

Institutions are not places that feature unstructured attention, instead attention is rigorously devoted to the particular function the particular institution. Attention is directed in. Many workplaces do not feature windows for most of the workforce, which has given rise to the corner office which promises a window, likely reflecting the visionary status of an individual that looks outward to direct the efforts of company. School children are chided for looking out a window when they should be focusing on the task at hand. Since we do not spend most of our habitual time in museums and schools, and since the time we spend in those institutions is designed to keep our attention and focus on a task performed in those spaces (looking at displays, learning something), anything that detracts from that focus cannot be seen as contributing to that focus. Thus, a view out of a window is non-essential in the activity sequence.

However, the functional role of museum and school are different from dwelling; the emphasis on the internal contents and activities of a museum are the typical attentional patterns. In the utterances in (15), (17), (18), and (19), perhaps it is that the view is only a secondary feature of the school or the museum that there is the shift to dynamic language; the view is an unexpected bonus that is a side effect of the design of the structure, not a primary offering of the institution. More likely the dynamic language that is ascribed to the edifice reflects that the 
institutional edifice is habitually occupied by the institution and not the patrons. This leaves the dwelling to be occupied habitually, and the view to be construed as an object to be apprehended, rather than a behavior of the building.

The linguistic conceptualization of space in (15), (17), (18), and (19), hinges on the content of their contextual domain. The dwelling is habitually occupied and the occupiers do the habitual viewing out the window. The institution is not habitually occupied (except for the identity of the institution) and so the institution edifice engages in the viewing. What is known about the domain (polis and oikos) from broader encyclopedic knowledge converges in the choices of linguistic construal (139, Oakley 2009), this can be seen in the choice to construe one set of views in a dynamic manner, and another set of views as static objects.

As mentioned earlier, attention can be directed, and Steve may have been engaged in the directing of attention in his choice of construing the view as an object. Steve directs by alerting and orienting attention on the photographic stimuli and directed the attention to detect corresponding relevance between the utterance and the image. This direction of attention to detect relevance seems to be more prominent in (18) and (19) where the view is objectified. Oakley describes detecting as "...the semantic side of event construal in the orienting of attention" which identifies linguistic elements as functioning to facilitate further processing of the referents of the linguistic constructions (138, Oakley: 2009). With this in mind, perhaps the intention of Steve was to invite further processing 
of the photographs (006 \& 009) to orient attention on the entirety of the view rather than on some specific element in the view (i.e., the Seine, the courtyard). Steve provides descriptions of the view with what Oakley describes as an attempt to "direct other minds to facets of reality in harmonized synchrony" to "sustain attention on it for some time" by placing "participants in the right position to "see" it" (114, Oakley: 2009).

Steve is operating in the domain of description for both the view constructions and the overlooking constructions, but in former he utilizes hypostatic constructions and in the latter he utilizes hypotyposic constructions.

The difference between the two ((15) \& (17) vs. (18) \& (19)) has to come from the expected attentional channels of the two different locations: the institution vs. the dwelling. This is where we see a functional difference that makes a difference in the way we interpret the displayed visual content. It is even reflected in the FM construction choice and consequently the grammar. In effect, the institution is doing something atypical, so it is marked with motion. The dwelling, on the other hand, is doing something natural, and so it is left unmarked, in its state as an object of attention rather than as a path of attention. As an object of attention it does not need the fictive description to direct attention along a trajectory, instead it only needs to be presented as a trajector figure set against a landmark ground. 


\subsubsection{A final note on palpability and time:}

Palpability is less of a determining factor in these view-related fictive motion construals, instead, the view-related FM relates to the semiotic domain differences of the view location. The salient locations in Steve and Joanna's Paris travel itinerary are those that are temporally non-durative and relatively infrequent. These infrequent locations are construed with fictive motion, whereas the non-salient and habitual location of the apartment is not construed with fictive motion.

In effect, at the level of analysis that considers the overall trip itinerary as a series of figures and grounds, it is time that determines what is figural. Could it be said then that it is also this sort of experiential time that modulates the production of fictive motion? In this case, the answer seems to be yes; the temporally unstable figure gets construed with the fictive motion while the temporally stable ground receives the veridical description. This sort of temporal factor is unexpected in Talmy's palpability parameters, none of the parameters directly account for time as an influence. An exception could be the Accessibility-to-Consciousness parameter, which one could argue as permitting temporally figural elements as being more accessible to consciousness and temporally ground elements as being less accessible to consciousness. 
Perhaps the functional relationship between experiential time and its resultant figure-ground distinctions in routine schedules of daily life ought to be considered in the analysis of the production of fictive motion. Linguistic time (tense and aspect) certainly factors into fictive motion processing as seen in Matlock, Ramscar, \& Boroditsky (2005), and also in general cognitive simulation as seen in Bergen \& Wheeler (2010). However, the scale of time in the present study is more qualitative than temporally precise, this distinguishes between the time discussed in this study from other studies of time in FM processing.

It seems that in this data, in the production of fictive motion, that routine experiential time highlights the non-routine (infrequent) segments of experiential time by imbuing them with figural salience in the day-to-day schedule. This oscillation of experienced figures provides the foundation for establishing a semiotic understanding of the production of fictive motion allowing a reading that sees the background location of the apartment as default in the oikos domain, and the institutional locations as marked figures that stand apart from oikos with placement in the domain of polis. It is beyond the scope of the present work to consider the generalizable pattern of temporal figure-ground distinctions in the production of fictive motion at large. However, future work on the semiotics of fictivity should consider how speakers understand habitual time as governing what is available for FM construal from a temporal figure-ground perspective. 


\section{CONCLUSIONS}

\subsection{The Stanford Trail study:}

It seems that the presence of a SYMBOL in the map world facilitates the production of Fictive Motion when the SYMBOL represents the SUBSTRATE of the terrain world. This might reflect a general tendency toward reducing a scene to human scale to provide for complete mental scanning of the entity being described by the fictive motion. 67 out of 99 cases of fictive motion in the Stanford Trail study used the SYMBOL form as the trajector in FM constructions.

Fictive motion is a conceptual blend that achieves human scale through the process of compression. The act of compressing the input space of static scene with the input space of the trajector in general motion produces a blend in which static entities are able to be construed as entities in motion. But what happens when the input space is itself already a compression of reality? When a map is one of the input spaces into a fictive motion blend, that map brings a precompressed representation of the terrain world. Arguably, this pre-compressed input should facilitate fictive motion blending because of the minimal compression that needs to take place in order to produce a SYMBOL FM construction.

Additionally, when a map displays compressed space, elements like linear trails become available to be trajectors in FM constructions, and to take on elements of 
directionality that might not be present in the actual terrain world. For instance, a road becomes construed as heading in a particular direction when in fact the physical substrate of the road is bi-directional, or underspecifies direction.

What was found in this study is that when producing fictive motion in the wild subjects readily respond to the presence of a map and project the precompressed SYMBOL world into the fictive motion blend, resulting in FM which features SYMBOL trajectors, in fact this occurs more often than the case where subjects choose to project SUBSTRATE elements into the FM blend.

Subjects also featured rich path shape descriptions that came from the ability to scan the length of the trail on the map. Without a map, subjects could only describe what they could see ahead of them and what they had already seen as they walked along the trail. This reduced visibility did not facilitate the same raw frequency of FM construal as did the increased visibility that accompanied the map. Additionally, the participant perspective of the trail did not lend to apprehending path shape; trees, hills, and turns on the trail converged to limit visibility. The consequence of the limited visibility was the limited ability to scan the trail and to abstract the trail schema from unaided vision. While subjects understood the general SOURCE-PATH-GOAL schema from general cognition, they had trouble applying it to the entire trail when they did not know anything about the goal. Instead, they accrued knowledge of the trail incrementally as they walked along the trail. Subjects with the map not only had access to the 
general SOURCE-PATH-GOAL schema, but they could also comprehend the trail from start point to end point and see the variation in path shape and terrain contour that lay in between the two points.

Subjects without the map relied on the general figure-ground distinction manifest in the differences of the worn trail to the surrounding untrodden terrain. Subjects with the map had access to the same figure-ground distinction plus the highly salient figure of the path shape on the detailed ground of the map. This increased salience rendered the trail a more concretely palpable element in the walking experience, and offered the end-to-end trail as a trajectory path for potential abstractly palpable experiences of attentional scanning along that concrete trail to produce FM. Additionally, not only was the overall trail more palpable, but each path shape feature became more palpable as subjects could see the shape of the switch-backs and turns and curves of the trail as it weaved its way from start to finish. Palpability, then, is significant in the ability to attend to the elements necessary for scanning a static scene for construal in fictive motion.

It is good to mention again that this does not entail that FM cannot be produced without the scannable symbol of the trail, just that the symbolic representation facilitates FM construal in the subjects in this study.

The difficulty in producing FM about the trail without access to a map is resonant with what Hutchins has to say about the difficulties in orienting a graphical 
representation of space to the actual space; the participant perspective is the experiential perspective, having the spectator perspective is rarely achieved by the participant, and so lining them up is difficult. It is hard to take on the spectator perspective for a subject who is actively a participant. This is why maps are a solution to helping people find their way through three-dimensional space, they enable the participant to see what the spectator sees and to blend the two together to view the surrounding environment from two perspectives. When the second perspective (i.e., the spectator) pre-compresses the environmental world into two-dimensional space, it is a jump up on the process of blending the terrain in a fictive motion blend.

\subsection{The Paris study:}

It seems like views and viewpoints are important elements of emanation fictive motion in the Paris data, whether those views are down long boulevards, towards landmarks, or out windows, some view typically occurs alongside emanation path fictive motion construals.

As is well known, the ability to distinguish between figure and ground is equally important in the ability to select a trajector for the fictive motion, and that ability was seen to relate to palpability of the salient figure. At times the figure-ground distinction is nested within a larger figure-ground distinction, such as in photographs where subjects describe something as topically salient but which is 
barely visible and not compositionally salient in the photograph. This use of nested figures is a result of subjects orienting and directing attention on the nested figure. These nested figure-ground relationships develop a pattern of shedding the encompassing figure-ground as subjects walk towards the nested figure increases its size and salience until this intended figure becomes the primary figure in the photograph.

Access paths are important in reconstructing the memory of place, and since the attentional chain of figure-ground distinctions that occurred as subjects were walking was also being captured in the sequence of images, the slideshow provides an artifact of the progressively increasing awareness of the figure role played by a focal element.

The palpability of an element is sometimes linked to its significance in the Paris landscape, being a focal element of cultural significance the magnetism of the landmark compounds the palpability until it dominates general observer attention.

At one point, speculative analysis explores an incomplete predicate by looking at the subject's denial assertions that interrupt the initial utterance. By denying the entailment of the predicate, it is possible to reconstruct the predicate and read the fragment for its original intention as an access path. 
Four images that share similar visual content were explored because the accompanying descriptions differ in their use of fictive motion. Two images looking out a window were described with prospect path fictive motion, while the other two images were not described with fictive motion (or at best described with access path fictive motion). Despite the structural similarities of the images there was this distinct difference in fictive motion construal choice. In an attempt to explain the differences it was discovered that functional differences of the subject's vantage point were the clearest source of differentiation between the images and utterances. Grammatical structure was compared and revealed no significant motivating differences. Image compositional structure was compared without finding significant differences.

Clearly structure as a unit of analysis was not helpful in this case, all four images were views out the windows of buildings; instead, the functional differences between the structures was seen to influence the need to use fictive motion in a way that ascribed a sort of agency to the buildings whose view afforded the FM construction. For instance, the views from a cooking school kitchen, and a second floor museum were construed with prospect path fictive motion, whereas the view from an apartment was hypostatic in description. It was seen that the difference between the habitual dwelling in the apartment placed the apartment as a default ground to the subject's experience of Paris, and as a ground it was relatively stable. The apartment was inhabited by the subject on a continual basis, the view out the window was exclusively their view. The institutions that 
were not dwelling places were not habitually inhabited, and the persona of the building took on the role of viewing (overlooking the Seine, overlooked this courtyard).

It was argued that habitual backgrounding of the generic dwelling place does not feature structured attention within the dwelling (apartment building), but that the figural nature of the institutions do feature highly structured task-oriented attention. The difference between the institution dynamic construal and the dwelling static construal came from the expected attentional channels of the two types of buildings. The view out the window of the apartment was habitual and natural, something that did not need marked by a fictive construal, whereas the institutional views were atypical and marked with motion. This is why with the apartment the descriptions of the views out the windows only need to be presented in a figure-ground relation.

What all of the findings in this chapter say about the nature of fictive motion is that views and emanation path fictive motion are strong tools for directing attention and they feature strongly in the process of reconstructing memory. Memory can have mistakes that come out in the retelling of the memory, even when memories feature highly palpable elements in well-organized figure-ground relations. Some aspects of the memories are immutable, such as the way that duration of an experience backgrounds the domain of that experience - the more time spent in a location the deeper the anchoring of that location as a default 
element of the experienced world (i.e., a habitual dwelling). The temporal and sporadic interface with locations for short points in time sets those experiences as figures against the stable anchored ground. These aspects of the world pervade even the attention patterns of agents in those locations and this may be reflected in the way that descriptions of those places feature dynamic fictive motion construals.

In short, what we see more frequently we know more intimately, and salient features of the world prompt for fictive motion descriptions, especially in the case of highly salient cultural landmarks in a tourist destination city.

\subsection{General conclusions about the facilitation of fictive motion:}

Several factors seem to have converged to facilitate the production of fictive motion in different instances. While neither exhaustive, nor definitive, the results of this study suggest that the following elements may play a role in the production of fictive motion construals (categorized by relevance to the semiotic typology of fictive motion):

\section{SYMBOL:}

- the compression of scale (human scale)

- concreteness of symbolic artifact (presence or absence)

\section{SYMBOL - SUBSTRATE - SUBSTANCE - EXPERIENCE:}

- concreteness of visual image (palpability)

- palpability as a feature of ception of objects (Talmy 2000)

- palpability as a feature of objects (an extension of Talmy) 
EXPERIENCE:

- the combination of perspectives (participant + spectator)

- significance of memory (palpability)

- temporal figure-ground relations (rhythmic palpability)

It is interesting that coextension path fictive motion tends to be the type of fictive motion discussed in current research, while other types such as emanation paths are less explored. The trail study was designed with coextension paths in mind, for instance the trail itself was chosen because of its coextensive zigzagging properties. Coextension path fictive motion was produced, but the interesting phenomena ended up being the facilitating effect of the coextensive SYMBOL on the map artifact. While coextension paths can be SYMBOL based (as seen in the trail study) it is largely recognized as being related to physical elements. This makes it ideal for classification in the SUBSTRATE and SUBSTANCE types in the semiotic typology. However, these did not prominently feature in the facilitation of FM production; there is comparatively little coextension path FM that is SUBSTRATE based in this study. A major unanswered question here is what factors converge in the facilitation of SUBSTRATE and SUBSTANCE based fictive motion construals? This is outside the scope of this study, but might provide an area of fruitful research.

\subsection{Areas for further research:}

The suggestions in this study point toward an important gap in the study of the role of fictive motion in conceptual blends featured in wayfinding. It also points to 
the facilitating role of compression in the production of fictive motion. However, this is only the surface of a more intensive research program that is needed to provide statistically valid evidence of the correspondence between human scale blending and the production of fictive motion. A broader study must be conducted and must include a larger sample to provide the beginnings of a body of conclusive evidence.

An under-explored, but fascinating area of research emerges from the trail study, specifically, the role of telicity in situational awareness and event structure. For instance, subjects with a map had a sense of telic knowledge about the length and duration of the trail, since their location on the map moved as an index of their location along the trail represented on the map and they could see the end of the trail on the map. Subjects without the map had atelic knowledge about the trail and only knew what they were experiencing without the foresight to know when and where the trail would terminate. Does telicity factor into the production of fictive motion? This could be one explanation of the facilitating role of the map, but it needs further exploration. Additionally, other questions need to be asked, such as: what role does telicity play in the facilitation of other types of mental processing?; how do telicity judgements change with experience?; and does telicity help in metaphorically relating event structure to spatial structure?

Additionally, the role that palpability plays in the production of fictive motion has been explored in broad strokes in this study, most notably illuminating the 
inherent networked complexity of palpability with situated use. In short, palpability matters. Palpability matters for this data because it was seen to interact with the contextual environment in all cases. For the trail and the SYMBOL-SUBSTRATE relationship with the map, palpability of the representational map enhanced palpability of the physical trail, making it available for attentional scanning in FM construals (2.10). For the view-related factive descriptions palpability was seen to modulate fictive-factive construals of scenes in a way that confirmed broader figure-ground relations between the locations and their significance on a temporal scale (3.3.1 \& 3.3.4). For other landmark-oriented FM construals, concrete palpability of a landmark was seen to be a factor of the subject's memory of that landmark even when that landmark was only abstractly palpable in a photograph (3.2.1), or as an element on a sketch-map (3.2.2). These last two landmark-oriented construals suggest that the subject's concretely palpable memory of that landmark made the abstract element prompt for the fictive construal. In all of these cases, concreteness is contingent on other external factors in the process of ception, causing palpability to be a highly dependent parameter, perhaps insufficiently described by the gradient scale of concreteness. Further research would help to shore up the roles played by palpability in the processes of dynamic construal. The semiotic typology seems to be a promising approach to sorting out this complexity.

Finally, as mentioned, further research into the validity of the semiotic typology of fictive motion should be advanced. Notably, extending the current level of study 
into the under explored SUBSTANCE type, with more careful attention to EXPERIENCE type as well. SYMBOL and SUBSTANCE would naturally be included in further research involving maps and human scale blends like the Oriented Travel Blend. 


\section{APPENDIX A: DATA TABLES}

\section{Table 5.1 FM data from Stanford Trail Study}

\begin{tabular}{|c|c|c|c|c|c|}
\hline$\#$ & Type & Line & FM Sentence & FM verbs & $\begin{array}{l}\text { Trial \& } \\
\text { Group }\end{array}$ \\
\hline 1 & SYMBOL & 1.037 & $\begin{array}{l}\text { Badger: I noticed that it looks like it ends at a water falls; } \\
\text { "Brandywine Falls" }\end{array}$ & 1 & A-CNTRL \\
\hline 2 & SYMBOL & 1.044 & Regina: How can you tell it's going uphill? & 1 & A-CNTRL \\
\hline 3 & SUBSTRATE & 1.072 & $\begin{array}{l}\text { Badger: I don't feel like you can really...outside of the fact } \\
\text { that it looks like it's going uphill }\end{array}$ & 1 & A-CNTRL \\
\hline 4 & SYMBOL & 1.100 & $\begin{array}{l}\text { Regina: its, ki, since these are going up, like that, that } \\
\text { must mean that was a steep area that we just walked } \\
\text { through. }\end{array}$ & 1 & A-CNTRL \\
\hline 5 & SYMBOL & 1.102 & Regina: going down & 1 & A-CNTRL \\
\hline 6 & SUBSTRATE & 1.105 & Badger: ...either that or, it could be going down. & 1 & A-CNTRL \\
\hline 7 & SYMBOL & 1.106 & $\begin{array}{l}\text { Regina: See, that looks steep to me, going, these are } \\
\text { going up. }\end{array}$ & 1 & A-CNTRL \\
\hline 8 & SYMBOL & 1.107 & $\begin{array}{l}\text { Regina: And that looks like it's kinda going down, like it } \\
\text { wouldn't be as steep, if I'm reading it right, I don't know. }\end{array}$ & 1 & A-CNTRL \\
\hline 9 & SUBSTRATE & 1.137 & Regina: that's pretty much followed us & 1 & A-CNTRL \\
\hline 10 & SUBSTRATE & 1.144 & $\begin{array}{l}\text { Regina: uh, I, um, I'm cur, I'm curious to see if there was } \\
\text { always like a creek following us, cause there was always } \\
\text { like a, like a ridge, to our... left as we were walking, um. }\end{array}$ & 1 & A-CNTRL \\
\hline 11 & SYMBOL & 1.151 & $\begin{array}{l}\text { Regina: When the red lines are going down that means } \\
\text { that you're going to have a decline in the "terrain"? }\end{array}$ & 1 & A-CNTRL \\
\hline 12 & SYMBOL & 1.153 & $\begin{array}{l}\text { Badger: I don't know if you can say "that" cause, you could } \\
\text { also say they're going up. }\end{array}$ & 1 & A-CNTRL \\
\hline 13 & SYMBOL & 1.160 & Badger: so that's all going down & 1 & A-CNTRL \\
\hline 14 & SUBSTRATE & 1.202 & Badger: Well, the trail got... & 1 & A-CNTRL \\
\hline 15 & SUBSTRATE & 1.223 & $\begin{array}{l}\text { Badger: I like how the, uh, river has gotten, or whatever you } \\
\text { want to call it, creek, has gotten, has gotten wider. }\end{array}$ & 1 & A-CNTRL \\
\hline 16 & SYMBOL & 1.293 & $\begin{array}{l}\text { Badger: I thought we'd go, I thought we'd be going, yeah, I } \\
\text { didn't know that this was going to be downhill, right here, } \\
\text { I thought it was going to be, basically like we'd just be } \\
\text { walking up the entire up, I didn't realize it was up and down. }\end{array}$ & 1 & A-CNTRL \\
\hline 17 & SYMBOL & 1.294 & $\begin{array}{l}\text { Regina: And I, I'm obviously reading this wrong, which I } \\
\text { didn't really know about this anyway, but I thought if it, if it } \\
\text { curves up like this that means you're going up, if it curves } \\
\text { down like this that means you're going down, if it curves } \\
\text { like this, then I, this is where I got confused. }\end{array}$ & 3 & A-CNTRL \\
\hline
\end{tabular}




\begin{tabular}{|c|c|c|c|c|c|}
\hline$\#$ & Type & Line & FM Sentence & FM verbs & $\begin{array}{l}\text { Trial \& } \\
\text { Group }\end{array}$ \\
\hline 18 & SYMBOL & 2.026 & $\begin{array}{l}\text { Raleigh: Well, it looks like it kind of zigzags through } \\
\text { some...short, uh, well for Ohio, moderate like ridges, } \\
\text { kind of uh weaves its way through, goes around one, } \\
\text { goes kinda through another... }\end{array}$ & 4 & A-CNTRL \\
\hline 19 & SYMBOL & 2.030 & Raleigh: It also looks like it, uh, intersects with another & 1 & A-CNTRL \\
\hline 20 & SYMBOL & 2.032 & Raleigh: intersects with another trail & 1 & A-CNTRL \\
\hline 21 & SYMBOL & 2.035 & Raleigh: It crosses several uh & 1 & A-CNTRL \\
\hline 22 & SYMBOL & 2.040 & $\begin{array}{l}\text { Raleigh: And then it, uh, ends up by Brandywine Falls } \\
\text { and then another trail... }\end{array}$ & 1 & A-CNTRL \\
\hline 23 & SYMBOL & 2.047 & $\begin{array}{l}\text { Raleigh: Um, its definitely hilly, like its a series of ridges, it } \\
\text { looks like, that uh, the water tends to run alongside of and } \\
\text { the trail goes through, it looks like t...two or three ridges, } \\
\text { and also around several others. }\end{array}$ & 1 & A-CNTRL \\
\hline 24 & SUBSTRATE & 2.081 & Nicole: lovelily studded with roots & 1 & A-CNTRL \\
\hline 25 & SUBSTRATE & 2.089 & $\begin{array}{l}\text { Raleigh: Well, we went uphill quite a bit, and it leveled out, } \\
\text { then we went downhill, then back uphill, and it leveled } \\
\text { out,... }\end{array}$ & 2 & A-CNTRL \\
\hline 26 & SUBSTRATE & 2.090 & $\begin{array}{l}\text { Nicole: But so far, pretty even, as far as not going steeply } \\
\text { up and down,... }\end{array}$ & 1 & A-CNTRL \\
\hline 27 & EVENT? & 2.162 & $\begin{array}{l}\text { Raleigh: Um, we came downhill quite a bit, down the side of } \\
\text { a ridge and then flattened out at the base. And windy. }\end{array}$ & 1 & A-CNTRL \\
\hline 28 & SUBSTANCE & 2.169 & $\begin{array}{l}\text { Raleigh: Uh, still woody, I feel like the trees have thinned } \\
\text { out a bit, they're not as dense, but maybe I'm just } \\
\text { imagining. }\end{array}$ & 1 & A-CNTRL \\
\hline 30 & SUBSTANCE & 2.179 & Nicole: I see stones approaching & 1 & A-CNTRL \\
\hline 31 & SUBSTRATE & 2.188 & Nicole: It breaks off and its three paths. & 1 & A-CNTRL \\
\hline 32 & SUBSTANCE & 2.191 & $\begin{array}{l}\text { Raleigh: Um, a little hilly, not moderately so, just a little up } \\
\text { and down, um the trees are actually thinning behind us, } \\
\text { um, yeah. }\end{array}$ & 1 & A-CNTRL \\
\hline 33 & SUBSTRATE & 2.192 & Nicole: and sloping up to the left & 1 & A-CNTRL \\
\hline 34 & SYMBOL & 2.197 & $\begin{array}{l}\text { Nicole: So we are right here where everything... (see line } \\
35 \text { for FM verb): }\end{array}$ & & A-CNTRL \\
\hline 35 & SYMBOL & 2.199 & Nicole: ...meets & 1 & A-CNTRL \\
\hline 36 & SUBSTRATE & 2.200 & $\begin{array}{l}\text { Raleigh: detours, um, we are on the edge of going up, if we } \\
\text { could go up, another incline, or ridge, but since we can't, um. }\end{array}$ & 1 & A-CNTRL \\
\hline 37 & SYMBOL & 3.022 & $\begin{array}{l}\text { Don: and it looks coming back on the same trail, I'm } \\
\text { guessing because there's only one trail going that } \\
\text { way...that's about it. }\end{array}$ & 1 & A-TEST \\
\hline 38 & SYMBOL & 3.024 & $\begin{array}{l}\text { Don: What's the brown trail? Oh, that's "Brandywine Trail", } \\
\text { Kinda paralleling that for a while. }\end{array}$ & 1 & A-TEST \\
\hline
\end{tabular}




\begin{tabular}{|c|c|c|c|c|c|}
\hline$\#$ & Type & Line & FM Sentence & FM verbs & $\begin{array}{l}\text { Trial \& } \\
\text { Group }\end{array}$ \\
\hline 39 & SUBSTRATE & 3.092 & $\begin{array}{l}\text { Don: there was one spot where it was covered with the } \\
\text { leaves pretty good and yeah and I wanted to confirm that } \\
\text { we were on the trail, but she could tell by looking up } \\
\text { ahead that the trail continued. }\end{array}$ & 1 & A-TEST \\
\hline 40 & SUBSTRATE & 3.102 & $\begin{array}{l}\text { Don: You know what is funny I didn't really see the ravine on } \\
\text { the map, that we were walking along, so like right here, } \\
\text { here's we're on this bridge, that ravine ran beside the trail, } \\
\text { and I wouldn't have thought by looking at the map that that } \\
\text { was a ravine. }\end{array}$ & 1 & A-TEST \\
\hline 41 & SYMBOL & 3.103 & $\begin{array}{l}\text { Don: You know it just doesn't, it just doesn't really show, but } \\
\text { this is what's going on is the ravine is coming right } \\
\text { through here. }\end{array}$ & 1 & A-TEST \\
\hline 42 & SYMBOL & 3.108 & $\begin{array}{l}\text { Don: so here is that re...[coughs], excuse me, here is the } \\
\text { ravine right here. And it's going to come through here, I'm } \\
\text { guessing. }\end{array}$ & 1 & A-TEST \\
\hline 43 & SYMBOL & 3.109 & $\begin{array}{l}\text { Don: It's going to come through here up ahead here, so } \\
\text { we probably won't see the ravine until we're on top of the a } \\
\text { bridge I'm guessing, }\end{array}$ & 1 & A-TEST \\
\hline 44 & SUBSTRATE & 3.115 & $\begin{array}{l}\text { Don: The trail looks like it goes that way, but it doesn't, } \\
\text { the trail goes that way. Alright. [indistinct] }\end{array}$ & 2 & A-TEST \\
\hline 45 & SYMBOL & 3.128 & $\begin{array}{l}\text { Don: Yeah, see, here's the, see, the trail's going this way, } \\
\text { and, and, we're going downhill, }\end{array}$ & 1 & A-TEST \\
\hline 46 & SYMBOL & 3.129 & $\begin{array}{l}\text { Don: see so the lines are this way so that's the elevation } \\
\text { climbing up, so we're going down so we're down }\end{array}$ & 1 & A-TEST \\
\hline 47 & SYMBOL & 3.203 & Natasha: and as they widen out it gets lower? & 1 & A-TEST \\
\hline 48 & SUBSTRATE & 3.235 & $\begin{array}{l}\text { Don: Got narrow, uh, towards this bridge, it narrowed } \\
\text { out. }\end{array}$ & 2 & A-TEST \\
\hline 49 & SYMBOL & 4.017 & $\begin{array}{l}\text { RD: um, where the green meets the brown. [researcher's } \\
\text { use of fictive motion] }\end{array}$ & 4 & - \\
\hline 50 & SYMBOL & 4.023 & $\begin{array}{l}\text { Tripper: And uh, we're going to be going down some sort of } \\
\text { relatively winding trail...with alternate trails we're not taking, } \\
\text { to get here. }\end{array}$ & 0 & A-TEST \\
\hline 51 & SYMBOL & 4.040 & $\begin{array}{l}\text { Tripper: and then here we're going....all this steep happens } \\
\text { this direction, we're going this direction, so I think we're } \\
\text { going to be avoiding, we're going to be surrounded by } \\
\text { steep, where, we're probably in a valley, maybe in a peak, } \\
\text { but, it looks like we're avoiding elevation change by going } \\
\text { this way, verses this way where there would be much more } \\
\text { elevation change. }\end{array}$ & 1 & A-TEST \\
\hline 52 & & 4.062 & $\begin{array}{l}\text { Tripper: Um, still going straight and flat, crossing a river, } \\
\text { and then we're going to have some elevation change, with } \\
\text { some back and forth, maybe to compensate for the elevation } \\
\text { change. [trail is trajector] }\end{array}$ & 2 & A-TEST \\
\hline
\end{tabular}




\begin{tabular}{|c|c|c|c|c|c|}
\hline$\#$ & Type & Line & FM Sentence & FM verbs & $\begin{array}{l}\text { Trial \& } \\
\text { Group }\end{array}$ \\
\hline 53 & SYMBOL & 4.063 & $\begin{array}{l}\text { Tripper: Then we're going to be finding ourselves in what } \\
\text { l'm guessing is going to be a valley, and then take a path } \\
\text { through what might be a valley, crossing another bridge?, } \\
\text { back-tracking on ourselves, seeing a choice of paths, } \\
\text { staying on this trail, more uh, if in fact this is a valley this is } \\
\text { probably going up the hill again. Bridge. Flat. Bridge. } \\
\text { Turn. Down, down, down, or maybe up, up, up. Ok. }\end{array}$ & 1 & A-TEST \\
\hline 54 & SUBSTRATE & 4.067 & $\begin{array}{l}\text { Tripper: This terrain is relatively flat, although, we're } \\
\text { surrounded by big hills especially that direction, }\end{array}$ & 1 & A-TEST \\
\hline 55 & SYMBOL & 4.068 & $\begin{array}{l}\text { Tripper: so without even trying to get my bearings, l'm } \\
\text { guessing from what this says about flat going to hills, and } \\
\text { I'm seeing flat, and see hills in that direction, I'm guessing } \\
\text { we're going that direction. }\end{array}$ & 1 & A-TEST \\
\hline 56 & SYMBOL & 4.090 & $\begin{array}{l}\text { Tripper: The trail...itself, in this direction, this area, couple } \\
\text { flat sections, muddier than one might like, less populated } \\
\text { than it was a few minutes ago, and at some point the trail } \\
\text { beyond my field of vision, is going to take a sharp turn } \\
\text { to what would be my right, this trail is going to ascend or } \\
\text { descend, and uh, there we are. }\end{array}$ & 3 & A-TEST \\
\hline 57 & SUBSTRATE & 4.128 & $\begin{array}{l}\text { Tripper: um, surrounded on both ends by a little bit more } \\
\text { challenge but easy and pretty right now. }\end{array}$ & 1 & A-TEST \\
\hline 58 & SYMBOL & 4.135 & $\begin{array}{l}\text { Tripper: The map, uh, we finished the last bridge, I guess } \\
\text { we're now at the point where the paths combine because } \\
\text { I seem to be seeing a convergence of three different lines, } \\
\text { and I see a trail that seems to confirm that um, going that } \\
\text { way, I think that's telling me if I go that way I'm going the } \\
\text { opposite way on the Brandywine trail. }\end{array}$ & 1 & A-TEST \\
\hline 59 & SYMBOL & 4.154 & $\begin{array}{l}\text { Tripper: This is a map of the trail we just completed, and we } \\
\text { started here and we ended where the paths joined, we } \\
\text { came back. }\end{array}$ & 1 & A-TEST \\
\hline 60 & SUBSTRATE & 5.068 & $\begin{array}{l}\text { Holly: It seems like it was um, went from, easy got harder, } \\
\text { easy again, so we'll see if the trail gets any harder or not. }\end{array}$ & 2 & B-CNTRL \\
\hline 61 & SUBSTRATE & 5.086 & $\begin{array}{l}\text { Carl: kind of windy, this this part of it was anyways, kind of } \\
\text { did a lot of uh, winding. }\end{array}$ & 1 & B-CNTRL \\
\hline 62 & SUBSTRATE & 5.123 & $\begin{array}{l}\text { Carl: Uh, it was kind of just, like a little windy, sloped uh, } \\
\text { area coming around, um, are you talking about from like for } \\
\text { the whole trail, or just like from that... }\end{array}$ & 1 & B-CNTRL \\
\hline 63 & SYMBOL & 5.186 & $\begin{array}{l}\text { Carl: It'd be us going into the woods, and then us kinda } \\
\text { going up that uh, kinda going up uphill towards the top and } \\
\text { then um we kinda walked straight for a minute, and then we } \\
\text { started walking I would say up a little more, this way, and } \\
\text { then uh, I would, uh, you know we kinda walked straight for } \\
\text { a minute and then we kinda made another like left, and then } \\
\text { here, I guess, I guess there would be a little more cause this } \\
\text { is like where it kinda split off, like you could either go } \\
\text { straight or this way, and, uh, we kinda went more this way, } \\
\text { and then there was another, oh I guess this was a, you } \\
\text { know, the first bridge here, and then there was another small } \\
\text { bridge over here, and then there was another bridge here, } \\
\text { and the last bridge was around over here. }\end{array}$ & 1 & B-CNTRL \\
\hline
\end{tabular}




\begin{tabular}{|c|c|c|c|c|c|}
\hline$\#$ & Type & Line & FM Sentence & FM verbs & $\begin{array}{l}\text { Trial \& } \\
\text { Group }\end{array}$ \\
\hline 64 & SYMBOL & 5.191 & $\begin{array}{l}\text { Holly: Ok. This is where we started off, walking, then we } \\
\text { come to the first bridge, there's a little bit of an incline and a } \\
\text { curve, then we come, um, uphill, to the second bridge, then } \\
\text { we came down, to the next bridge, then we went back } \\
\text { uphill where it kind of veered around, to another bridge, } \\
\text { and then we walked uh, well kind of flat here, and then it } \\
\text { split. }\end{array}$ & 2 & B-CNTRL \\
\hline 65 & SUBSTANCE & 5.204 & $\begin{array}{l}\text { Carl: ...it was muddy at first, a little bit, and then it kind of uh, } \\
\text { kind of seemed like if there were more leaves on the ground } \\
\text { it got absorbed a little bit and then as the sun came up } \\
\text { kinda, maybe the dew had lifted, }\end{array}$ & 1 & B-CNTRL \\
\hline 66 & SUBSTRATE & 6.075 & $\begin{array}{l}\text { Ariane: The trail began to descend, it was still muddy, } \\
\text { and... }\end{array}$ & 1 & B-TEST \\
\hline 67 & SUBSTRATE & 6.120 & $\begin{array}{l}\text { Ariane: We've noticed that where the path leads us, the } \\
\text { leaves are worn so you can kind of tell where to go, whereas } \\
\text { these leaves are more }\end{array}$ & 1 & B-TEST \\
\hline 68 & SUBSTRATE & 6.168 & Bob: Um. It was kind of, what would you say, winding? & 0 & B-TEST \\
\hline 69 & SYMBOL & 7.026 & $\begin{array}{l}\text { Eliza: It connects from the towpath, and you go past } \\
\text { Stanford Road, it twists and winds a lot, and... }\end{array}$ & 3 & C-CNTRL \\
\hline 70 & SYMBOL & 7.027 & $\begin{array}{l}\text { Herman: Uh, it looks like its, based on the topography...I'm } \\
\text { not sure, I'm trying to decide if it's going around the } \\
\text { large.., the steepest parts of the hills, or, making a purpose } \\
\text { to, uh, um,...uh, hit the steepest parts of the hills based } \\
\text { on, you know, if its a harder trail or an easier trail. }\end{array}$ & 2 & C-CNTRL \\
\hline 71 & SYMBOL & 7.059 & $\begin{array}{l}\text { Herman: Uh, Brandywine Gorge Trail is more of a leisure } \\
\text { walk because it contours to the topographical map, the } \\
\text { trail does, like the, the the going around hills and going } \\
\text { through the valleys I guess, there's not mo, they aren't } \\
\text { mountains, but, I guess you could consider them valleys. }\end{array}$ & 3 & C-CNTRL \\
\hline 72 & SYMBOL & 7.081 & $\begin{array}{l}\text { Herman: So that's not, I mean, [clears throat]. They both } \\
\text { have "steep steps" and they're both "moderate to difficult" } \\
\text { so, where the Stanford Trail [clears throat] is, looks longer } \\
\text { the Brandywine Gorge Trail goes around in circles. }\end{array}$ & 1 & C-CNTRL \\
\hline 73 & SYMBOL & 7.086 & $\begin{array}{l}\text { Herman: The Stanford Trail, is, um, well, it uh, looks steeper } \\
\text { than the [clears throat] Brandywine Gorge Trail, because, } \\
\text { um, based on the topographical map, it um, does, it does } \\
\text { go around some of the hills but I can see in some parts it } \\
\text { is um going up the hills, down the hills, and, in, in one } \\
\text { portion it levels out over here by uh Stanford House, um } \\
\text { and obviously it becomes less difficult, but um, over by the } \\
\text { Averill Pond this is where the most of the, probably the } \\
\text { heavy-duty hiking will uh, be taking place. }\end{array}$ & 4 & C-CNTRL \\
\hline 74 & SYMBOL & 8.014 & Polonius: uh, it goes from, it goes east-west, uh, & 1 & C-CNTRL \\
\hline 75 & SYMBOL & 8.016 & Polonius: crosses three creeks, it is... & 1 & C-CNTRL \\
\hline 76 & SYMBOL & 8.018 & $\begin{array}{l}\text { Polonius: it doesn't complete a loop or anything, its } \\
\text { just,...whereas the Brandywine Trail does }\end{array}$ & 1 & C-CNTRL \\
\hline
\end{tabular}




\begin{tabular}{|c|c|c|c|c|c|}
\hline$\#$ & Type & Line & FM Sentence & FM verbs & $\begin{array}{l}\text { Trial \& } \\
\text { Group }\end{array}$ \\
\hline 77 & SYMBOL & 8.019 & $\begin{array}{l}\text { Polonius: it looks like it follows the low lying areas, } \\
\text { mostly, it doesn't look like it goes over a peak } \\
\text { necessarily, maybe here }\end{array}$ & 2 & C-CNTRL \\
\hline 78 & SYMBOL & 8.023 & $\begin{array}{l}\text { Polonius: It starts pretty easy, but I guess it does go } \\
\text { over some hills here, and it looks like it comes } \\
\text { down...and it winds around, um, it looks like it goes } \\
\text { back over some ridges here, and... }\end{array}$ & 5 & C-CNTRL \\
\hline 79 & SYMBOL & 9.016 & $\begin{array}{l}\text { Marian: It's a map of, what?, the Brandywine Falls area, um, } \\
\text { it shows major, you know, um, highways, intersecting } \\
\text { roads, um, I forget what the, like uh, topography I guess is } \\
\text { showing to you }\end{array}$ & 1 & C-TEST \\
\hline 80 & SYMBOL & 9.021 & $\begin{array}{l}\text { Marian: Um, well, I guess it runs, um, from West to East, } \\
\text { or East to West, more so than North to South, um. I'm trying } \\
\text { to think what else can I tell you about it [laughs], I don't } \\
\text { know. }\end{array}$ & 1 & C-TEST \\
\hline 81 & SYMBOL & 9.031 & $\begin{array}{l}\text { Marian: Um, because just, um, and this is an assumption, } \\
\text { that the topography that's shown on here, I would imagine } \\
\text { that these go upward }\end{array}$ & 1 & C-TEST \\
\hline
\end{tabular}

\section{Table 5.2 FM Data from Paris slide show}

\begin{tabular}{|c|c|c|c|}
\hline$\#$ & Line & FM Sentence & Type \\
\hline 1 & 1.008 & $\begin{array}{l}\text { Steve: Um, and, like Notre Dame was down here on these islands, the uh, the } \\
\text { Louvre }\end{array}$ & ACCESS \\
\hline 2 & 1.008 & *Steve: ...uh, is up here kinda along, just north of the river & ACCESS \\
\hline 3 & 1.017 & $\begin{array}{l}\text { Steve: So we we there was like a construction site and it had sandbags holding down } \\
\text { some of the scaffolding and our bags were just sitting next to the bags so when her } \\
\text { dog went up there to go to the bathroom she didn't think anything of it. }\end{array}$ & ADVENT \\
\hline 4 & 1.018 & $\begin{array}{l}\text { Steve: it was, it was, it was turned out, so we just had to keep telling ourselves that } \\
\text { this is an adventure, like these are just co, an adventure has things like this that } \\
\text { pop up. }\end{array}$ & $\begin{array}{l}\text { Metaphorical } \\
\text { Motion }\end{array}$ \\
\hline 5 & 1.022 & $\begin{array}{l}\text { *Steve: So this was the view of the, as we're sitting at the table looking out onto the } \\
\text { square, and Victor Hugo's house, uh, apartment, was down around the corner from } \\
\text { here, and um, }\end{array}$ & ACCESS \\
\hline 6 & 1.022 & $\begin{array}{l}\text { Joanna: so it was a poached egg in chicken gelatin surrounded with raw bacon in like } \\
\text { a little hockey puck thing, it was like the grossest, so there were two of them, and they } \\
\text { were so gross [laughs] }\end{array}$ & ADVENT \\
\hline 7 & 1.027 & $\begin{array}{l}\text { *Steve: that was cool, that cat was just kind of hovering there, there's no, that's not } \\
\text { supported by the wall [cantilevered sculpture] }\end{array}$ & ADVENT \\
\hline 8 & 1.034 & $\begin{array}{l}\text { FM: Steve: so we went up inside and there was, a museum that overlooked this } \\
\text { courtyard. }\end{array}$ & PROSPECT \\
\hline 9 & 1.04 & *Steve: There's statues on every corner [laughs] & ADVENT \\
\hline
\end{tabular}




\begin{tabular}{|c|c|c|c|}
\hline$\#$ & Line & FM Sentence & Type \\
\hline 10 & 1.04 & $\begin{array}{l}\text { * Steve: So there's two islands, which is where, two islands in the middle of the Seine } \\
\text { which is where Paris was originally built up around was these two islands, and } \\
\text { on one island is the Notre Dame, and the city kinda grew from either side of the } \\
\text { banks off of these islands, }\end{array}$ & COEXTENSION \\
\hline 11 & 1.04 & $\begin{array}{l}\text { *Steve: Lots of old trees there just kinda like hanging out, hanging over the river, } \\
\text { lots of um, boat tours going up and down the river. }\end{array}$ & COEXTENSION \\
\hline 12 & 1.041 & $\begin{array}{l}\text { *Steve: [indistinct] What I find interesting was that the river, all the way around these } \\
\text { islands was just built up, this retention wall, and I'm wondering what the island } \\
\text { originally looked like before there was all these manmade walls all framing in the } \\
\text { island. }\end{array}$ & ADVENT \\
\hline 13 & 1.041 & $\begin{array}{l}\text { *Steve: um, this is the Louvre, and we entered from the one side and went through like } \\
\text { a courtyard, or a little interior part, and then we wal, yeah, we walked through here } \\
\text { and there's this big fountain in the middle, and beyond that was the I. M. Pei } \\
\text { glass pyramid in the middle that is now the entrance into the museum. }\end{array}$ & ACCESS \\
\hline 14 & 1.043 & *Steve: That's looking down into the pyramid & LINE OF SIGHT \\
\hline 15 & 1.043 & *Steve: I like this picture, the way the building reflects off the pyramid & RADIATION \\
\hline 16 & 1.052 & $\begin{array}{l}\text { Steve: that well, like, the um, the drain spouts were like statues planking I thought } \\
\text { it was pretty funny...not like they invented planking }\end{array}$ & COEXTENSION \\
\hline 17 & 1.058 & $\begin{array}{l}\text { Steve: So now we're all the way across the bridge, we're on the other side of the river, } \\
\text { Steve: and um, there's like a ff, like a high speed road like going underneath us and } \\
\text { stuff, Steve: and um, we started looking and I looked and there's like a pathway down } \\
\text { right next to the river, like you go down a bunch of steps, there you can see right } \\
\text { there in front of , the, right, the tr, right here in front you can like go down these steps, }\end{array}$ & $\begin{array}{l}\text { COEXTENSION, } \\
\text { ACCESS }\end{array}$ \\
\hline 18 & 1.059 & $\begin{array}{l}\text { Steve: But then I zoomed in and l'm like "holy cow, like that's the merry-go-round } \\
\text { underneath the archway of this thing. }\end{array}$ & TARGETING \\
\hline 19 & 1.063 & $\begin{array}{l}\text { Steve: That's it, uh, it lights up for five minutes or so every hour, starts flashing and } \\
\text { sparkling, I left the shutter open longer so you could see all of the flashing }\end{array}$ & RADIATION \\
\hline 20 & 1.063 & $\begin{array}{l}\text { Joanna: and so right before we left, she said: "Oh, yeah, you should try to be walking } \\
\text { down the stairs from the Eiffel Tower as it's sparkling". }\end{array}$ & RADIATION \\
\hline 21 & 1.064 & $\begin{array}{l}\text { Steve: So the elevator goes up one of those legs, like at a slant, and then } \\
\text { straightens out }\end{array}$ & COEXTENSION \\
\hline 22 & 1.064 & $\begin{array}{l}\text { FM: Steve: So up top you have this beautiful view, like that's the Arc de Triomphe } \\
\text { kinda diagonally across the way, and the, this, there's a spotlight that circles, uh, } \\
\text { at the top of the Eiffel Tower that you can just see like swooshing all the way } \\
\text { around. }\end{array}$ & $\begin{array}{l}\text { ACCESS, } \\
\text { DEMONSTRATI } \\
\text { VE }\end{array}$ \\
\hline 23 & 1.066 & $\begin{array}{l}\text { Steve: And here's the, these are the strobes that flash, they're all over, they skin } \\
\text { the whole, all over the place, over all the beams and everything }\end{array}$ & $\begin{array}{l}\text { RADIATION, } \\
\text { ADVENT }\end{array}$ \\
\hline 24 & 1.066 & $\begin{array}{l}\text { Steve: [laughs] This is, the } p \text {, the place we had that pizza that I was telling you } \\
\text { about, was over here, down here around this corner and so we went across the } \\
\text { street this way and across the river }\end{array}$ & ACCESS \\
\hline 25 & 1.068 & Steve: That's the Notre Dame, just kind of glowing there. & RADIATION \\
\hline 26 & 1.073 & $\begin{array}{l}\text { Steve: So this is on top, you, uh, you hike up and it's like this tightly wound spiral } \\
\text { staircase, but um... }\end{array}$ & ADVENT \\
\hline
\end{tabular}




\begin{tabular}{|c|c|c|c|}
\hline$\#$ & Line & FM Sentence & Type \\
\hline 27 & 1.075 & $\begin{array}{l}\text { Steve: That's the, um, the um, they made the modern version of the Arc de Triomphe, } \\
\text { down in their main town, it's supposed to be facing it, but when they built it, it's } \\
\text { slightly off-skew so it's a little bit crooked, but it's supposed to be facing it. [laughs] }\end{array}$ & $\begin{array}{l}\text { ALIGNMENT/ } \\
\text { PROSPECT }\end{array}$ \\
\hline 28 & 1.075 & Steve: It's perfectly lined up with another & $\begin{array}{l}\text { ALIGNMENT/ } \\
\text { PROSPECT }\end{array}$ \\
\hline 29 & 1.076 & $\begin{array}{l}\text { Joanna: But I guess, the story we had heard from someone was that the French were } \\
\text { happy, the French people were happy because they didn't like the modern one so they } \\
\text { didn't really care that it didn't line up or something }\end{array}$ & $\begin{array}{l}\text { ALIGNMENT/ } \\
\text { PROSPECT }\end{array}$ \\
\hline 30 & 1.084 & $\begin{array}{l}\text { FM Steve: I like these rooftops, look at, if you look at all of the, the clay chimneys } \\
\text { dotting all over the place. }\end{array}$ & ADVENT \\
\hline 31 & 1.099 & $\begin{array}{l}\text { FM: Steve: It was a really cool studio, like the kitchen was on the second floor } \\
\text { overlooking the Seine across the street }\end{array}$ & PROSPECT \\
\hline 32 & 1.101 & Steve: and they're like permanently attached to the stone wall that borders the river & COEXTENSION \\
\hline 33 & 1.119 & $\begin{array}{l}\text { Joanna: And this kept Steve occupied for the fifty minutes until the sparkling lights } \\
\text { started sparkling. }\end{array}$ & RADIATION \\
\hline 34 & 1.119 & FM: Steve: it trades off, [FM about reported activity] & RADIATION \\
\hline
\end{tabular}




\section{BIBLIOGRAPHY}

Bergen, B. \& Wheeler, K. (2010). Grammatical aspect and mental simulation. Brain \& Language 112 150-158

Bohnemeyer, J. (2003). The unique vector constraint: The impact of direction changes on the linguistic segmentation of motion events. In E. van der Zee and J. Slack (eds.), Representing direction in language and space. Oxford: Oxford University Press. 86-110.

Fauconnier, G. (1997). Mappings in thought and language. Cambridge: Cambridge University Press.

Fauconnier, G \& Turner, M. (2002). The way we thing: Conceptual blending and the mind's hidden complexities. New York: Basic Books.

Hendon, J. (2010). Houses in a landscape: Memory and everyday life in Mesoamerica. Durham: Duke University Press.

Hutchins, E. (1995). Cognition in the wild. Cambridge: MIT Press.

Kjellström, B. \& Kjellström Elgin, C. (2010). Be expert with map and compass: The complete orienteering handbook. (third edition). New Jersey: John Wiley \& Sons.

Matlock, T. (2004a). Fictive motion as cognitive simulation. Memory \& Cognition, 32, 1389-1400.

Matlock, T. (2004b). The conceptual motivation of fictive motion. In G. Radden \& K.U. Panther (Eds.), Studies in linguistic motivation (pp. 221-248). Berlin: Mouton de Gruyter.

Matlock, T., Ramscar, M., \& Boroditsky, L. (2005) On the experiential link between spatial and temporal language. Cognitive Science 29 655-664

Oakley, T. (2009). From attention to meaning: Explorations in semiotics, linguistics, and rhetoric.

Bern: Peter Lang

Stjernfelt, F. (2007). Diagrammatology: An investigation on the borderlines of phenomenology, ontology, and semiotics. Dordrecht: Springer.

Talmy, L. (2000). Toward a cognitive semantics. Vol I. Cambridge: MIT Press.

Turner, M. (1996). The literary mind: The origins of thought and language. Oxford: Oxford University Press.

Zwarts, J. (2003). Vectors across spatial domains: From place to size, orientation, shape, and parts. In E. van der Zee and J. Slack (eds.), Representing direction in language and space. Oxford: Oxford University Press. 39-68.

Research conducted under National Park Service Scientific Research \& Collecting Permit: CUVA-2011-SCI-0014 